\title{
Interface-Engineering for All-Oxide Solid-State Batteries
}

T.A. Hendriks 



\title{
INTERFACE-ENGINEERING FOR ALL-OXIDE SOLID-STATE BATTERIES
}

\author{
Theodoor Anton Hendriks
}





\title{
INTERFACE-ENGINEERING FOR ALL-OXIDE SOLID-STATE BATTERIES
}

\section{PROEFSCHRIFT}

\author{
ter verkrijging van \\ de graad van doctor aan de Universiteit Twente, \\ op gezag van de rector magnificus, \\ prof. dr. T.T.M. Palstra, \\ volgens besluit van het College voor Promoties \\ in het openbaar te verdedigen \\ op woensdag 02 oktober 2019 om 12:45 uur
}

door

\section{Theodoor Anton Hendriks}

geboren op 6 december 1989

te Groningen, Nederland 
Dit proefschrift is goedgekeurd door de promotoren:

prof. dr. ing. A.J.H.M. Rijnders

prof. dr. ir. M. Huijben

Cover:

The cover shows a Scanning Electron Microscope image of a cross-section of an All-Oxide Solid-State Battery thin film grown on a $\mathrm{Nb}: \mathrm{SrTiO}_{3}-111$ substrate. Manganese purple is used for the $\mathrm{LiMn}_{2} \mathrm{O}_{4}$ cathode layer, Lanthanum green for the $\mathrm{Li}_{3 \mathrm{x}} \mathrm{La}_{2 / 3-\mathrm{x}} \mathrm{TiO}_{3}$ electrolyte, and Titanium blue for the $\mathrm{Li}_{4} \mathrm{Ti}_{5} \mathrm{O}_{12}$ anode.

Printed by: IPSKamp Printing, Enschede, The Netherlands

Lay-out: Theodoor Anton Hendriks

ISBN: $978-90-365-4865-6$

DOI: $10.3990 / 1.9789036548656$

The research presented in this thesis was carried out at the Inorganic Materials Science group, Department of Science and Technology, and the MESA+ Institute of Nanotechnology at the University of Twente, The Netherlands. The research was financially supported by the Netherlands Organization for Scientific Research (NWO) under the VIDI grant: 13456 'Selfassembled 3D Solid-State Batteries'.

(C) 2019 Enschede, The Netherlands. All rights reserved. No parts of this thesis may be reproduced, stored in a retrieval system or transmitted in any form or by any means without permission of the author. Alle rechten voorbehouden. Niets uit deze uitgave mag worden vermenigvuldigd, in enige vorm of op enige wijze, zonder voorafgaande schriftelijke toestemming van de auteur. 


\section{PROMOTIE COMMISSIE:}

Voorzitter/secretaris: Prof. dr. J.L. Herek

Promotoren: $\quad$ Prof. dr. ing. A.J.H.M. Rijnders

Prof. dr. ir. M. Huijben

Leden: $\quad$ Prof. dr. ir. M. Wagemaker (TU Delft)

Prof. dr. habil. D. Fattakhova (FZ-Jülich)

Prof. dr. G. Mul (University of Twente)

Prof. dr. ir. J.W.M. Hilgenkamp (University of Twente)

Prof. dr. ir. J.E. ten Elshof (University of Twente) 



\section{Table of Contents}

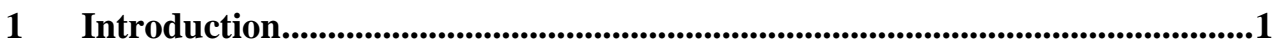

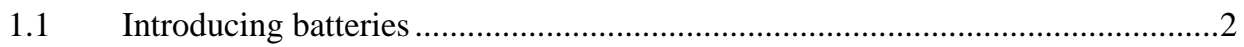

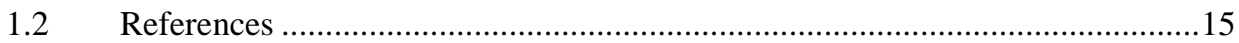

2 Orientation dependence in epitaxial engineered $\mathrm{LiMn}_{2} \mathrm{O}_{4}$ model systems ...19

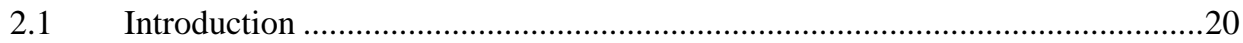

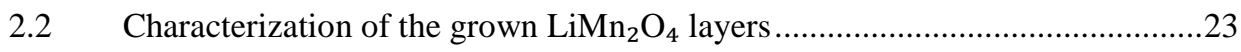

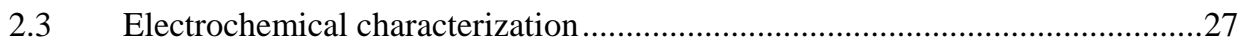

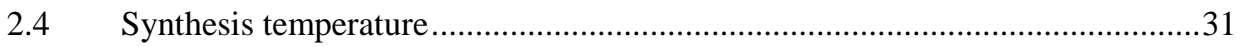

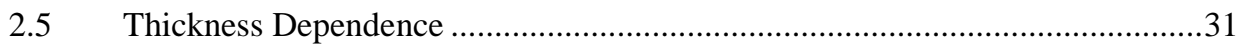

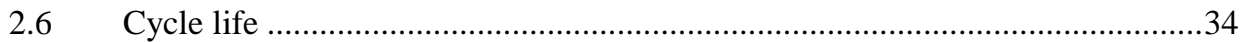

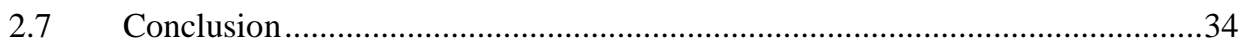

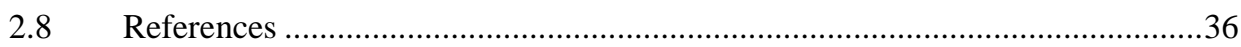

3 Modeling the electrochemical behavior of $\mathrm{LiMn}_{2} \mathrm{O}_{4}$ thin film cathode..........41

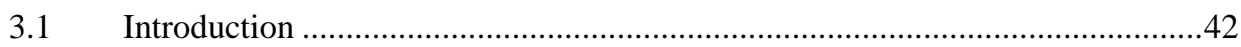

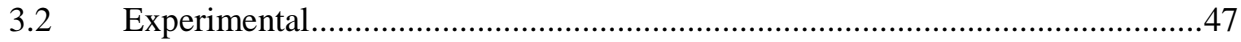

3.3 Results and Discussion ............................................................................48

$3.4 \quad$ Calculating the diffusion coefficient ……………………………………....52

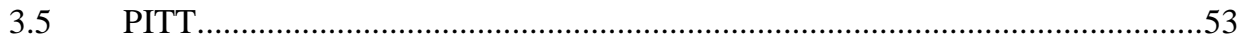

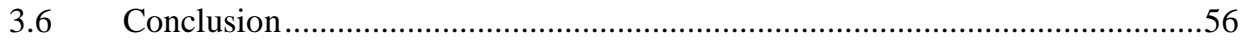

$3.7 \quad$ References: ....................................................................................58

4 Electrochemical behavior of $\mathrm{LiMn}_{2} \mathrm{O}_{4}$ thin film cathode during different loads, and through time ....................................................................................61

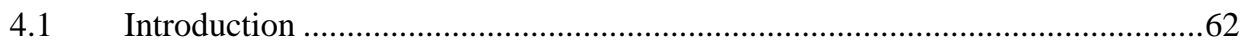

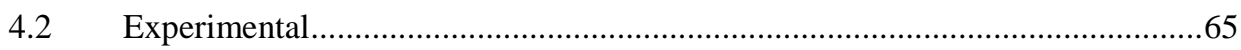

4.3 Effect of current on potential plateaus of $\mathrm{LiMn}_{2} \mathrm{O}_{4}$ around $4 \mathrm{~V}$..........................65

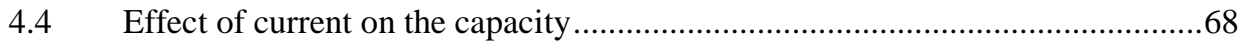

4.5 Electrochemical response through time ..........................................................70 


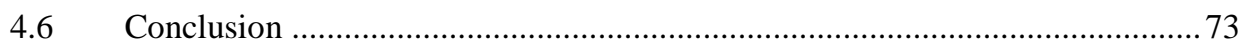

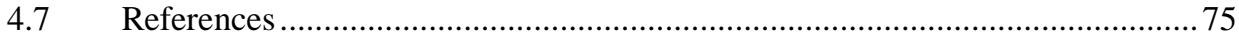

5 Electrochemical response of overlithiated $\mathrm{Li}_{2} \mathrm{Mn}_{2} \mathrm{O}_{4}$ thin film cathode....... 79

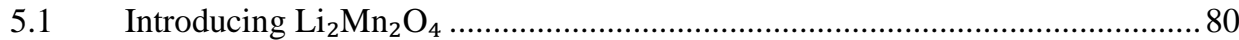

5.2 Experimental results on 100-oriented $\mathrm{Li}_{x} \mathrm{Mn}_{2} \mathrm{O}_{4}$ thin film cathodes................. 82

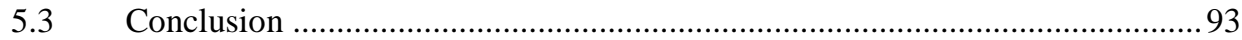

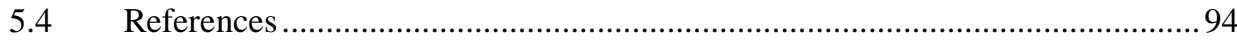

6 Solid-state electrolyte $\mathrm{Li}_{3 x} \mathrm{La}_{2 / 3-x} \mathrm{TiO}_{3}$ in thin film batteries ............................ 97

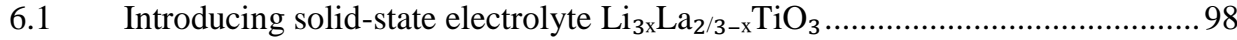

6.2 Thin film $\mathrm{Li}_{3 \times} \mathrm{La}_{2 / 3-x} \mathrm{TiO}_{3}$ solid-state electrolyte ..................................... 100

6.3 All-oxide full solid state batteries ................................................................. 104

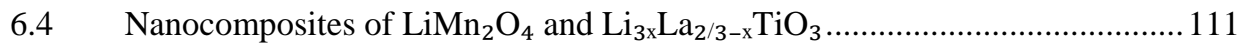

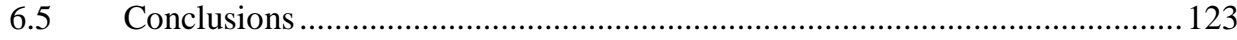

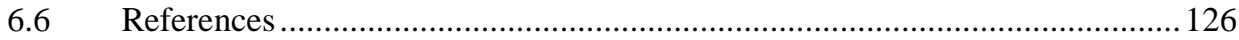

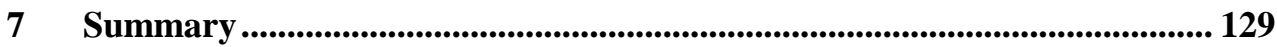

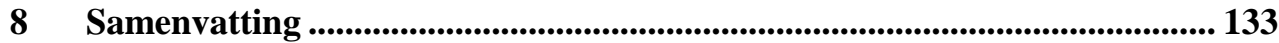

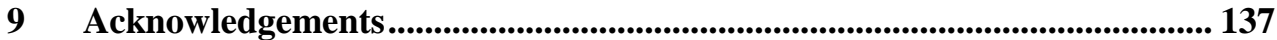




\section{Introduction}




\subsection{Introducing batteries}

Since their introduction in the 1990s, lithium ion (Li-ion) batteries have become the main power source for portable electronics and power tools applications. As society transitions towards electric and zero emission mobility, next generation electric cars require lithium batteries with superior energy and power density (respectively $W h \cdot m^{-3}$ and $W \cdot m^{-3}$ ), without compromising safety and environmental concerns [1,2]. Also for stationary applications (such as grid stabilization and uninterruptable power supplies) lithium batteries become more popular due to their high energy and power density [3].

Energy density is the amount of energy (usually Wh) a certain volume or weight contains. Power density is the rate of energy flow a volume is capable of. An example of power density differences can be given by how fast a battery can be charged or discharged. At high power densities a car or electric motorcycle can be quickly charged or can have high power outputs and quickly accelerate. Two examples are shown in figure 1.

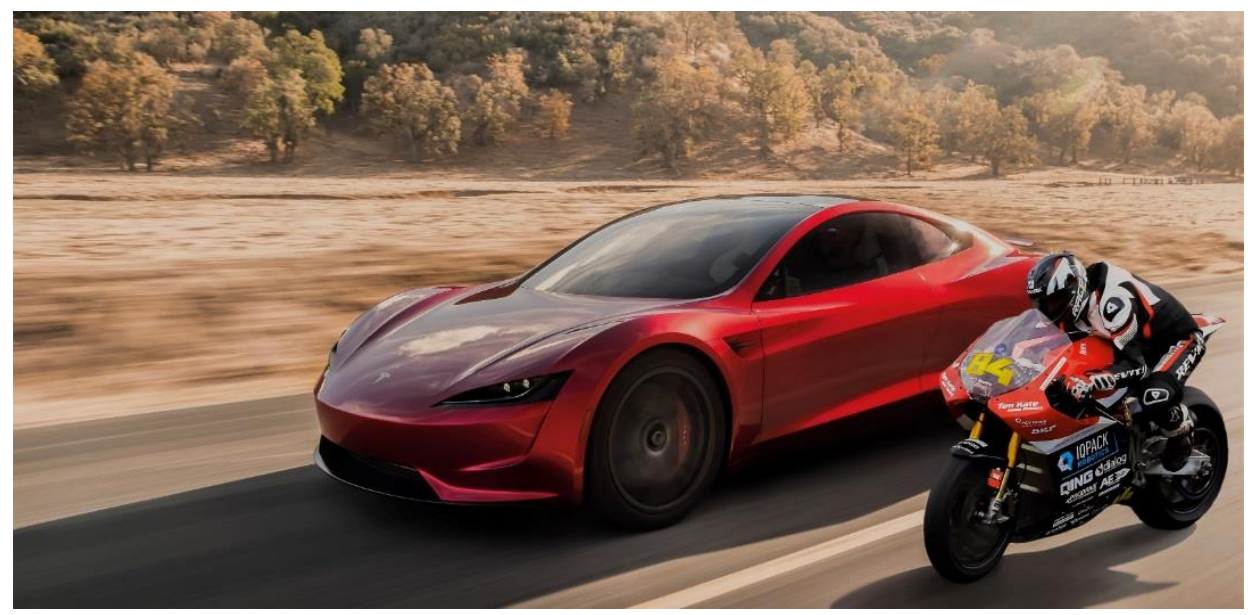

Figure 1, A popular electric car brand concept car and an electric motorcycle both exceeding speeds above $200 \mathrm{~km} / \mathrm{h}$. These high speeds are possible through the high power density and therefore output of their respective batteries. 
There are many energy storage technologies available and under research. The main difference being their specific energy density as shown in figure 2 [4]. Super capacitors are known for their ability to quickly charge and discharge, and thus give off a lot of power. However, their energy density is limited. Lead acid is still largely used in car industry as the standard for starting, lighting and ignition power source. The Nickel-Cadmium (Ni-Cd) chemistry is widely known for its use in the old rechargeable batteries and as battery packs in electric tools. However, as Ni-Cd batteries suffer from memory effect, where the last discharge capacity is "remembered" and a consecutive use cannot discharge beyond this point, the Nickel Metal Hydrate (Ni-MH) chemistry does not. With the addition of a higher energy density, Ni-MH has taken the place of Ni-Cd. The Sodium Nickel Chloride chemistry $\left.\mathrm{Na} / \mathrm{NiCl}_{2}\right)$ is to the author's knowledge not widely used. As it functions on higher temperatures this might be the main reason for the limited application of this chemistry in everyday appliances.

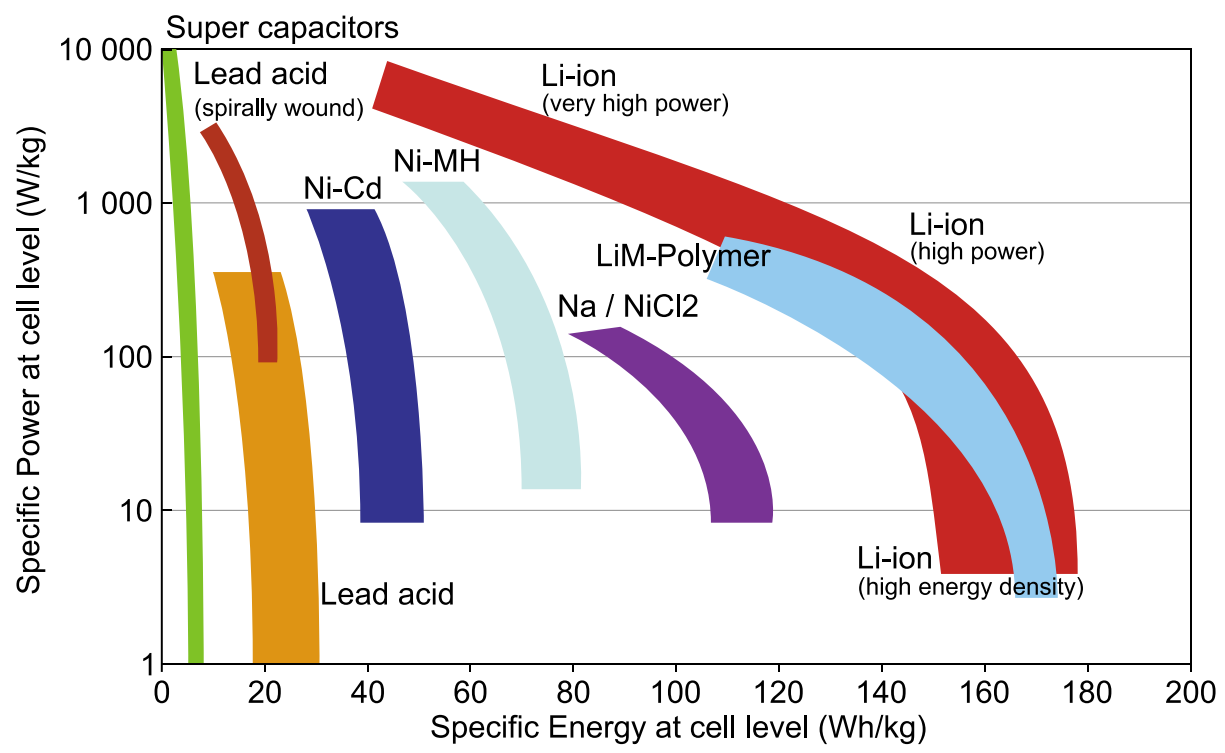

Figure 2, Battery technologies in terms of specific power density (W/kg) and energy density (Wh/kg). Adapted from [4] 
The main reason for the popularity of lithium lies within its high energy density since it is the most electropositive (-3 V versus hydrogen) as well as the lightest metal $(6.94 \mathrm{~g} / \mathrm{mol}$ and $0.53 \mathrm{~g} / \mathrm{cm}^{3}$ ) [5]. Batteries that are based on a lithium chemistry where the lithium ion is transported back and forth within the cell are so-called Li-ion batteries (rocking chair technology). The general build-up of such a li-ion battery is shown in figure 3 . A cell consists of at least 5 parts: an anode, an electrolyte, a cathode, a current collector for the anode and the cathode, and a housing that contains these parts.

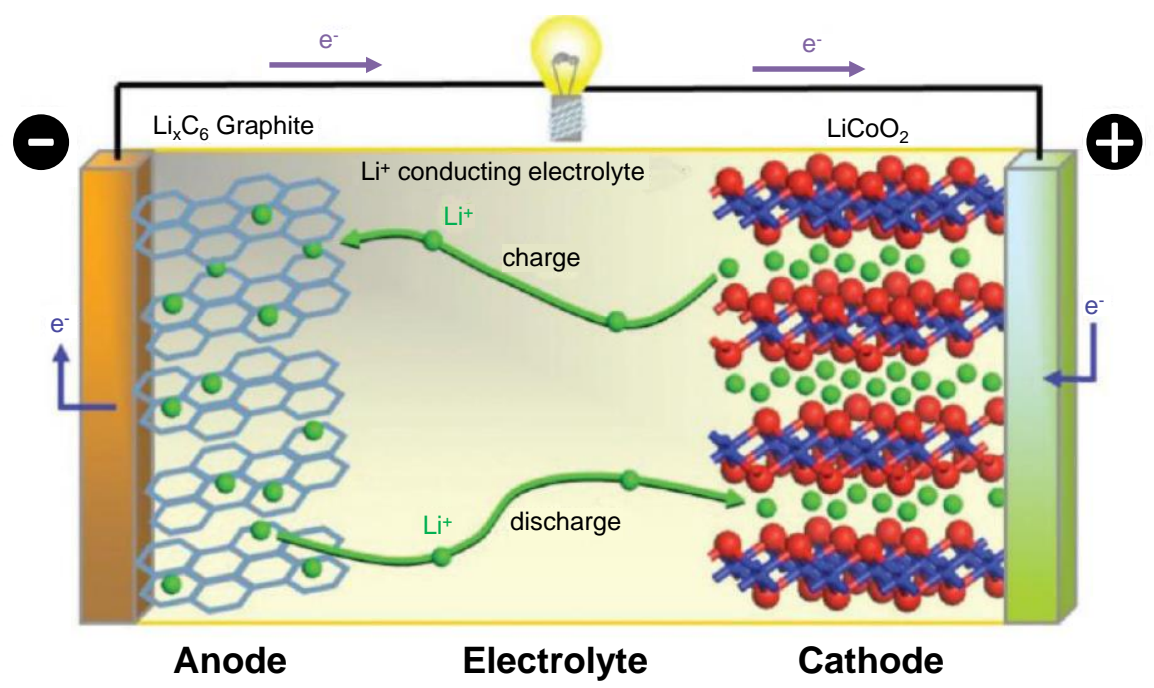

Figure 3, Working principle of a rechargeable lithium-ion battery. Upon discharge $\mathrm{Li}^{+}$ions travel from anode to cathode through electrolyte while electrons travel outside the cell from anode to cathode powering anything in between. Upon charge $\mathrm{Li}^{+}$-ions are pushed from cathode to anode by an external force that supplies the electrons. Adapted from [6].

At their introduction in the '90s the common materials used for the anode and cathode were graphite and $\mathrm{LiCoO}_{2}$. As electrolyte, a liquid was used. This is often $\mathrm{LiPF}_{6}$ dissolved in 
EC:DMC with additional additives to influence the reactions that take place within this acidic medium and on the anode and cathode. When the liquid electrolyte gets into contact with the anode and/or cathode an interphase between the two is often (not always) created. This interphase consists of electrolyte components that have degraded and reacted partly with the electrode, forming a solid layer. Therefore, this layer is called a Solid-ElectrolyteInterphase layer, or SEI-layer for short.

Within the packaging of a cell, a separator is needed to avoid contact between anode and cathode when a liquid electrolyte is used. This takes up space and therefore decreases energy density. However, when this separator is made too thin, and a connection between anode and cathode is made (a short), it often causes a dramatic failure of the cell. Furthermore, during battery misuse or sometimes over the lifetime of a battery, dendrites are forming. The dendrites consist of metallic lithium and can sometimes penetrate the separator causing a short and therewith irreparable damage to the cell.

During discharge $\mathrm{Li}^{+}$-ions from the anode move towards the cathode while the material/metal (M, usually a transition metal) at the cathode is reduced from $\mathrm{M}^{\mathrm{n}}$ to $\mathbf{M}^{\mathrm{n}-1}$. Upon charging a reversal process is forced; the material at the cathode goes back from $\mathrm{M}^{\mathrm{n}-1}$ to $\mathrm{M}^{\mathrm{n}}$ and the $\mathrm{Li}^{+}$-ion moves towards the anode. An example reaction scheme can be seen below:

\section{Charged $\stackrel{\text { Discharge }}{\longrightarrow}$ Discharged $\stackrel{\text { Charge }}{\longrightarrow}$ Charged}

$\begin{array}{cccccc}\text { Anode } & \mathrm{Li}_{x} \mathrm{C}_{6} & \rightarrow & \mathrm{Li}_{x-1} \mathrm{C}_{6}+\mathrm{Li}^{+}+e^{-} & \rightarrow & \mathrm{Li}_{x} \mathrm{C}_{6} \\ \text { Cathode } & \lambda-\mathrm{Co}^{4+} \mathrm{O}_{2}^{4-}+\mathrm{Li}^{+}+e^{-} & \rightarrow & \mathrm{Li}^{+} \mathrm{Co}^{3+} \mathrm{O}_{2}^{4-} & \rightarrow & \lambda-\mathrm{Co}^{4+} \mathrm{O}_{2}^{4-}+\mathrm{Li}^{+}+e^{-}\end{array}$


In the reaction scheme the same materials as in figure 3 are used. There are, however, many more materials available, not only for the cathode and anode, but also the electrolyte. The 'challenge' in industry is finding the right combination with the right additives to design the best battery for a certain application. This has led to the common chemistry where a graphite anode is used with $\mathrm{LiPF}_{6}$ as salt in the electrolyte and a cathode consisting of $\mathrm{LiCoO}_{2}$ [6]. While other anodes such as Silicon, Li-metal and $\mathrm{Li}_{4} \mathrm{Ti}_{5} \mathrm{O}_{12}$ exist, they contain more limitations than the standard used graphite $\mathrm{Li}_{\mathrm{x}} \mathrm{C}_{6}$. Silicon suffers from large volume changes during charge-discharge, causing loss of connection with the electrode and trapping of $\mathrm{Li}^{+}$. Li-metal is very reactive, causing decomposition of the electrolyte and making the battery unsafe. $\mathrm{Li}_{4} \mathrm{Ti}_{5} \mathrm{O}_{12}$ is a very stable anode, but due to its high potential vs. $\mathrm{Li}(\sim 1.5 \mathrm{~V})$ the voltage of the battery is much lower, decreasing the energy density. For the electrolytes, the $\mathrm{LiPF}_{6}$ salt offers the highest ion-mobility while the organic compounds it is dissolved in (EC:DMC) offers a large enough stability versus the reactive conditions inside the cell, providing a reasonable safe battery. Therefore, the materials mentioned above (graphite, $\mathrm{LiPF}_{6}$ and $\mathrm{LiCoO}_{2}$ ) are the industry standard [6]. For the cathode, mostly intercalating materials are used. In these materials the $\mathrm{Li}^{+}$-ion can travel within the material's framework. The three major materials are the olivine $\mathrm{LiFePO}_{4}$, the layered $\mathrm{LiCoO}_{2}$ and the spinel $\mathrm{LiMn}_{2} \mathrm{O}_{4}$ (figure 4).

Due to the differences in their lithium diffusion pathways (which influence the lithium diffusivity through the materials) the three materials shown can behave differently with respect to their orientation. Limited diffusion pathways can influence the cycle-life and lifetime, which are dependent on the nature of the interphases between the electrodes and electrolyte. Furthermore, safety is a function of the stability of the electrode materials and their interfaces with the electrolyte [8-10]. 
Olivine $\mathrm{LiFePO}_{4}$

1D
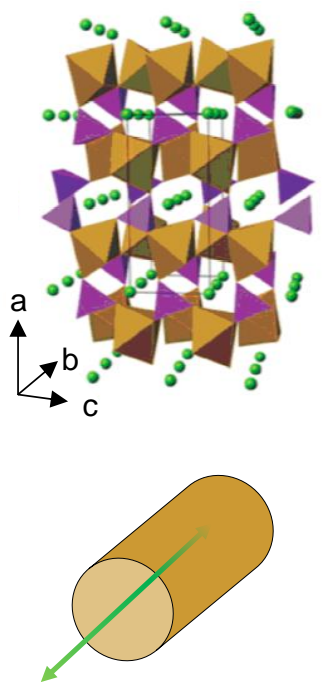

Layered $\mathrm{LiCoO}_{2}$

2D
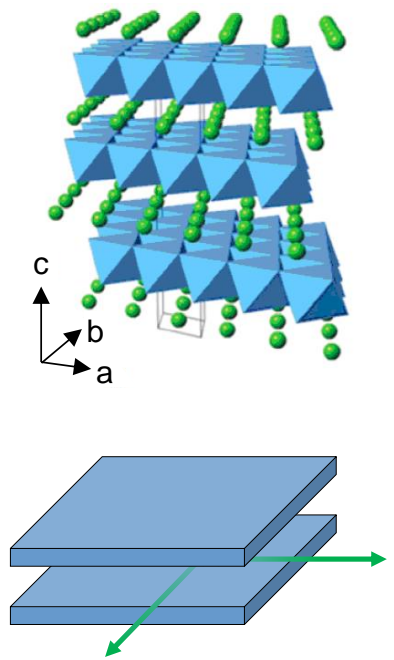

Spinel $\mathrm{LiMn}_{2} \mathrm{O}_{4}$

3D
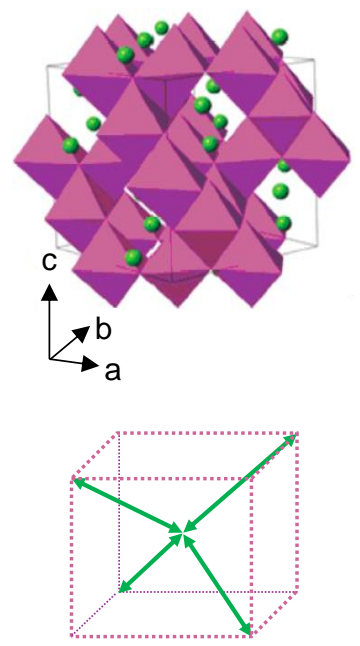

Figure 4, The structure and lithium diffusion pathways are shown for three major intercalation cathode materials; the olivine $\mathrm{LiFePO}_{4}$, the layered $\mathrm{LiCoO}_{2}$ and the spinel $\mathrm{LiMn}_{2} \mathrm{O}_{4}$. Adapted from [7].

Existing batteries, using conventional layered oxide cathodes are not only reaching their power and energy density limits, but their application in electric mobility and large applications is also limited by their inadequate cycle life and inherently poor safety features [11].

$\mathrm{LiCoO}_{2}$ allows for fast Li-diffusion combined with a high energy density of $272 \mathrm{mAh} / \mathrm{g}$ with a voltage of $4 \mathrm{~V}$. However, for structural stability reasons only about half that energy density can be used (140 mAh/g). Furthermore, Co is expensive and environmental unfriendly [5].

On the other hand, the spinel $\mathrm{LiMn}_{2} \mathrm{O}_{4}$, is a promising cathode material for next generation lithium batteries $[12,13]$ due to its relatively high operating voltage $(4.1 \mathrm{~V}$ vs $\mathrm{Li})$ and 
comparable energy density (theoretically $148 \mathrm{mAh} / \mathrm{g}$, typical $125 \mathrm{mAh} / \mathrm{g}$ ) combined with low cost and absence of direct environmental or safety hazards. Table 1 below shows the three major cathodes with their specific capacity (and practical capacity), average potential and (practical) energy density.

\begin{tabular}{|c|c|c|c|c|}
\hline Framework & Compound & $\begin{array}{l}\text { Specific } \\
\text { Capacity } \\
{\left[\mathrm{mAh} \mathrm{g}^{-1}\right]}\end{array}$ & $\begin{array}{l}\text { Average } \\
\text { Potential } \\
{\left[\mathrm{V} \text { vs } \mathrm{Li}^{0} / \mathrm{Li}^{+}\right]}\end{array}$ & $\begin{array}{l}\text { Energy Density } \\
{\left[\mathrm{Wh} \mathrm{kg}^{-1} \text { ) }\right.}\end{array}$ \\
\hline \multirow[t]{2}{*}{ Layered } & $\mathrm{LiCoO}_{2}$ & $272(140)$ & 4.0 & $1088(560)$ \\
\hline & $\mathrm{LiNi}_{1 / 3} \mathrm{Mn}_{1 / 3} \mathrm{Co}_{1 / 3} \mathrm{O}_{2}$ & $272(200)$ & 4.0 & $1088(800)$ \\
\hline \multirow[t]{2}{*}{ Spinel } & $\mathrm{LiMn}_{2} \mathrm{O}_{4}$ & $148(125)$ & 4.1 & $607(513)$ \\
\hline & $\mathrm{LiNi}_{0.5} \mathrm{Mn}_{1.5} \mathrm{O}_{4}$ & $148(125)$ & 4.7 & $696(588)$ \\
\hline \multirow[t]{2}{*}{ Olivine } & $\mathrm{LiFePO}_{4}$ & $170(160)$ & 3.45 & $587(552)$ \\
\hline & $\mathrm{LiFe}_{1 / 2} \mathrm{Mn}_{1 / 2} \mathrm{PO}_{4}$ & $170(160)$ & $3.4 / 4.1$ & $638(600)$ \\
\hline
\end{tabular}

Table 1, Comparison of multiple material compounds and their capacities, potentials and energy densities. Adapted from [7]. Values in brackets are numbers that are achieved in practice.

As the energy density of $\mathrm{LiCoO}_{2}(560 \mathrm{Wh} / \mathrm{kg})$ achieved in practice is comparable to that of $\mathrm{LiMn}_{2} \mathrm{O}_{4}(513 \mathrm{Wh} / \mathrm{kg})$ with $\mathrm{LiMn}_{2} \mathrm{O}_{4}$ being cheaper, safer and more environmental friendly it is clear why it is a promising material [7]. However, compared to the $\mathrm{LiNi}_{1 / 3} \mathrm{Co}_{1 / 3} \mathrm{Mn}_{1 / 3} \mathrm{O}_{2}$ (NCM) the energy density is much lower while NCM uses less cobalt. On the other hand, the NCM is still costly and less safe than $\mathrm{LiMn}_{2} \mathrm{O}_{4}[12,13]$. 
In the spinel $\mathrm{LiMn}_{2} \mathrm{O}_{4}$ (space group $\mathrm{Fd} \overline{3} \mathrm{~m}$ ), lithium (Li) and manganese (Mn) occupy tetrahedral (8a) and octahedral (16d) sites in the intervening cubic close-packed array of oxygen $(\mathrm{O})$ atoms (32e sites). The crystal structure is shown in figure $5 \mathrm{~b}$.
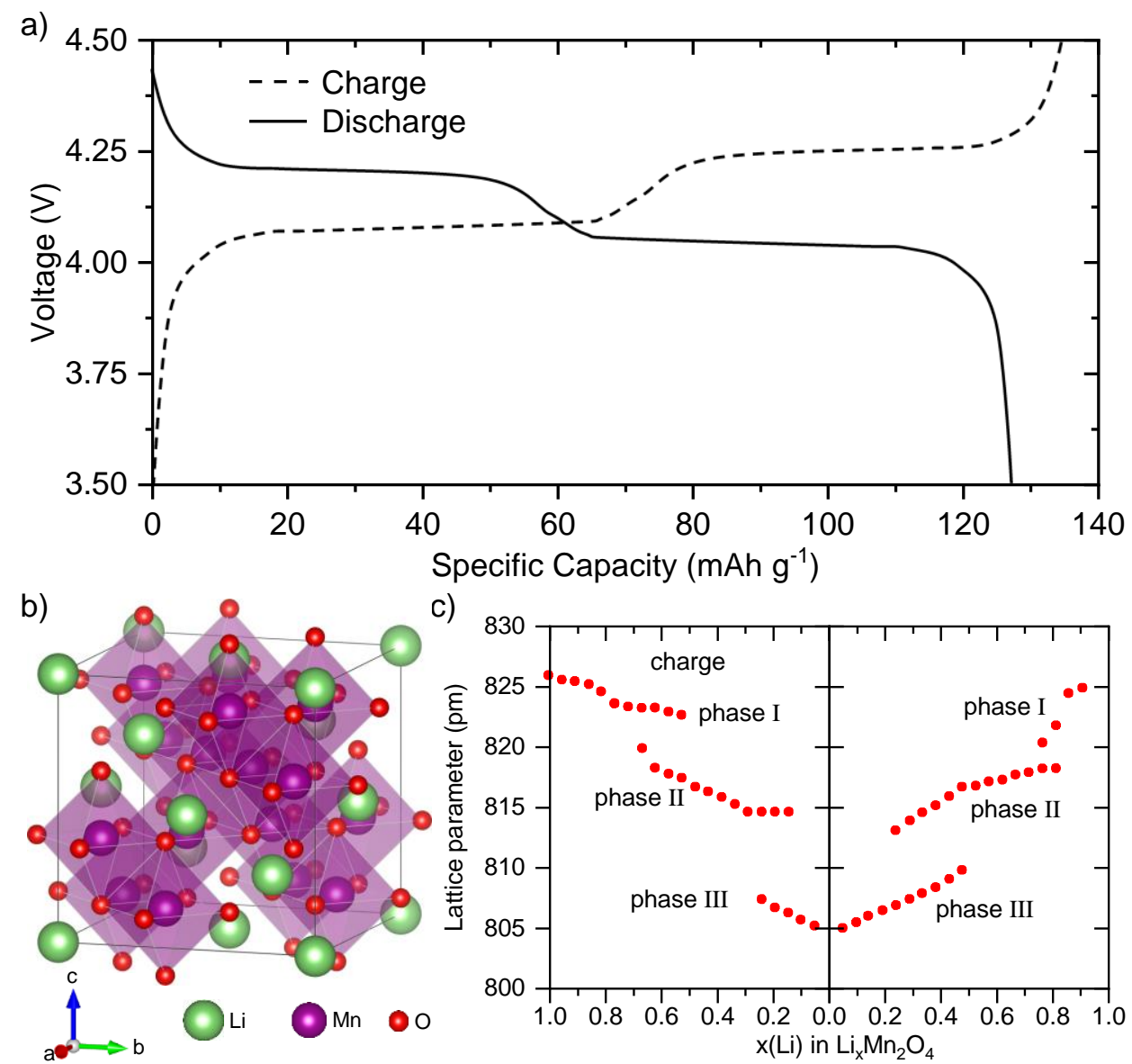

Figure 5, a) Characteristic $\sim 4 \mathrm{~V}$ plateaus of $\mathrm{LiMn}_{2} \mathrm{O}_{4}$ cathode material versus Li-metal upon charge and discharge. b) Crystal structure of the spinel $\mathrm{LiMn}_{2} \mathrm{O}_{4}$. c) The change of the lattice parameter of $\mathrm{Li}_{x} \mathrm{Mn}_{2} \mathrm{O}_{4}$ over lithium content. At $x=0$ the cathode is charged, the voltage is above the 2 plateaus and the lattice parameter is around $8.05 \AA . c$ ) is adapted from [7]. 
The edge-shared octahedral $\mathrm{Mn}_{2} \mathrm{O}_{4}$ host framework provides structural stability and interconnects face-shared tetrahedral lithium (8a) sites and empty octahedral (16c) sites. These interconnected pathways allow the three-dimensional diffusion of lithium-ions within the $\mathrm{Mn}_{2} \mathrm{O}_{4}$ framework, making $\mathrm{LiMn}_{2} \mathrm{O}_{4}$ suitable for high power applications. The lithium (de)intercalation at ( $8 \mathrm{a}$ ) tetrahedral sites results into the characteristic $\sim 4 \mathrm{~V}$ voltage plateaus (figure 5a) without distorting the spinel symmetry. Interestingly, this $\mathrm{Mn}_{2} \mathrm{O}_{4}$ framework can further host lithium into empty octahedral (16c) sites, resulting in a $3 \mathrm{~V}$ voltage plateau, almost doubling its capacity. Where the theoretical capacity of $\mathrm{LiMn}_{2} \mathrm{O}_{4}$ is $148 \mathrm{mAh} / \mathrm{g}$, intercalating a second lithium ion increases the theoretical capacity of $\mathrm{Li}_{2} \mathrm{Mn}_{2} \mathrm{O}_{4}$ to 288 $\mathrm{mAh} / \mathrm{g}$. While intercalating the second lithium ion the spinel undergoes a cubic to tetragonal phase transition (figure 6). This transition makes the cubic-spinel, with a lattice parameter of $8.25 \AA$, transform to a tetragonal spinel with lattice parameters of $9.24 \AA \cdot(5.65 \AA)^{2}$.

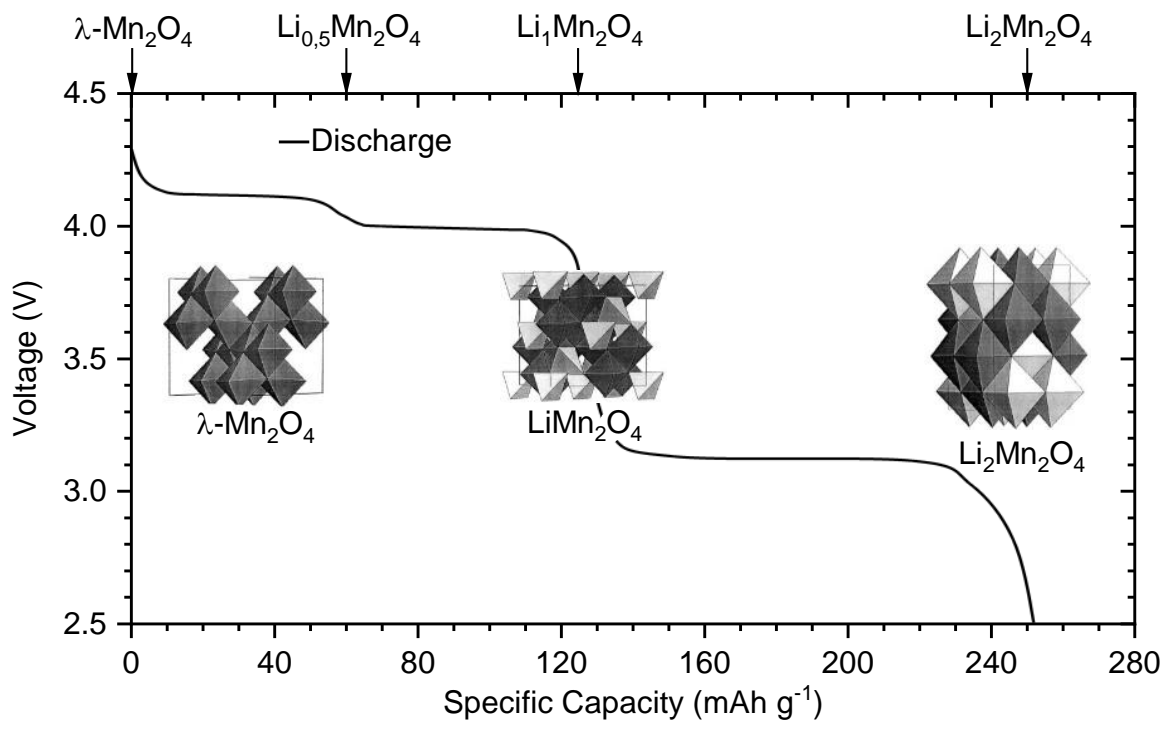

Figure 6, Discharge profile when including the $3 \mathrm{~V}$ plateau together with the crystal structure throughout lithiation. Inset crystal structures are adapted from [15]. 
Also interesting is the possibility to increase the operating voltage to $\sim 5 \mathrm{~V}$ by partially substituting $\mathrm{Mn}$ with $\mathrm{Ni}$ in the $\mathrm{Mn}_{2} \mathrm{O}_{4}$ framework to achieve a $\mathrm{Ni}_{0.5} \mathrm{Mn}_{1.5} \mathrm{O}_{4}$ framework [14].

However, despite these advantageous properties, $\mathrm{LiMn}_{2} \mathrm{O}_{4}$ cathodes suffer from fading capacity and poor cycle life performance [16]. The origin of this capacity loss is attributed to two factors: first, the onset of Jahn-Teller distortion in deeply discharged electrodes $[1,5,17,18]$, and second, the dissolution of $\mathrm{Mn}$ ions from the $\mathrm{Mn}_{2} \mathrm{O}_{4}$ framework [19]. The Jahn-Teller distortion, accompanied by the cubic to tetragonal phase transition, irreversibly damages the structural integrity of the spinel framework during deep cycling below $\sim 3 \mathrm{~V}$ and causes permanent capacity loss. However, this Jahn-Teller distortion can be avoided by limiting the charging and discharging to the $\sim 4 \mathrm{~V}$ plateaus. Mn dissolution causes continuous loss of active material and consequently blocking of 3D lithium diffusion pathways, thereby impeding the overall cell performance and remaining the key limitation for using $\mathrm{LiMn}_{2} \mathrm{O}_{4}$ cathodes [2]. Previous studies have suggested that acidification of electrolyte, caused by reaction of the lithiumhexafluorophosphate $\left(\mathrm{LiPF}_{6}\right)$ salt in electrolyte with $\mathrm{H}_{2} \mathrm{O}$, coupled with oxygen loss at the cathode surface, to be the origin of Mn dissolution $[8,9,19]$. The underlying mechanism can be understood via a disproportional reaction of $\mathrm{Mn}^{3+}$ generating soluble $\mathrm{Mn}^{2+}$ :

$$
4 \mathrm{H}^{+}+2 \mathrm{Li}\left(\mathrm{Mn}^{3+} \mathrm{Mn}^{4+}\right) \mathrm{O}_{4} \rightarrow 3 \lambda-\mathrm{Mn}^{4+} \mathrm{O}_{2}+\mathrm{Mn}^{2+}+2 \mathrm{Li}^{+}+2 \mathrm{H}_{2} \mathrm{O}
$$

Various strategies have been suggested to mitigate the Mn dissolution of $\mathrm{LiMn}_{2} \mathrm{O}_{4}$, such as aliovalent doping, surface coating, nanostructuring, mixed phase synthesis $[8,10-13,15$, $16,20-26]$. Although these strategies have indisputably shown significant enhancement in $\mathrm{LiMn}_{2} \mathrm{O}_{4}$ performance, it remains far from the desired level for usage in applications. However, studies have shown that the specific crystal facet in contact with the electrolyte plays an important role in the electrochemical reactions occurring at the cathode surface for 
single crystalline nanowires [27], truncated structures [28], and thin films [29]. Highly

controlled thin films make excellent model systems to study the lithiation mechanisms, as well as to elucidate the possible limiting factors, including Li-ion diffusion, Li-ion transport, and electronic transport. Epitaxial engineering is applied in Chapter $\mathbf{2}$ to control the crystal orientation of $\mathrm{LiMn}_{2} \mathrm{O}_{4}$ thin films by growing on different oriented $\mathrm{Nb}: \mathrm{SrTiO}_{3}$ substrates. This enables a unique insight into the relation between electrochemistry, interface and crystal directionality, not obtainable in single crystals or polycrystalline samples, and previously not fully explored for epitaxial films [30 - 33].

Even though this material is considered a 3-dimentional material (i.e. lithium and electrons can move in 3 directions) interactions with the electrolyte and the substrate can be different for the different planes of the $\mathrm{LiMn}_{2} \mathrm{O}_{4}$ crystal. The surface of the cathode and anode interact with the electrolyte, the reaction products of which form a solid-electrolyte-interface (SEI). The different surface-planes of $\mathrm{LiMn}_{2} \mathrm{O}_{4}$ react differently with the electrolyte [29], however, detailed knowledge on this is limited. Therefore, in Chapter 3 this electrochemical behavior of the cell is modeled in detail by Electrochemical Impedance Spectroscopy (EIS) to get more in-depth knowledge of the electrochemical response of each layer within the cell. Subsequently, for thorough understanding of $\mathrm{LiMn}_{2} \mathrm{O}_{4}$ its behavior under different loads and over time is elucidated in Chapter 4.

For $\mathrm{LiMn}_{2} \mathrm{O}_{4}$ it is known that the Jahn-Teller distortion at $\sim 3 \mathrm{~V}$ causes rapid capacity loss due to the structural change from cubic- to tetragonal-spinel, damaging the framework and making material lose connection to the electrode. This is avoided by limiting the potential window to around $4 \mathrm{~V}$. However, when the cell is allowed to further discharge to below 3 $\mathrm{V}$, the capacity of the cathode can double. Looking back at table 1 and incorporating the additional discharge to $\mathrm{Li}_{2} \mathrm{Mn}_{2} \mathrm{O}_{4}$, the energy density values show an interesting increase: 


\begin{tabular}{|c|c|c|c|c|}
\hline Framework & Compound & $\begin{array}{l}\text { Specific Capacity } \\
{\left[\mathrm{mAh} \mathrm{g}^{-1}\right]}\end{array}$ & $\begin{array}{l}\text { Average Potential } \\
\left.\text { [V vs } \mathrm{Li}^{0} / \mathbf{L i}^{+}\right]\end{array}$ & $\begin{array}{l}\text { Energy Density } \\
{\left[\mathrm{Wh} \mathrm{kg}^{-1}\right)}\end{array}$ \\
\hline Spinel & $\mathrm{LiMn}_{2} \mathrm{O}_{4}$ & $148(125)$ & 4.1 & 607 (513) \\
\hline t-Spinel & $\mathrm{Li}_{2} \mathrm{Mn}_{2} \mathrm{O}_{4}$ & $288(245)$ & $4.1 / 3$ & $1027(873)$ \\
\hline
\end{tabular}

Table 2, Comparison of cubic-spinel $\mathrm{LiMn}_{2} \mathrm{O}_{4}$ to tetragonal-spinel $\mathrm{Li}_{2} \mathrm{Mn}_{2} \mathrm{O}_{4}$. The capacities, potentials and energy densities are shown with numbers achieved in practice within brackets. Adapted from [7].

As energy density is such an important feature in batteries, the electrochemical response of the additional discharge to $\mathrm{Li}_{2} \mathrm{Mn}_{2} \mathrm{O}_{4}$, with a focus on structure stability and the proposed rapid capacity loss is studied in Chapter $\mathbf{5}$.

Next to energy density, power density plays a crucial role in the performance and safety of a battery. An important role is laid out here for the electrolyte. For liquid and gel electrolytes more literature is already available and these electrolytes are already widely used in commercial batteries. With regard to safety, a comment has to be made that for the gel and liquid electrolytes a separator is needed to avoid an internal electronic connection between the anode and cathode (a short) as this quickly discharges the battery and creates a lot of heat in the process. This heat can cause components of the electrolyte to start to decompose, react and add to the heat, causing a thermal runaway. Furthermore, the electrolyte together with the separator take up room but do not contribute to the total energy density. Therefore, the thinner the separator the better. Currently, the separator is usually made out of plastics such as polypropylene and polyethylene (PP \& PE) and has a thickness of 10-25 $\mu \mathrm{m}$ [1].

A promising alternative comes from the use of solid-state electrolytes. These do not need the separator due to their inherent structural integrity. Therefore, the electrolyte can be made 
thinner, to the point of it being a (nano)coating for the anode and/or cathode. As the

electrolyte can be made thinner, the room used for materials contributing to the energy density is maximized. Furthermore, solid-state electrolytes are safer due to their stability at higher temperatures, but are often said to suffer from lower ionic conductivities and lower chemical and electrochemical stability windows [34]. However, the lower ionic conductivity is partly negated by a higher transference number, and recent research also shows larger stability windows [35].

Epitaxial systems of the cathode and electrolyte allow for model systems, which subsequently allow to research the link between interfaces and the electrochemical response with, in addition, also the lithium diffusion pathways. Therefore, in Chapter 6, first the model $\mathrm{LiMn}_{2} \mathrm{O}_{4}$ systems will be combined with the well-known and state-of-the-art solidstate electrolyte $\left(\mathrm{Li}_{3 x} \mathrm{La}_{2 / 3}-\mathrm{TiO}\right)$, after which also the anode material $\left(\mathrm{Li}_{4} \mathrm{Ti}_{5} \mathrm{O}_{12}\right)$ is included to create full-solid-state epitaxial thin film batteries.

This allows for model epitaxial ceramic battery systems, which are currently unavailable. 


\subsection{References}

[1] T. B. Reddy, Linden's Handbook of Batteries, 4th ed. New York: McGraw-Hill, 2011.

[2] N. Nitta, F. Wu, J. T. Lee, and G. Yushin, "Li-ion battery materials: Present and future," Mater. Today, vol. 18, no. 5, pp. 252-264, 2015, DOI: 10.1016/j.mattod.2014.10.040.

[3] T. Xu, W. Wang, M. L. Gordin, D. Wang, and D. Choi, "Lithium-ion batteries for stationary energy storage,” JOM, vol. 62, no. 9, pp. 24-30, Sep. 2010, DOI: 10.1007/s11837-010-0131-6.

[4] International Energy Agency, “Technology Roadmaps: Electric and Plug-in Hybrid Electric Vehicles," (Original source: Johnson Control - SAFT 2005 and 2007.), 2009.

[5] J.-M. Tarascon and M. Armand, "Issues and challenges facing rechargeable lithium batteries,” Nature, vol. 414, no. 6861, pp. 359-367, 2001, DOI: 10.1038/35104644.

[6] Y. Kato et al., "High-power all-solid-state batteries using sulfide superionic conductors," Nat. Energy, vol. 1, no. 4, p. 16030, Mar. 2016, DOI: 10.1038/nenergy.2016.30.

[7] C. M. Julien, A. Mauger, K. Zaghib, and H. Groult, "Comparative Issues of Cathode Materials for Li-Ion Batteries,” Inorganics, vol. 2, pp. 132-154, 2014, DOI: 10.3390/inorganics2020132.

[8] A. C. Luntz, J. Voss, and K. Reuter, "Interfacial Challenges in Solid-State Li Ion Batteries," J. Phys. Chem. Lett., vol. 6, no. 22, pp. 4599-4604, 2015, DOI: 10.1021/acs.jpclett.5b02352.

[9] K. X. Wang, X. H. Li, and J. S. Chen, "Surface and interface engineering of electrode materials for lithium-ion batteries," Adv. Mater., vol. 27, no. 3, pp. 527545, 2015, DOI: 10.1002/adma.201402962.

[10] Y. Yuan, K. Amine, J. Lu, and R. Shahbazian-Yassar, "Understanding materials challenges for rechargeable ion batteries with in situ transmission electron microscopy," Nat. Commun., vol. 8, no. May, pp. 1-14, 2017, DOI: 10.1038/ncomms 15806 .

[11] F. Lin et al., "Surface reconstruction and chemical evolution of stoichiometric layered cathode materials for lithium-ion batteries," Nat. Commun., vol. 5, pp. 19, 2014, DOI: 10.1038/ncomms4529.

[12] M. M. Thackeray, "Manganese oxides for lithium batteries," Prog. Solid State Chem., vol. 25, no. 1-2, pp. 1-71, 1997, DOI: 10.1016/S0079-6786(97)81003-5.

[13] M. J. Lee, S. Lee, P. Oh, Y. Kim, and J. Cho, "High performance LiMn2O4cathode materials grown with epitaxial layered nanostructure for Li-Ion batteries," Nano Lett., vol. 14, no. 2, pp. 993-999, 2014, DOI: 10.1021/nl404430e. 
[14] J. Ma, P. Hu, G. Cui, and L. Chen, "Surface and Interface Issues in Spinel LiNi0.5Mn1.5O4: Insights into a Potential Cathode Material for High Energy Density Lithium Ion Batteries," Chem. Mater., vol. 28, no. 11, pp. 3578-3606, 2016, DOI: 10.1021/acs.chemmater.6b00948.

[15] J. E. Greedan, "Geometrically frustrated magnetic materials," J. Mater. Chem., vol. 11, no. 1, pp. 37-53, 2001, DOI: 10.1039/b003682j.

[16] R. J. Gummow, A. de Kock, and M. M. Thackeray, "Improved capacity retention in rechargeable $4 \mathrm{~V}$ lithium/lithium-manganese oxide (spinel) cells," Solid State Ionics, vol. 69, no. 1, pp. 59-67, 1994, DOI: 10.1016/0167-2738(94)90450-2.

[17] A. Van der Ven, C. Marianetti, D. Morgan, and G. Ceder, "Phase transformations and volume changes in spinel $\mathrm{Li}_{\mathrm{x}} \mathrm{Mn}_{2} \mathrm{O}_{4}$," Solid State Ionics, vol. 135, no. 1-4, pp. 21-32, Nov. 2000, DOI: 10.1016/S0167-2738(00)00326-X.

[18] M. M. Thackeray, W. I. F. David, P. G. Bruce, and J. B. Goodenough, "Lithium insertion into manganese spinels," Mater. Res. Bull., vol. 18, no. 4, pp. 461-472, 1983, DOI: 10.1016/0025-5408(83)90138-1.

[19] J. C. Hunter, "Preparation of a new crystal form of manganese dioxide: $\lambda-\mathrm{MnO}_{2}$," J. Solid State Chem., vol. 39, no. 2, pp. 142-147, 1981, DOI: 10.1016/00224596(81)90323-6.

[20] A. Bhandari and J. Bhattacharya, "Review-Manganese Dissolution from Spinel Cathode: Few Unanswered Questions,” J. Electrochem. Soc., vol. 164, no. 2, pp. A106-A127, Dec. 2017, DOI: 10.1149/2.0101614jes.

[21] M.-J. Lee, E. Lho, P. Bai, S. Chae, J. Li, and J. Cho, "Low-Temperature Carbon Coating of Nanosized $\mathrm{Li}_{1.015} \mathrm{Al}_{0.06} \mathrm{Mn}_{1.925} \mathrm{O}_{4}$ and High-Density Electrode for HighPower Li-Ion Batteries,” Nano Lett., vol. 17, no. 6, pp. 3744-3751, Jun. 2017, DOI: 10.1021/acs.nanolett.7b01076.

[22] D. K. Kim et al., "Spinel $\mathrm{LiMn}_{2} \mathrm{O}_{4}$ nanorods as lithium ion battery cathodes," Nano Lett., vol. 8, no. 11, pp. 3948-3952, 2008, DOI: 10.1021/n18024328.

[23] S.-T. Myung, K.-S. Lee, D.-W. Kim, B. Scrosati, and Y.-K. Sun, "Spherical coreshell $\mathrm{Li}\left[\left(\mathrm{Li}_{0.05} \mathrm{Mn}_{0.95}\right) 0.8\left(\mathrm{Ni}_{0.25} \mathrm{Mn}_{0.75}\right) 0.2\right]_{2} \mathrm{O}_{4}$ spinels as high performance cathodes for lithium batteries," Energy Environ. Sci., vol. 4, no. 3, p. 935, 2011, DOI: 10.1039/c0ee00298d.

[24] C. D. Amos, M. A. Roldan, M. Varela, J. B. Goodenough, and P. J. Ferreira, "Revealing the Reconstructed Surface of $\mathrm{Li}\left[\mathrm{Mn}_{2}\right] \mathrm{O}_{4}$," Nano Lett., vol. 16, no. 5, pp. 2899-2906, May 2016, DOI: 10.1021/acs.nanolett.5b03926.

[25] F. Jiao, J. Bao, A. H. Hill, and P. G. Bruce, "Synthesis of Ordered Mesoporous LiMn-O Spinel as a Positive Electrode for Rechargeable Lithium Batteries," Angew. Chemie, vol. 120, no. 50, pp. 9857-9862, Dec. 2008, DOI: 10.1002/ange. 200803431 . 
[26] S. Bin Park, H. C. Shin, W. G. Lee, W. Il Cho, and H. Jang, "Improvement of capacity fading resistance of $\mathrm{LiMn}_{2} \mathrm{O}_{4}$ by amphoteric oxides," J. Power Sources, vol. 180, no. 1, pp. 597-601, 2008, DOI: 10.1016/j.jpowsour.2008.01.051.

[27] E. Hosono, T. Kudo, I. Honma, H. Matsuda, and H. Zhou, "Synthesis of Single Crystalline Spinel $\mathrm{LiMn}_{2} \mathrm{O}_{4}$ Nanowires for a Lithium Ion Battery with High Power Density," 2009, DOI: 10.1021/n1803394v.

[28] J. S. Kim, K. Kim, W. Cho, W. H. Shin, R. Kanno, and J. W. Choi, "A truncated manganese spinel cathode for excellent power and lifetime in lithium-ion batteries," Nano Lett., vol. 12, no. 12, pp. 6358-6365, 2012, DOI: 10.1021/nl303619s.

[29] M. Hirayama et al., "Characterization of Electrode/Electrolyte Interface with XRay Reflectometry and Epitaxial-Film $\mathrm{LiMn}_{2} \mathrm{O}_{4}$ Electrode,” J. Electrochem. Soc., vol. 154, no. 11, p. A1065, 2007, DOI: 10.1149/1.2778853.

[30] K. Suzuki, K. Kim, S. Taminato, M. Hirayama, and R. Kanno, "Fabrication and electrochemical properties of $\mathrm{LiMn}_{2} \mathrm{O}_{4} / \mathrm{SrRuO}_{3}$ multi-layer epitaxial thin film electrodes," J. Power Sources, vol. 226, pp. 340-345, 2013, DOI: 10.1016/j.jpowsour.2013.07.051.

[31] X. Gao et al., "Structural Distortion and Compositional Gradients Adjacent to Epitaxial $\mathrm{LiMn}_{2} \mathrm{O}_{4}$ Thin Film Interfaces,” Adv. Mater. Interfaces, vol. 1, no. 8, pp. 1-10, 2014, DOI: 10.1002/admi.201400143.

[32] Y. H. Ikuhara et al., "Epitaxial Growth of $\mathrm{LiMn}_{2} \mathrm{O}_{4}$ Thin Films by Chemical Solution Deposition for Multilayer Lithium-Ion Batteries,” J. Phys. Chem. C, vol. 118, no. 34, pp. 19540-19547, 2014, DOI: 10.1021/jp504305q.

[33] K. Suzuki et al., "Interfacial Analysis of Surface-Coated $\mathrm{LiMn}_{2} \mathrm{O}_{4}$ Epitaxial Thin Film Electrode for Lithium Batteries," J. Electrochem. Soc., vol. 162, no. 13, pp. A7083-A7090, 2015, DOI: 10.1149/2.0111513jes.

[34] N. Kamaya et al., “A lithium superionic conductor,” Nat. Mater., vol. 10, no. 9, pp. 682-686, 2011, DOI: 10.1038/nmat3066.

[35] Z. Zheng, H. -z. Fang, Z. -k. Liu, and Y. Wang, “A Fundamental Stability Study for Amorphous $\mathrm{LiLaTiO}_{3}$ Solid Electrolyte,” J. Electrochem. Soc., vol. 162, no. 1, pp. A244-A248, 2014, DOI: 10.1149/2.0011503jes. 


\section{Orientation dependence in epitaxial engineered $\mathrm{LiMn}_{2} \mathrm{O}_{4}$ model systems}

This Chapter is based on the publication:

T.A. Hendriks, D.M. Cunha, D.P. Singh, M. Huijben, "Enhanced Lithium Transport by Control of Crystal Orientation in Spinel $\mathrm{LiMn}_{2} \mathrm{O}_{4}$ Thin Film Cathodes", ACS Appl. Energy Mater., 2018, 1 (12), pp 7046-7051, DOI: 10.1021/acsaem.8b01477 


\subsection{Introduction}

Spinel $\mathrm{LiMn}_{2} \mathrm{O}_{4}$ has emerged as a promising cathode material for next generation lithium batteries $[1,2]$ due to its relatively high operating voltage (4.1 V vs Li) and comparable energy density (theoretically $148 \mathrm{mAh} / \mathrm{g}$, typical $120 \mathrm{mAh} / \mathrm{g}$ ) combined with low cost and absence of direct environmental or safety hazards. As mentioned in chapter 1, the edgeshared octahedral $\mathrm{Mn}_{2} \mathrm{O}_{4}$ host framework provides structural stability and the pathways within the framework allow the three-dimensional diffusion of lithium ions. The $\mathrm{Mn}_{2} \mathrm{O}_{4}$ framework can further host another lithium-ion, resulting in a $3 \mathrm{~V}$ voltage plateau, thereby almost doubling its capacity (theoretical capacity of $\mathrm{Li}_{2} \mathrm{Mn}_{2} \mathrm{O}_{4}$ is $288 \mathrm{mAh} / \mathrm{g}$ ) while the framework undergoes a cubic to tetragonal phase transition. Furthermore, by partially substituting $\mathrm{Mn}$ with $\mathrm{Ni}$ in the $\mathrm{Mn}_{2} \mathrm{O}_{4}$ framework the operating voltage of $\mathrm{LiMn}_{2} \mathrm{O}_{4}$ can be increased to $\sim 5 \mathrm{~V}[3]$.

Despite this, the $\mathrm{LiMn}_{2} \mathrm{O}_{4}$ cathode suffers from a fading capacity and poor performing cycle life [4]. Two factors contribute to this: the dissolution of $\mathrm{Mn}$ ions from the $\mathrm{Mn}_{2} \mathrm{O}_{4}$ framework [8], and second, the onset of the Jahn-Teller distortion around $3 \mathrm{~V}$ for deeply discharged cells [5-7]. The distortion leads to a cubic to tetragonal phase transition that irreversibly damages the integrity of the spinel framework when the $3 \mathrm{~V}$ plateau is included in cycling, causing permanent capacity loss. By limiting the use to only the $4 \mathrm{~V}$ plateau, it can be avoided but only the theoretical energy density of $148 \mathrm{mAh} / \mathrm{gram}$ can then be achieved. Mn dissolution causes a continuous loss of active material and can block parts of the 3D lithium diffusion pathways, impeding the overall cell performance. This thereby remains the key limitation for using $\mathrm{LiMn}_{2} \mathrm{O}_{4}$ cathodes [9]. The origin of the dissolution is thought to be due to acidification of electrolyte, caused by a reaction of lithiumhexafluorophosphate $\left(\mathrm{LiPF}_{6}\right)$ salt in electrolyte with $\mathrm{H}_{2} \mathrm{O}$ traces and coupled with oxygen loss at the cathode surface as explained through a disproportional reaction of $\mathrm{Mn}^{3+}$ generating soluble $\mathrm{Mn}^{2+}[8,10,11]$ : 


$$
4 \mathrm{H}^{+}+2 \mathrm{Li}\left(\mathrm{Mn}^{3+} \mathrm{Mn}^{4+}\right) \mathrm{O}_{4} \rightarrow 3 \lambda-\mathrm{Mn}^{4+} \mathrm{O}_{2}+\mathrm{Mn}^{2+}+2 \mathrm{Li}^{+}+2 \mathrm{H}_{2} \mathrm{O}
$$

A few strategies have been proposed to decrease the amount of $\mathrm{Mn}$ dissolution in $\mathrm{LiMn}_{2} \mathrm{O}_{4}$ such as aliovalent doping, surface coating, nanostructuring, and mixed phase synthesis [14,10,12-20]. Even though these methods have shown a significant mitigation of the Mn dissolution, and, consequently, enhancement in $\mathrm{LiMn}_{2} \mathrm{O}_{4}$ performance, it is not yet ready for usage in applications. Studies with single crystalline nanowires [21], truncated structures [22] and thin films [23] show that the specific crystal facet in contact with the electrolyte plays an important role in the electrochemical reactions occurring at the cathode surface.

Therefore, control of the interfacial properties between the electrodes and electrolyte is needed but remains a great challenge. Detailed understanding of the electrochemical behavior of specific crystal facets of battery materials can only be obtained when a single crystal orientation interfacing the electrolyte can be controlled. This requirement can be achieved by epitaxial thin film technology, in which the flat surface and restricted lattice plane of the thin film cathode can simplify the reaction mechanism at such highly ordered cathode-electrolyte interface as compared to an uncontrolled interface. Most studies on $\mathrm{LiMn}_{2} \mathrm{O}_{4}$ thin films have investigated polycrystalline samples, while only limited experimental research has been performed on single crystalline thin films [23-29]. Characterization of such epitaxial thin films has previously been focused on the structural properties, and only few reports have shown electrochemical properties by clear redox peaks in the cyclic voltammetry, and discharge capacities of $\sim 125 \mathrm{mAh} / \mathrm{g}$ with clear plateau regions in the charge-discharge curves $[26,28,29]$. Detailed insight into the relation between the specific crystal orientation towards the adjacent electrolyte and its electrochemical behavior has been lacking, which has hampered the development of high-quality $\mathrm{LiMn}_{2} \mathrm{O}_{4}$ cathode with high cyclability. Hirayama et al. concluded from surface X-ray diffraction 
measurements that a solid-electrolyte interface (SEI) was present on both (111) and (110) surfaces, although the (110) surface was less stable and indicated a higher Mn dissolution [25]. So far the electrochemical performance was only reported for $\mathrm{LiMn}_{2} \mathrm{O}_{4}$ thin films grown on (111)-oriented $\mathrm{SrTiO}_{3}$ substrates [26,29], where an additional $\mathrm{Li}_{3} \mathrm{PO}_{4}$ coating was added to prevent a phase transition of the surface region and to suppress Mn dissolution and desorption of oxygen from the surface.

Here, by structural engineering of stable and epitaxial $\mathrm{LiMn}_{2} \mathrm{O}_{4}$ thin films, the electrochemical properties can be controlled and enhanced as compared to polycrystalline samples. By changing the crystal orientation of the underlying single crystalline substrate ((100), (110) and (111)) we can control the specific orientation of the $\mathrm{LiMn}_{2} \mathrm{O}_{4}$ thin film and, therefore, the cathode surface towards the adjacent electrolyte. All three types of $\mathrm{LiMn}_{2} \mathrm{O}_{4}$ films exhibit surfaces exposing predominantly $\{111\}$ crystal facets, the lowest energy state surface for this spinel structure, which results in dramatic differences in surface morphology with pyramidal, rooftop or flat features for respectively (100), (110) and (111) $\mathrm{LiMn}_{2} \mathrm{O}_{4}$ films. Interestingly, the (100)-oriented films exhibited the highest capacities, (dis)charging rates up to $33 \mathrm{C}$, and good cyclability over a thousand cycles, demonstrating enhanced cycle life without excessive capacity fading as compared to polycrystalline studies [15].

To research the relation between electrochemistry and crystal directionality, epitaxial engineering can be used. Controlling the crystal orientation of $\mathrm{LiMn}_{2} \mathrm{O}_{4}$ thin films will enable a unique insight into this relation, not obtainable in single crystals or polycrystalline samples.

Experimental $\mathrm{LiMn}_{2} \mathrm{O}_{4}$ thin films were grown by pulsed laser deposition (PLD) at $600{ }^{\circ} \mathrm{C}$ on conducting Nb-doped (0.5 wt\%) single crystalline $\mathrm{SrTiO}_{3}((100),(110)$ and (111)) substrates from a sintered $\mathrm{LiMn}_{2} \mathrm{O}_{4}\left(20 \mathrm{wt} \%\right.$ excess $\left.\mathrm{Li}_{2} \mathrm{O}\right)$ target, using a $\mathrm{KrF}$ excimer laser 
operating at $248 \mathrm{~nm}$ and at a repetition rate of $2 \mathrm{~Hz}$. Flat $\mathrm{Nb}-\mathrm{SrTiO}_{3}$ substrates $(5 \times 5 \times 0.5$ $\mathrm{mm}^{3}$ ) with step terrace structure with unit cell height differences were obtained by annealing at $950{ }^{\circ} \mathrm{C}$ for $1.5 \mathrm{~h}$ in an oxygen flow of $150 \mathrm{ml} / \mathrm{min}$. The oxygen pressure during growth was 0.2 mbar, while the laser energy fluence was $2.3 \mathrm{~J} \mathrm{~cm}^{-2}$. After deposition, the thin films were slowly cooled down to room temperature in an oxygen pressure of 0.2 mbar at a rate of $10{ }^{\circ} \mathrm{C} \mathrm{min}-{ }^{1} .7200$ pulses resulted in a layer of roughly $100 \mathrm{~nm}$ as determined by crosssection SEM.

All $\mathrm{LiMn}_{2} \mathrm{O}_{4}$ (LMO) thin films were deposited under the same conditions and have a thickness of $\sim 110 \mathrm{~nm}$. A $50 \mathrm{~nm} \mathrm{SrRuO}_{3}$ (SRO) layer was deposited as an intermediate layer to enhance the electrical transport between the LMO cathode and the conducting $\mathrm{Nb}: \mathrm{STO}$ substrate [26].

\subsection{Characterization of the grown $\mathrm{LiMn}_{2} \mathrm{O}_{4}$ layers}

The structural quality of the LMO films was investigated by X-ray diffraction (XRD) analysis, as shown in figure 1a. The three types of LMO films grown on Nb:STO substrates with different orientations exhibit coherent growth in which the out-of-plane crystal orientation of the films is aligned with the orientation of the substrate. The $\mathrm{LMO}(111)$ and LMO(110) films exhibit a high epitaxial crystallinity, with a lattice parameter of $\sim 8.25 \AA$, without any impurity phase, in good agreement with previous studies of LMO growth on STO(111) and STO(110) substrates [23,26]. This suggests that the PLD process parameters (e.g. temperature, pressure, laser energy density, target composition) were optimized successfully to minimize loss of volatile lithium during ablation, nucleation and growth. Interestingly, the LMO films with (100)-orientation show minor contributions of a secondary phase, although all three LMO films were grown during the same deposition procedure. 
The extra peaks suggest the presence of a small amount of $\mathrm{Mn}_{2} \mathrm{O}_{3}$ with (400)-orientation [30], which has been previously investigated as a promising anode material [31]. However, in our case the coexistence of this lithium deficient phase could be due to the enhanced lithium volatility at the (100)-surface of $\mathrm{LiMn}_{2} \mathrm{O}_{4}[13]$.

The alignment of the out-of-plane crystal orientation for all types of LMO films suggests an epitaxial relation between the crystal structures of the deposited LMO films and the underlying Nb:STO substrates, although large differences exist between spinel LMO $(\mathrm{a}=$ $8.25 \AA)$ and perovskite STO $(\mathrm{a}=3.90 \AA)$. A preferred orientation of the LMO films is confirmed by detailed analysis of the in-plane orientation by XRD for the (100)-oriented films. There, the (113)-peaks of the substrate (Nb:STO) align with the (226)-peaks of the LMO thin film confirming the epitaxial relation (figure 1b). A Reciprocal Space Map (RSM) of the same peaks shows that although the LMO thin film is aligned with the crystal orientation of the $\mathrm{Nb}: \mathrm{STO}$ substrate, the LMO crystal structures has relaxed to its bulk parameters (figure 1c). 
a)

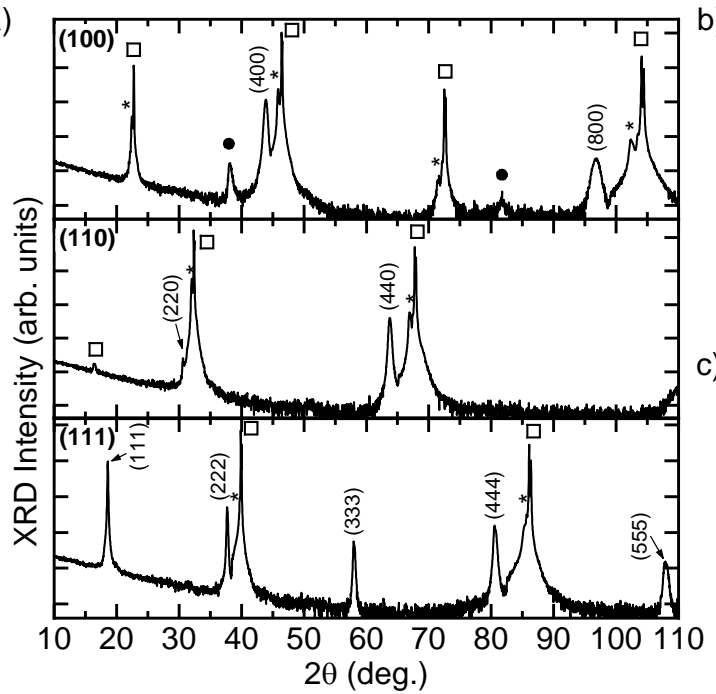

b)

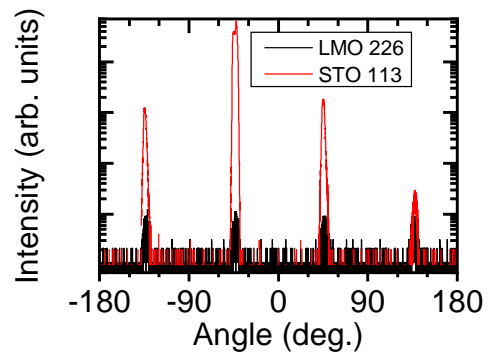

c)

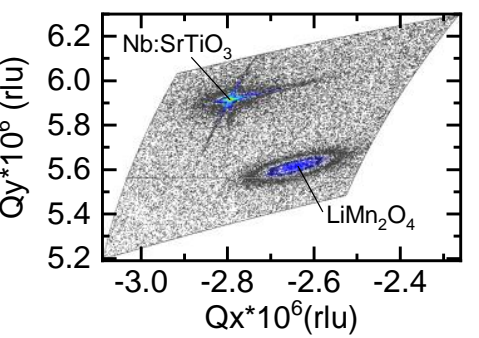

Figure 1, a) Out-of-plane XRD measurements of $110 \mathrm{~nm} \mathrm{LiMn}{ }_{2} \mathrm{O}_{4}$ epitaxial thin films on $50 \mathrm{~nm} \mathrm{SrRuO} \mathrm{O}_{3}$-coated $\mathrm{Nb}-\mathrm{SrTiO}_{3}$ substrates with different crystal orientations: (100), (110) and (111). $\mathrm{Nb}_{-} \mathrm{SrTiO}_{3}$ substrate peaks are indicated by $\square$, and $\mathrm{SrRuO}_{3}$ are indicated by *, while minor contributions of $\mathrm{Mn}_{2} \mathrm{O}_{3}$ phase are given by $\bullet$. b) Overlapping $\mathrm{Nb}: \mathrm{SrTiO}_{3}$ (113)- and $\mathrm{LiMn}_{2} \mathrm{O}_{4}$ (226)-peaks while the substrate is rotated in-plane. $\mathrm{c}$ ) Reciprocal Space Map of the $\mathrm{Nb}: \mathrm{SrTiO}_{3}$ substrate (113)-peak and the $\mathrm{LiMn}_{2} \mathrm{O}_{4}$ thin film (226)-peak.

The quality of the LMO films was further investigated by Atomic Force Microscopy (AFM) and Scanning Electron Microscopy (SEM) analysis, as shown in figure 2. The three types of LMO films grown on $\mathrm{Nb}$ :STO substrates with different orientations exhibit distinct surfaces due to the coherent growth in which the out-of-plane crystal orientation of the films is aligned with the orientation of the substrate. Furthermore, their surface features are in good agreement with the in-plane orientation shown above The surface of the LMO(100) film 
exhibits square-like structures with significant height differences $(\mathrm{RMS}=\sim 45 \mathrm{~nm}$ ), which is in good agreement with previously observed octahedron spinel structures [22,32].
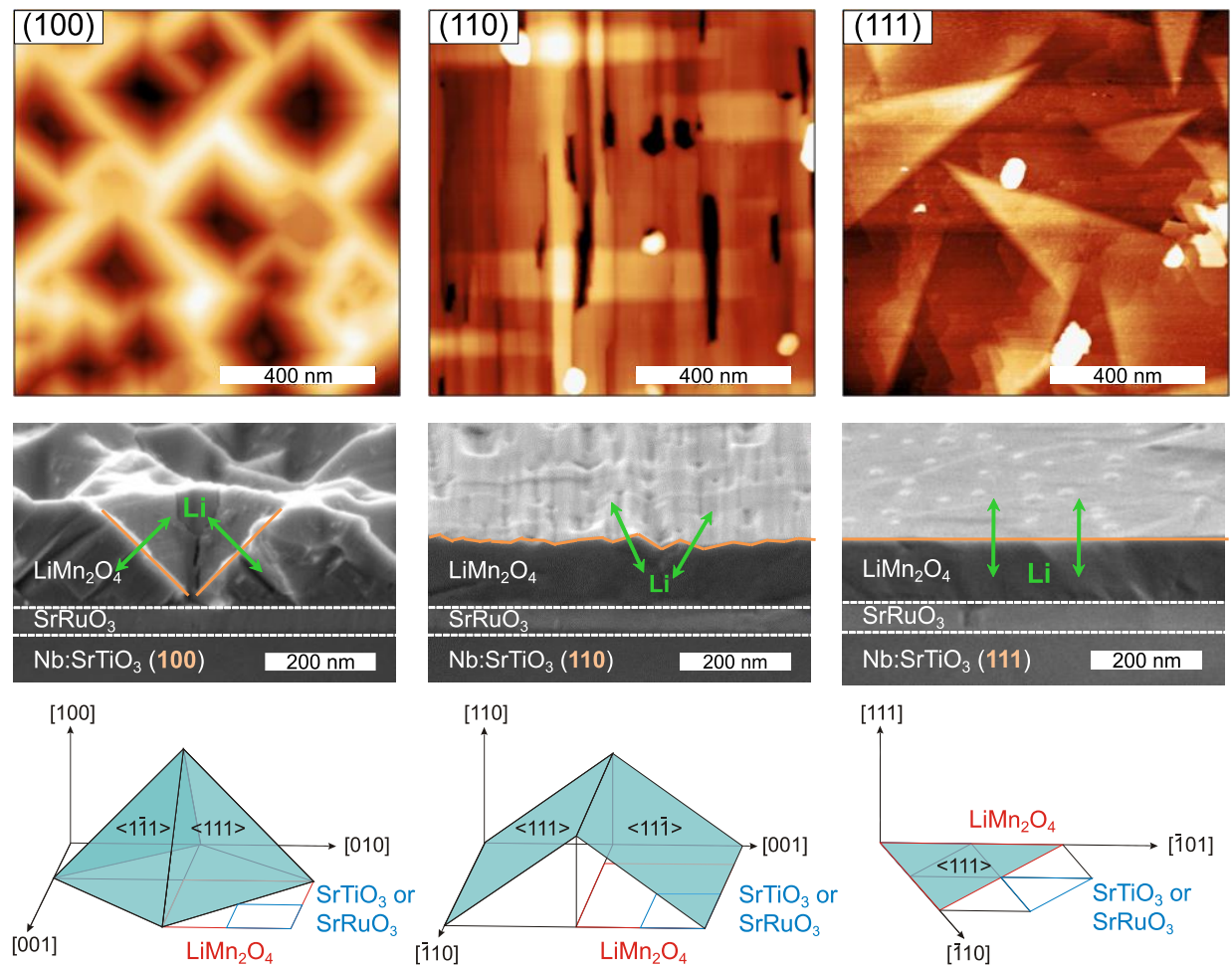

Figure 2, AFM (top) and SEM (middle) analysis of the surface morphology of $110 \mathrm{~nm}$ $\mathrm{LiMn}_{2} \mathrm{O}_{4}$ thin films on $\mathrm{SrRuO}_{3}$-coated $\mathrm{Nb}$-SrTiO $\mathrm{O}_{3}$ substrates with crystal orientations (100), (110) and (111). SEM images are taken after extensive electrochemical cycling and subsequent cleaning of the surfaces. Schematics (bottom) are shown of the expected crystal facets for the different surface morphologies.

Such pyramidal spinel structures consist of $\{111\}$-crystal facets on all four sides with an occasional presence of a truncated top of the pyramid exhibiting a (100)-crystal facet. The $\mathrm{LMO}(110)$ film forms a layer with rooftop-like structures and a lower surface roughness $(\mathrm{RMS}=\sim 5 \mathrm{~nm})$, caused by the anisotropic nature of the (110)-plane which favors diffusion 
of atoms along the [110] direction as compared to the [001] direction [33]. This results in elongated $\{111\}$-crystal facets exposed on the surface, which are all aligned in the same direction. Finally, the $\mathrm{LMO}(111)$ film forms a layer with triangle-like structures exhibiting a very low surface roughness $(\mathrm{RMS}=\sim 1.5 \mathrm{~nm})$. The triangular shape corresponds to the (111) plane in a cubic structure, for which two different types of in-plane triangle orientations can be observed. Therefore, all three types of LMO films with different out-ofplane orientations ((100), (110) and (111)) exhibit surfaces exposing predominantly $\{111\}$ crystal facets, which confirms that this is the lowest energy state surface of the spinel crystal structure [22].

\subsection{Electrochemical characterization}

To study the dependence of the lithium transport on the specific crystal orientation of the LMO, the films were transferred to an argon atmosphere glovebox $\left(<0.1 \mathrm{ppm}\right.$ of $\mathrm{H}_{2} \mathrm{O}$ and $\mathrm{O}_{2}$ ) and placed on a hot plate for $\sim 10 \mathrm{~min}$ at $125{ }^{\circ} \mathrm{C}$ to remove any water content. Subsequently, they were positioned in an electrochemical EC-ref cell by EL-CELL and combined with a glass fiber separator of $1 \mathrm{~mm}$ thickness, $0.6 \mathrm{~mL}$ electrolyte with $1 \mathrm{M} \mathrm{LiPF}_{6}$ in 1:1 ethylene carbonate : dimethyl carbonate (EC:DMC) and a lithium metal anode. The electrochemical measurements were performed at $22{ }^{\circ} \mathrm{C}$ using a BioLogic VMP-300 system in a two-electrode setup in which the samples were cycled galvanostatically between 3.6 and 4.5 V with currents of $1,2,5,10,20$, and $50 \mu \mathrm{A}$, corresponding to $\mathrm{C}$ rates of approximately $0.7,1.3,3.3,6.6,13$, and $33 \mathrm{C}$, respectively. A potentiostatic period of $5 \mathrm{~min}$ is used to ensure complete charge or discharge before the next step.

Thin films fabricated by pulsed laser deposition typically exhibit densities very close to theoretical values with negligible porosity. Therefore, the mass of the samples has been determined by using the theoretical density of LMO $\left(4.28 \mathrm{~g} / \mathrm{cm}^{3}\right)$ together with the volume of the sample (thickness x $5 \mathrm{~mm}$ width x $5 \mathrm{~mm}$ length). Figure 3 shows charge-discharge 
curves for the LMO films with different orientations ((100), (110) and (111)) for various currents $(1-50 \mu \mathrm{A})$, resulting in (dis)charge rates in the range $0.7-33 \mathrm{C}$.

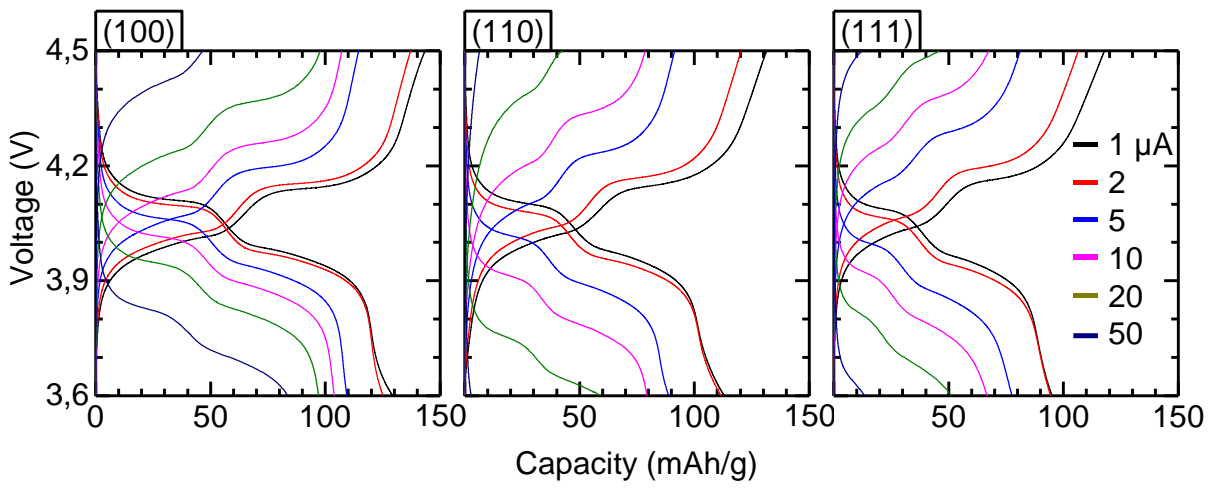

Figure 3, Charge-discharge analysis of $110 \mathrm{~nm} \mathrm{LiMn}_{2} \mathrm{O}_{4}$ films with different crystal orientations ((100), (110) and (111)) for various currents (1, 2, 5, 10, 20 and $50 \mu \mathrm{A}) . \mathrm{A}$ potentiostatic period of $5 \mathrm{~min}$. is used to ensure complete charge or discharge before the next step.

The characteristic voltage plateaus for these epitaxial LMO thin films are in good agreement with bulk LMO charge-discharge profiles [1]. The total discharge capacity for the slowest rate of $0.7 \mathrm{C}$ was the highest for the (100)-oriented LMO film $(\sim 129 \mathrm{mAh} / \mathrm{g})$, while the (110)and (111)-oriented LMO films exhibit discharge capacities of respectively $\sim 113 \mathrm{mAh} / \mathrm{g}$ and $\sim 95 \mathrm{mAh} / \mathrm{g}$. The large surface area of the (100)-oriented LMO film, caused by pyramidal surface morphology, is considered to cause enhanced lithium kinetics as compared to the other crystal orientations. The crystal facets on all films are predominantly (111), which eliminates any possible effect from local variations in crystal facets. The enhanced lithium kinetics for the (100)-oriented LMO films is also demonstrated by the large capacities still achievable during (dis)charging when using higher rates. The used high currents stress the material more and make the variations in lithium intercalation for the different crystal 
orientations more pronounced. For currents of $20 \mu \mathrm{A}(\sim 13 \mathrm{C})$ the discharge capacities for the (110)- and (111)-oriented films drop to $\sim 50 \mathrm{mAh} / \mathrm{g}$, while the (100)-oriented film still exhibits double the capacity $(\sim 100 \mathrm{mAh} / \mathrm{g})$. The initial drop in discharge capacity after the first charge-discharge cycles may be attributed to anionic reaction occurring at upper voltage cutoff combined with irreversible dissolution of surface lithium and manganese [20]. All films show a slightly higher charge capacity compared to the discharge capacity due to SEI formation and Mn dissolution. However, the difference in charge-discharge capacities are within acceptable coulombic efficiency limits: $>80 \%$ after the first and $>90 \%$ after 25 cycles.

The rate dependence of the discharge capacity is shown in more detail in figure 4 for the LMO films with different crystal orientations. After the initial 20 charge-discharge cycles with $3.3 \mathrm{C}$ the films are consecutively cycled at various rates in the range $0.7 \mathrm{C}-33 \mathrm{C}$ before finishing the sequence with 50 cycles at $3.3 \mathrm{C}$.

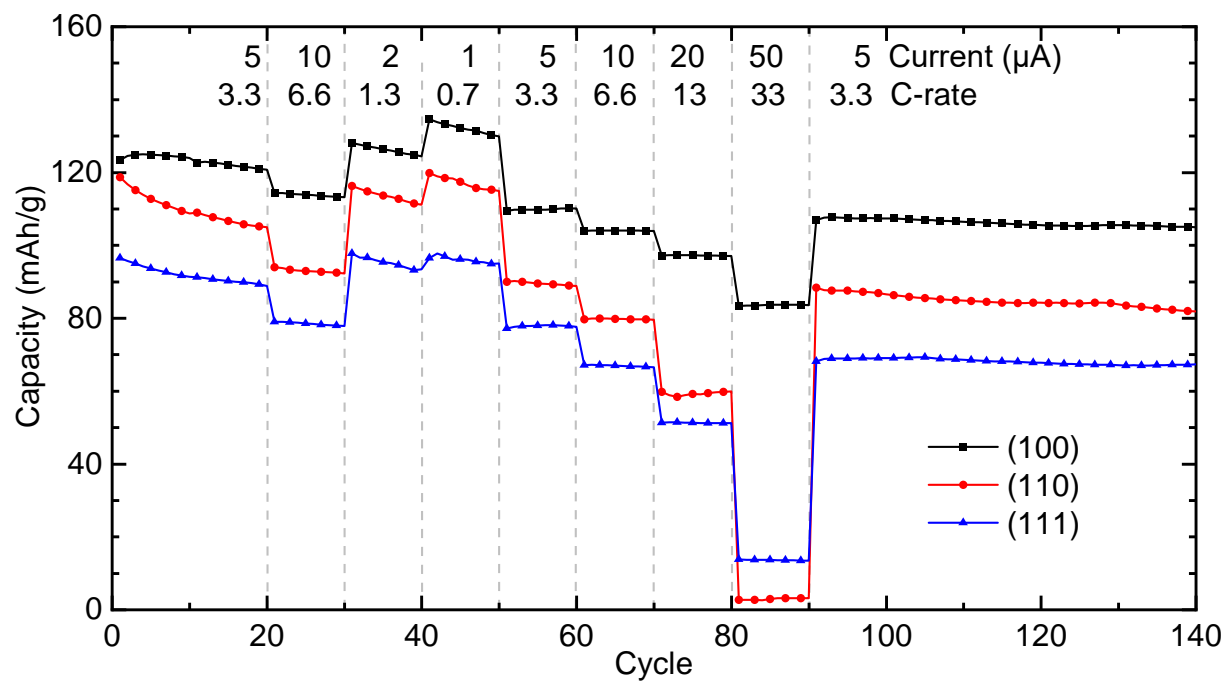

Figure 4, Rate performance analysis of $110 \mathrm{~nm} \mathrm{LiMn}{ }_{2} \mathrm{O}_{4}$ thin films on $\mathrm{SrRuO}$-coated $\mathrm{Nb}$ $\mathrm{SrTiO}_{3}$ substrates with different crystal orientations ((100), (110) and (111)) for various currents, and corresponding $C$ rates. 
The results show the stability of the LMO films during substantial cycling, as well as the enhanced performance of the (100)-oriented film as compared to the other orientations.

Interestingly, at the highest rate of $33 \mathrm{C}$ the (100)-oriented film still exhibits a capacity of about $84 \mathrm{mAh} / \mathrm{g}$, while the capacities of the (110)- and (111)-oriented films have almost reduced to zero. The observed variation in surface area between the differently oriented films (about 50\% more surface area for (100)-oriented films as compared to (110)- and (111)oriented films, see figure 2), cannot explain this dramatic difference in lithium kinetics.

Although the conventional understanding of the $\mathrm{Li}$ diffusion in $\mathrm{LiMn}_{2} \mathrm{O}_{4}$ is threedimensional in which the $\mathrm{Li}$ ions hop over the $8 \mathrm{a}$ and $16 \mathrm{c}$ sites along the interconnected pathways, these zigzagging chains form lithium diffusion channels in specific directions [34].

Previous studies have suggested that although the (111)-oriented facets exhibit the lowest surface energy $[13,35]$ the (100)- and (110)-oriented facets are better aligned to the lithium diffusion channels, thus increasing discharge capacities and facilitating high rate capabilities [36].

Our results demonstrate that very stable $\mathrm{LiMn}_{2} \mathrm{O}_{4}$ thin films with $\{111\}$-surface facets exhibit much higher rate capabilities for the (100)-direction as compared to the (110)direction. Theoretical modeling would provide detailed insight into the diffusion mechanism in which the ease of lithium diffusion through the bottleneck is studied. The triangular opening between the oxygen ions allowing Li-diffusion is formed at the contact face between the tetrahedron about $8 \mathrm{a}$ and the octahedron about $16 \mathrm{c}$ and depends on the displacement of the $\mathrm{O}$ atoms, which can vary in differently oriented epitaxial thin films. 


\subsection{Synthesis temperature}

During synthesis, Reflective High-Energy Electron Diffraction (RHEED) can be used to inspect the growth at the surface of the thin film. While increasing the temperature, a phasetransition above $600{ }^{\circ} \mathrm{C}$ was observed for the thin film of $\mathrm{LiMn}_{2} \mathrm{O}_{4}$ on (100)-Nb:SrTiO 3 as shown in figure 5.

Figure 5, Reflective High-Energy Electron Diffraction (RHEED) image for a thin film of $\mathrm{LiMn}_{2} \mathrm{O}_{4}$ grown on (100)-oriented $\mathrm{Nb}: \mathrm{SrTiO}_{3}$ at $600{ }^{\circ} \mathrm{C}$ after which the temperature was increased to $615^{\circ} \mathrm{C}$.

This RHEED pattern furthermore shows that the surface of the film is rough, as $3 \mathrm{D}$ spots are observed. This is in accordance with the rough surface (pyramids) as seen in AFM and SEM of the (100)-oriented thin LMO film in figure 2. At high temperatures and low oxygen background pressures a phase-transition for the $\mathrm{LMO}$ can be expected to either $\mathrm{Li}_{2} \mathrm{MnO}_{3}$ or $\mathrm{Mn}_{2} \mathrm{O}_{3}$ [1,37]. Due to lithium evaporation at high temperatures it is expected $\mathrm{Mn}_{2} \mathrm{O}_{3}$ is formed, which is characterized in XRD of figure 1. As the transformation into $\mathrm{Mn}_{2} \mathrm{O}_{3}$ resulted in thin films that are no longer electrochemically active, syntheses of thin films of $\mathrm{LiMn}_{2} \mathrm{O}_{4}$ are performed at $600{ }^{\circ} \mathrm{C}$.

\subsection{Thickness Dependence}

The capacity of the thin-film cathodes should follow a linear trend to the thickness of the layer for fixed substrate surface size and film density. The fixed area allows for the calculation of the theoretical capacity per nm through the theoretical energy density and the density of the material: 


$$
\text { Capacity }=\text { Thickness } * A * \rho_{\text {mat }} * \rho_{\text {Emat }}
$$

Here, the capacity $[\mathrm{mAh}]$ is a function of thickness $[\mathrm{m}]$, area $(\mathrm{A})\left[\mathrm{m}^{2}\right]$, material density $\left(\rho_{\mathrm{mat}}\right)$ $\left[\mathrm{g} \mathrm{m}^{-3}\right]$ and the material's energy density $\left(\rho_{\text {Emat }}\right)\left[\mathrm{mAh} \mathrm{g}^{-1}\right]$,

As the other parameters can be regarded as constant, capacity becomes linear related to thickness. However, size effects like nano-confinement and diffusion limitations can play a role as function of thickness. As the choice of substrate can have a large influence on the structure of the thin film, its density may also be influenced. Due to lattice parameter mismatch, strain might be present in the film. Although we have observed relaxation in the reciprocal space map of figure $1 \mathrm{c}$, films with reduced thicknesses could experience more strain. This strain and its relaxation can cause defects, such as Mn occupying Li sites, that could decrease the density or block lithium pathways, thereby decreasing the capacity.

Discharge capacities of samples are plotted versus their $\mathrm{LiMn}_{2} \mathrm{O}_{4}$ layer thickness in figure 6 . Due to the destructive nature of determining the thickness, this is done after cycling. Due to possible Mn-dissolution, the measured layer thickness could be an underestimation of the actual thickness right after thin film growth. However, the stability of the electrochemical behavior indicates a negligible effect of Mn-dissolution for the LMO thin films.

The capacity over layer thickness shows a clear linear behavior although the slope is lower (114 $\left.\mathrm{mAh} \mathrm{g}^{-1}\right)$ compared to that of the theoretical maximum $\left(148 \mathrm{mAh} \mathrm{g}^{-1}\right)$. Most studies in literature achieves an energy density of around $120 \mathrm{mAh} \mathrm{g}^{-1}[4,26,38,39]$. Therefore, the observed trend of $114 \mathrm{mAh} \mathrm{g}^{-1}$ is within the error margin of the thickness estimation through cross-section SEM analysis.

The $2^{\text {nd }}$ degree polynomial trendline is added to approximate the effects of limited diffusion of the $\mathrm{Li}^{+}$-ion into the LMO. 


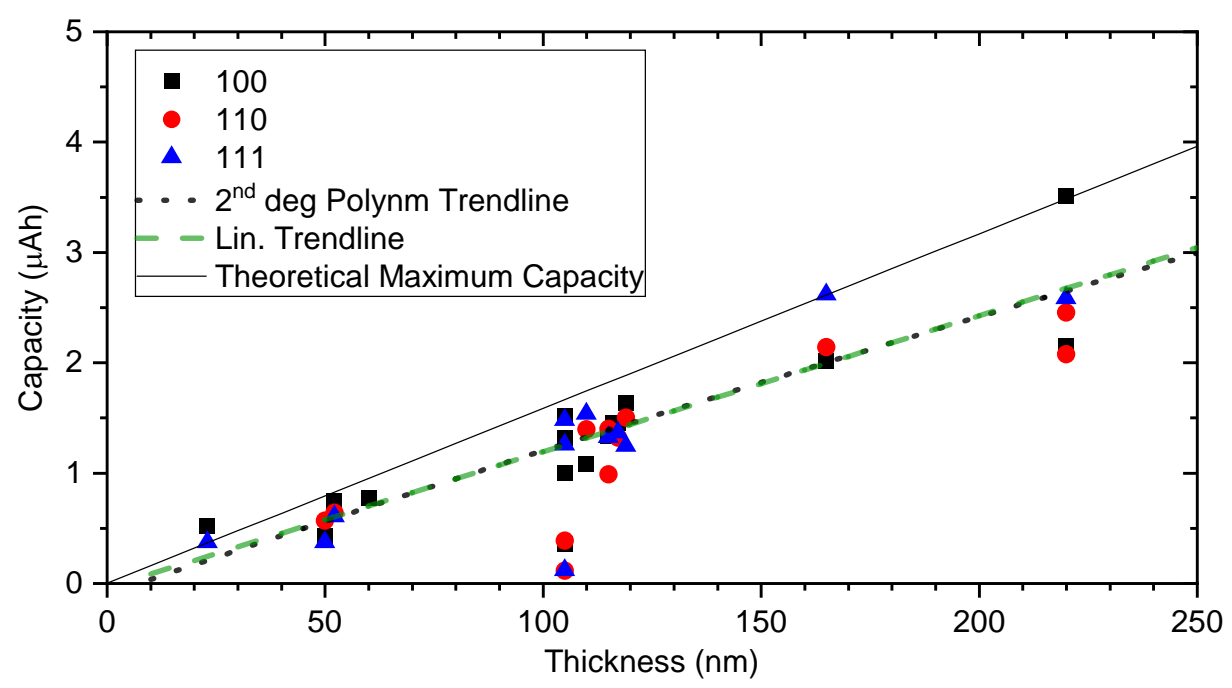

Figure 6, Capacity as function of thin-film layer thickness. The capacities for different orientations are shown in colored marks. Trendlines are added as guide to the eye where both the polynomial and linear trendline mostly overlap on this scale. The theoretical maximum capacity line is added to the graph and is based on $148 \mathrm{mAh} / \mathrm{g}, 4.28 \mathrm{~g} / \mathrm{cm}^{3}$ and a substrate size of $5 \times 5 \mathrm{~mm}^{2}$. Thicknesses are estimated through cross-section SEM analysis after cycling.

Fick's first law for one dimension states:

$$
J=-D \frac{d \varphi}{d x}
$$

The diffusion flux (J) is in $\left[\mathrm{mol} \mathrm{m} \mathrm{m}^{-2} \mathrm{~s}^{-1}\right]$, the diffusivity (D) is in $\left[\mathrm{m}^{2} \mathrm{~s}^{-1}\right]$ and the concentration gradient $\left(\frac{d \varphi}{d x}\right)$ is in $\left[\mathrm{mol} \mathrm{m}^{-4}\right]$.

As the film thickness increases, the time needed for lithium-ions to diffuse through it increases. However, as the charging current is kept constant at $5 \mu \mathrm{A}$ throughout the thickness range, the time needed to fill the capacity follows a linear trend just as the increase in time 
needed for lithium to diffuse. Therefore, a linear trend is logical until the diffusion changes drastically. As the observed capacity follows a linear trend in the thickness range of $20-$ $220 \mathrm{~nm}$ the diffusivity is presumed to be constant within this thickness range.

\subsection{Cycle life}

The cycle life of such high-performance (100)-oriented LMO films was investigated for several cells during prolonged battery cycling at similar conditions, see figure 7 . The electrochemical behavior of all four cells exhibited good uniformity with initial capacities of about 120-130 mAh/g, which still provided capacities of about $90 \mathrm{mAh} / \mathrm{g}$ after a thousand cycles. The stability of the voltage plateaus over the full thousand cycles is shown in figure $7 \mathrm{a}$ and $7 \mathrm{~b}$, and indicates the stable internal resistance during the complete prolonged cycling. Figure 7c displays the enhanced cycle life performance for (100)-oriented LMO films with significantly higher capacity and coulombic efficiency over thousand cycles as compared to previous studies on bulk and polycrystalline LMO for which the capacity drops below $80 \%$ within 50 cycles $[4,15]$.

\subsection{Conclusion}

In conclusion, structural engineering enables improved control over the electrochemical properties of $\mathrm{LiMn}_{2} \mathrm{O}_{4}$ thin films, which is unique for epitaxial thin films and cannot be obtained in single crystal or polycrystalline samples. Control of the specific crystal orientation of the LMO thin films resulted in dramatic differences in surface morphology with pyramidal, rooftop or flat features for respectively (100), (110) and (111) orientations. All three types of LMO films exhibit surfaces exposing predominantly $\{111\}$-crystal facets, which is predicted to be the lowest energy crystallographic surface for this spinel structure [13, 35]. 

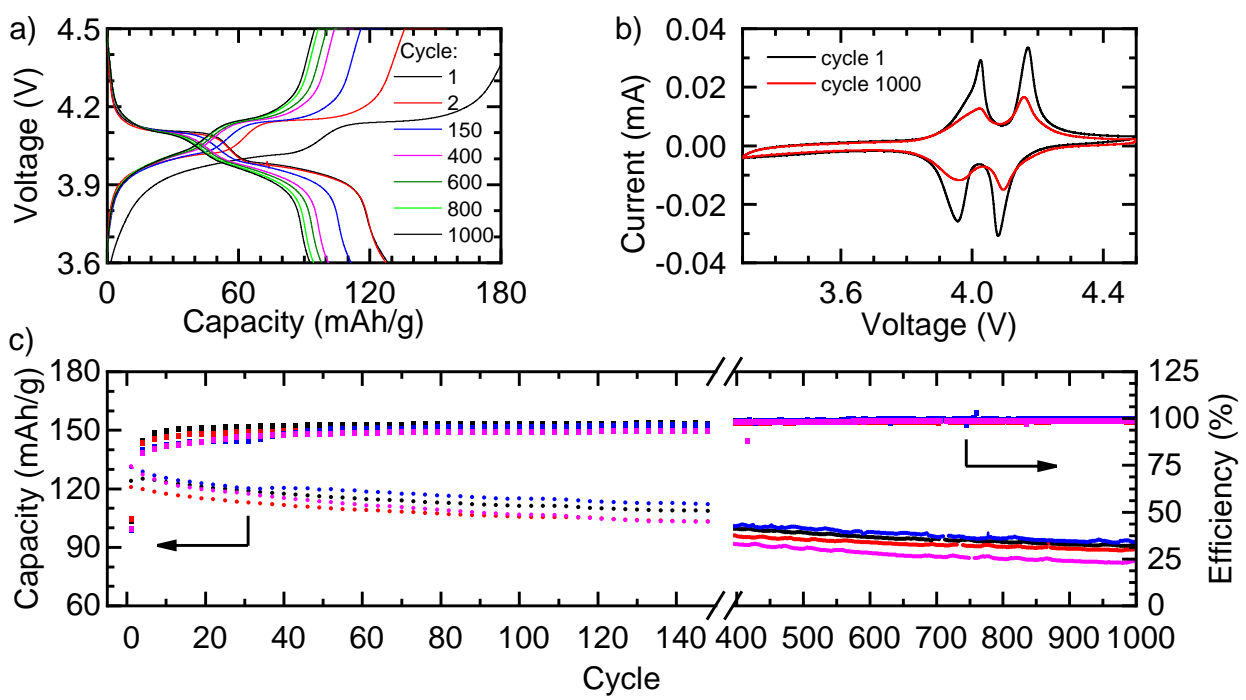

Figure 7, Cycle life analysis of four $110 \mathrm{~nm}$ (100)-oriented $\mathrm{LiMn}_{2} \mathrm{O}_{4}$ thin films on $\mathrm{SrRuO}_{3}$ coated $\mathrm{Nb}_{-} \mathrm{SrTiO}_{3}$ substrates. The evolution of charge-discharge (a) and cyclic voltammetry behaviors (b) are shown during prolonged cycling. c) The discharge capacity and coulombic efficiency are given for a thousand cycles. During the measurements a current of $5 \mu \mathrm{A}$ was used, which provided a (dis)charge rate of $3.3 \mathrm{C}$.

Alignment to lithium diffusion channels allows the (100)-oriented LMO films to exhibit the highest capacities and (dis)charging rates up to $33 \mathrm{C}$. The capacities of the epitaxial layers follow an expected linear trend with their thickness when $114 \mathrm{mAh} / \mathrm{g}$ is assumed. Good cyclability over a thousand cycles is achieved, demonstrating enhanced cycle life without excessive capacity fading as compared to previous polycrystalline studies. 


\subsection{References}

[1] M. M. Thackeray, "Manganese oxides for lithium batteries," Prog. Solid State Chem., vol. 25, no. 1-2, pp. 1-71, 1997, DOI: 10.1016/S0079-6786(97)81003-5.

[2] M. J. Lee, S. Lee, P. Oh, Y. Kim, and J. Cho, "High performance $\mathrm{LiMn}_{2} \mathrm{O}_{4}$ cathode materials grown with epitaxial layered nanostructure for Li-Ion batteries," Nano Lett., vol. 14, no. 2, pp. 993-999, 2014, DOI: 10.1021/nl404430e.

[3] J. Ma, P. Hu, G. Cui, and L. Chen, "Surface and Interface Issues in Spinel $\mathrm{LiNi}_{0.5} \mathrm{Mn}_{1.5} \mathrm{O}_{4}$ : Insights into a Potential Cathode Material for High Energy Density Lithium Ion Batteries," Chem. Mater., vol. 28, no. 11, pp. 3578-3606, 2016, DOI: 10.1021/acs.chemmater.6b00948.

[4] R. J. Gummow, A. de Kock, and M. M. Thackeray, "Improved capacity retention in rechargeable $4 \mathrm{~V}$ lithium/lithium-manganese oxide (spinel) cells," Solid State Ionics, vol. 69, no. 1, pp. 59-67, 1994, DOI: 10.1016/0167-2738(94)90450-2.

[5] T. B. Reddy, Linden's Handbook of Batteries, 4th ed. New York: McGraw-Hill, 2011.

[6] A. Van der Ven, C. Marianetti, D. Morgan, and G. Ceder, "Phase transformations and volume changes in spinel $\mathrm{Li}_{\mathrm{x}} \mathrm{Mn}_{2} \mathrm{O}_{4}$," Solid State Ionics, vol. 135, no. 1-4, pp. 21-32, Nov. 2000, DOI: 10.1016/S0167-2738(00)00326-X.

[7] M. M. Thackeray, W. I. F. David, P. G. Bruce, and J. B. Goodenough, "Lithium insertion into manganese spinels," Mater. Res. Bull., vol. 18, no. 4, pp. 461-472, 1983, DOI: 10.1016/0025-5408(83)90138-1.

[8] J. C. Hunter, "Preparation of a new crystal form of manganese dioxide: $\lambda-\mathrm{MnO}_{2}, " J$. Solid State Chem., vol. 39, no. 2, pp. 142-147, 1981, DOI: 10.1016/00224596(81)90323-6.

[9] N. Nitta, F. Wu, J. T. Lee, and G. Yushin, "Li-ion battery materials: Present and future," Mater. Today, vol. 18, no. 5, pp. 252-264, 2015, DOI: 10.1016/j.mattod.2014.10.040.

[10] A. C. Luntz, J. Voss, and K. Reuter, "Interfacial Challenges in Solid-State Li Ion Batteries," J. Phys. Chem. Lett., vol. 6, no. 22, pp. 4599-4604, 2015, DOI: 10.1021/acs.jpclett.5b02352.

[11] K. X. Wang, X. H. Li, and J. S. Chen, "Surface and interface engineering of electrode materials for lithium-ion batteries," Adv. Mater., vol. 27, no. 3, pp. 527545, 2015, DOI: 10.1002/adma.201402962.

[12] S.-T. Myung, K.-S. Lee, D.-W. Kim, B. Scrosati, and Y.-K. Sun, "Spherical coreshell $\mathrm{Li}\left[\left(\mathrm{Li}_{0.05} \mathrm{Mn}_{0.95}\right)_{0.8}\left(\mathrm{Ni}_{0.25} \mathrm{Mn}_{0.75}\right)_{0.2}\right]_{2} \mathrm{O}_{4}$ spinels as high performance cathodes for lithium batteries," Energy Environ. Sci., vol. 4, no. 3, p. 935, 2011, DOI: 10.1039/c0ee00298d.

[13] C. D. Amos, M. A. Roldan, M. Varela, J. B. Goodenough, and P. J. Ferreira, "Revealing the Reconstructed Surface of $\mathrm{LiMn}_{2} \mathrm{O}_{4}$," Nano Lett., vol. 16, no. 5, pp. 2899-2906, May 2016, DOI: 10.1021/acs.nanolett.5b03926. 
[14] F. Jiao, J. Bao, A. H. Hill, and P. G. Bruce, "Synthesis of Ordered Mesoporous LiMn-O Spinel as a Positive Electrode for Rechargeable Lithium Batteries," Angew. Chemie, vol. 120, no. 50, pp. 9857-9862, Dec. 2008, DOI: 10.1002/ange.200803431.

[15] S. Bin Park, H. C. Shin, W. G. Lee, W. Il Cho, and H. Jang, "Improvement of capacity fading resistance of $\mathrm{LiMn}_{2} \mathrm{O}_{4}$ by amphoteric oxides," J. Power Sources, vol. 180, no. 1, pp. 597-601, 2008, DOI: 10.1016/j.jpowsour.2008.01.051.

[16] Y. Yuan, K. Amine, J. Lu, and R. Shahbazian-Yassar, "Understanding materials challenges for rechargeable ion batteries with in situ transmission electron microscopy," Nat. Commun., vol. 8, no. May, pp. 1-14, 2017, DOI: 10.1038/ncomms15806.

[17] F. Lin, I. M. Markus, D. Nordlund, T.-C. Weng, M. D. Asta, H. L. Xin, and M. M. Doeff, "Surface reconstruction and chemical evolution of stoichiometric layered cathode materials for lithium-ion batteries," Nat. Commun., vol. 5, pp. 1-9, 2014, DOI: $10.1038 /$ ncomms 4529 .

[18] M.-J. Lee, E. Lho, P. Bai, S. Chae, J. Li, and J. Cho, "Low-Temperature Carbon Coating of Nanosized $\mathrm{Li}_{1.015} \mathrm{Al}_{0.06} \mathrm{Mn}_{1.925} \mathrm{O}_{4}$ and High-Density Electrode for HighPower Li-Ion Batteries," Nano Lett., vol. 17, no. 6, pp. 3744-3751, Jun. 2017, DOI: 10.1021/acs.nanolett.7b01076.

[19] D. K. Kim, P. Muralidharan, H. W. Lee, R. Ruffo, Y. Yang, C. K. Chan, H. Peng, R. a. Huggins, and Y. Cui, "Spinel $\mathrm{LiMn}_{2} \mathrm{O}_{4}$ nanorods as lithium ion battery cathodes," Nano Lett., vol. 8, no. 11, pp. 3948-3952, 2008, DOI: 10.1021/n18024328.

[20] A. Bhandari and J. Bhattacharya, "Review-Manganese Dissolution from Spinel Cathode: Few Unanswered Questions," J. Electrochem. Soc., vol. 164, no. 2, pp. A106-A127, Dec. 2017, DOI: 10.1149/2.0101614jes.

[21] E. Hosono, T. Kudo, I. Honma, H. Matsuda, and H. Zhou, "Synthesis of Single Crystalline Spinel $\mathrm{LiMn}_{2} \mathrm{O}_{4}$ Nanowires for a Lithium Ion Battery with High Power Density," 2009, DOI: 10.1021/nl803394v.

[22] J. S. Kim, K. Kim, W. Cho, W. H. Shin, R. Kanno, and J. W. Choi, "A truncated manganese spinel cathode for excellent power and lifetime in lithium-ion batteries," Nano Lett., vol. 12, no. 12, pp. 6358-6365, 2012, DOI: 10.1021/nl303619s.

[23] M. Hirayama, N. Sonoyama, M. Ito, M. Minoura, D. Mori, A. Yamada, K. Tamura, J. Mizuki, and R. Kanno, "Characterization of Electrode/Electrolyte Interface with X-Ray Reflectometry and Epitaxial-Film $\mathrm{LiMn}_{2} \mathrm{O}_{4}$ Electrode,” J. Electrochem. Soc., vol. 154, no. 11, p. A1065, 2007, DOI: 10.1149/1.2778853.

[24] N. Sonoyama, K. Iwase, H. Takatsuka, T. Matsumura, N. Imanishi, Y. Takeda, and R. Kanno, "Electrochemistry of $\mathrm{LiMn}_{2} \mathrm{O}_{4}$ epitaxial films deposited on various single crystal substrates," J. Power Sources, vol. 189, no. 1, pp. 561-565, Apr. 2009, DOI: 10.1016/j.jpowsour.2008.10.037.

[25] M. Hirayama, H. Ido, K. Kim, W. Cho, K. Tamura, J. Mizuki, and R. Kanno, "Dynamic structural changes at $\mathrm{LiMn}_{2} \mathrm{O}_{4}$ /electrolyte interface during lithium battery reaction," J. Am. Chem. Soc., vol. 132, no. 43, pp. 15268-15276, 2010, DOI: 10.1021/ja105389t. 
[26] K. Suzuki, K. Kim, S. Taminato, M. Hirayama, and R. Kanno, "Fabrication and electrochemical properties of $\mathrm{LiMn}_{2} \mathrm{O}_{4} / \mathrm{SrRuO}_{3}$ multi-layer epitaxial thin film electrodes," J. Power Sources, vol. 226, no. March 2013, pp. 340-345, 2013, DOI: 10.1016/j.jpowsour.2012.11.008.

[27] X. Gao, Y. H. Ikuhara, C. A. J. Fisher, H. Moriwake, A. Kuwabara, H. Oki, K. Kohama, R. Yoshida, R. Huang, and Y. Ikuhara, "Structural Distortion and Compositional Gradients Adjacent to Epitaxial $\mathrm{LiMn}_{2} \mathrm{O}_{4}$ Thin Film Interfaces," $A d v$. Mater. Interfaces, vol. 1, no. 8, pp. 1-10, 2014, DOI: 10.1002/admi.201400143.

[28] Y. H. Ikuhara, X. Gao, R. Huang, C. A. J. J. Fisher, A. Kuwabara, H. Moriwake, and K. Kohama, "Epitaxial Growth of $\mathrm{LiMn}_{2} \mathrm{O}_{4}$ Thin Films by Chemical Solution Deposition for Multilayer Lithium-Ion Batteries," J. Phys. Chem. C, vol. 118, no. 34, pp. 19540-19547, Aug. 2014, DOI: 10.1021/jp504305q.

[29] K. Suzuki, M. Hirayama, K. Kim, S. Taminato, K. Tamura, J.-Y. Son, J. Mizuki, and R. Kanno, "Interfacial Analysis of Surface-Coated $\mathrm{LiMn}_{2} \mathrm{O}_{4}$ Epitaxial Thin Film Electrode for Lithium Batteries," J. Electrochem. Soc., vol. 162, no. 13, pp. A7083A7090, 2015, DOI: 10.1149/2.0111513jes.

[30] H. Xia, Y. Wan, F. Yan, and L. Lu, "Manganese oxide thin films prepared by pulsed laser deposition for thin film microbatteries," Mater. Chem. Phys., vol. 143, no. 2, pp. 720-727, 2014, DOI: 10.1016/j.matchemphys.2013.10.005.

[31] Y. Qiu, G. L. Xu, K. Yan, H. Sun, J. Xiao, S. Yang, S. G. Sun, L. Jin, and H. Deng, "Morphology-conserved transformation: Synthesis of hierarchical mesoporous nanostructures of $\mathrm{Mn}_{2} \mathrm{O}_{3}$ and the nanostructural effects on Li-ion insertion/deinsertion properties," J. Mater. Chem., vol. 21, no. 17, pp. 6346-6353, 2011, DOI: 10.1039/c1jm00011j.

[32] F. Wang, X. Wang, Z. Chang, Y. Zhu, L. Fu, X. Liu, and Y. Wu, "Electrode materials with tailored facets for electrochemical energy storage," Nanoscale Horizons, vol. 1, no. 4, pp. 272-289, 2016, DOI: 10.1039/c5nh00116a.

[33] G. Antczak and G. Ehrlich, "Jump processes in surface diffusion," Surf. Sci. Rep., vol. 62, no. 2, pp. 39-61, 2007, DOI: 10.1016/j.surfrep.2006.12.001.

[34] N. Ishiwaza and K. Tateishi, "Diffusion of $\mathrm{Li}$ atoms in $\mathrm{LiMn}_{2} \mathrm{O}_{4}-\mathrm{A}$ structural point of view -," J. Ceram. Soc. Japan, vol. 117, no. 1361, pp. 6-14, 2009, DOI: 10.2109/jcersj2.117.6.

[35] S. Kim, M. Aykol, and C. Wolverton, "Surface phase diagram and stability of (001) and (111) $\mathrm{LiMn}_{2} \mathrm{O}_{4}$ spinel oxides," Phys. Rev. B, vol. 92, no. 11, p. 115411, Sep. 2015, DOI: 10.1103/PhysRevB.92.115411.

[36] C. Jiang, Z. Tang, S. Wang, and Z. Zhang, "A truncated octahedral spinel $\mathrm{LiMn}_{2} \mathrm{O}_{4}$ as high-performance cathode material for ultrafast and long-life lithium-ion batteries," J. Power Sources, vol. 357, pp. 144-148, Jul. 2017, DOI: 10.1016/j.jpowsour.2017.04.079.

[37] J. M. Paulsen and J. R. Dahn, "Phase Diagram of Li-Mn-O Spinel in Air," Chem. Mater., vol. 11, no. 11, pp. 3065-3079, Nov. 1999, DOI: 10.1021/cm9900960. 
[38] M. Kitta, T. Akita, and M. Kohyama, "Preparation of a spinel $\mathrm{LiMn}_{2} \mathrm{O}_{4}$ single crystal film from a MnO wafer," J. Power Sources, vol. 232, pp. 7-11, 2013, DOI: 10.1016/j.jpowsour.2012.12.096.

[39] G.-L. Xu, Q. Wang, J.-C. Fang, Y.-F. Xu, J.-T. Li, L. Huang, and S.-G. Sun, “Tuning the structure and property of nanostructured cathode materials of lithium ion and lithium sulfur batteries," J. Mater. Chem. A, vol. 2, no. 47, pp. 19941-19962, 2014, DOI: 10.1039/C4TA03823A. 
3 Modeling the electrochemical behavior of $\mathrm{LiMn}_{2} \mathrm{O}_{4}$ thin film cathode 


\subsection{Introduction}

It has been shown that the different surface-planes of $\mathrm{LiMn}_{2} \mathrm{O}_{4}$ react differently with the electrolyte [1], however, detailed knowledge on this is limited. How much does the $\mathrm{LiMn}_{2} \mathrm{O}_{4}$-electrolyte interphase influence the rate performance for the different orientations of the cathode, the degradation over cycling and the observed capacity? Furthermore, what is the lithium diffusion coefficient and how does it compare to literature? By modelling the electrochemical behavior of the cell, focusing on the electrochemical response of each layer within the cell, this can be elucidated.

In a simplified picture, the rate performance of the cell is linked to Ohm's law: as the discharge current increases so does the voltage drop as determined by the internal resistance. However, the diffusivity of the lithium-ions through the thin film cathode, SEI, and liquid electrolyte plays a crucial role in the rate performance. The internal resistance and the diffusivity can be relatively simple to determine. The total internal resistance can be calculated from the shift in the voltage plateau while charging and discharging at multiple current rates. The diffusivity can be calculated through techniques such as Cyclic Voltammetry, Potentiostatic Intermitted Titration Technique (PITT) and Electrochemical Impedance Spectroscopy (EIS).

The total internal resistance is composed out of many components as can be seen in table 1 . However, it remains difficult to establish the components of the internal resistance. The values of components within the total internal resistance, especially with respect to the layers they are made up of, and how to control them, cannot be obtained with the voltage shift during charge-discharge. To get in-depth knowledge on the processes that take place in the differently oriented ((100), (110) \& (111)) $\mathrm{LiMn}_{2} \mathrm{O}_{4}$ thin films cathodes, Electrochemical Impedance Spectroscopy (EIS) will be used. 


\begin{tabular}{|l|l|}
\hline Type of resistance & $\begin{array}{l}\text { Internal resistance of cell }\left(\mathrm{R}_{\mathrm{i}}=\text { ionic resistance }+\right. \\
\text { electrical resistance }+ \text { interfacial resistance) }\end{array}$ \\
\hline Ionic & $\begin{array}{l}\text { - Electrode (cathode and anode) particle } \\
\text { - Electrolyte }\end{array}$ \\
\hline Electrical & - Electrode (cathode and anode) particle \\
& - Conductive additives \\
& - Percolation network of additives in electrode \\
& - Current collectors \\
\hline Interfacial & - Electrical taps \\
& - Between electrolyte and electrodes \\
& - Between electrode particles and conductive additives \\
& - Between conductive additives and current collector \\
\hline
\end{tabular}

Table 1, Components of the total internal resistance of the cell. Adapted from [2]

EIS allows to model the electrochemical cell in detail by separating the behaviors of the different layers and interphases in the time domain. This allows to understand the ionic and electronic processes taking place within the thin film cathode while it sits inside a cell. By measuring the current response for small AC voltage perturbations, at different frequencies while the system is in thermodynamic equilibrium, the impedance as a function of frequency can be analyzed. Furthermore, by measuring at multiple voltages, the electrochemical behavior as function of lithiation can be obtained. Initially, the cell's voltage is set to obtain thermodynamic equilibrium after which the system is perturbed with a $10 \mathrm{mV}$ sinusoidal voltage of which the frequency is swept from $1 \mathrm{MHz}$ down to $1 \mathrm{mHz}$.

It is important to stress that the system should be in thermodynamic equilibrium. The material / cell that is measured can have both linear and non-linear behavior that varies with time or is constant. For the analysis it is assumed that the system shows linear behavior and does not change over time. However, it is known that the battery cell changes over time and shows non-linear behavior: the voltage of a plateau depends on the applied current and the capacity depends on the current and the amount of material. Therefore, it is assumed that the non-linear behavior can be approximated by applying a small perturbation around a set 
voltage, which allows to characterize the material's behavior around that voltage. Furthermore, each measurement is done fast enough to be able to assume the material / cell did not age while allowing enough time to reach equilibrium after a new set voltage. Lastly, the quality of the measurements is checked through the indicators given by the software (BioLogic's EC-Lab), which give a >1\% error for frequencies above $0.6 \mathrm{~Hz}$.

Figure 1 shows an EIS measurement with the simplest circuit that would physically behave similar to a battery cell. The relation between the real and imaginary parts of the impedance are shown in figure 1a. Where an arrow indicates the direction in which the frequency increases.

a)

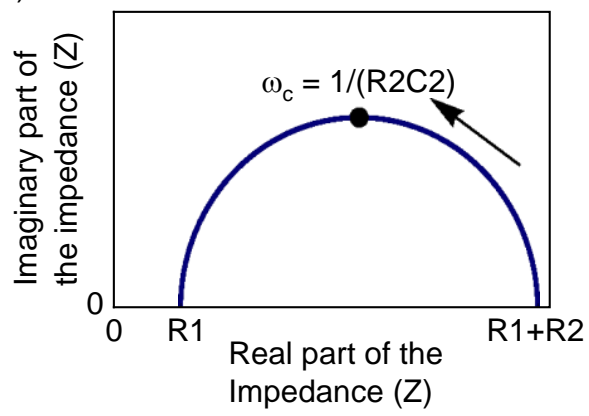

b)

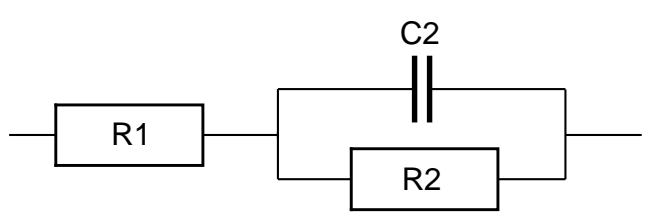

$\mathrm{R} 1+\mathrm{R} 2 / \mathrm{C} 2$

Figure 1, a) Measured Impedance in Nyquist diagram and, b), physical representation through an equivalent circuit. Adapted from [13].

In figure $1 \mathrm{~b}$ an equivalent circuit (EQC) is developed to model the measured impedance. In this case it exists of two resistors (R1 and R2) and a capacitor (C2). The angular frequency $\left(\omega_{c}\right)$ indicates the time constant at which the real impedance component of the capacity $(\mathrm{C} 2)$ equals that of the resistance (R2). However, other EQC's can be used to represent the same impedance results shown in $1 \mathrm{a}$. The circuits shown in figure 2 have the same impedance as function of frequency, however have different physical representations. 
a)

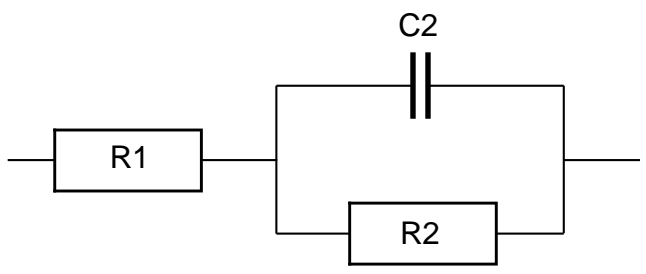

$\mathrm{R} 1+\mathrm{R} 2 / \mathrm{C} 2$

b)

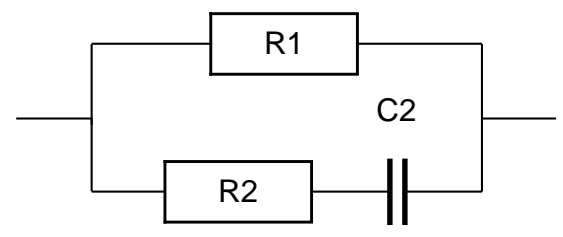

$\mathrm{R} 1 /(\mathrm{R} 2+\mathrm{C} 2)$

Figure 2, Two equivalent circuits a) and b) that have similar impedance as function of frequency but different physical representations. Adapted from [13].

As a real battery (cell) is much more complex, also more complex circuits will be used. The challenge then lies in finding a model that fits the measured impedance while being a correct physical representation. A few assumptions, however, can already be made.

1. There will be a resistance present already at the highest frequencies. This resistance is due to cables, different connections, electronic conductivity through the cell's external housing, conductivity through the substrate, and ionic conductivity through the electrolyte [2].

2. Furthermore, at the interface between the electrolyte and the cathode a double layer capacitance in formed. Adsorbed ions from the solution on the cathode form a double layer. The value depends on many factors as electrode potential, temperature, ionic concentrations, types of ions, oxide layers, electrode roughness, and impurity adsorption [2-4].

3. Additionally, a resistance to lithium transport resides inside the film. Due to lithium needing to find a place inside the electrode one gets a resistance to charge transfer.

$$
\mathrm{M} \Leftrightarrow \mathrm{M}^{\mathrm{n}+}+\mathrm{ne}^{-}
$$

The total reaction inside the whole cell is a continuous process with a net flux of zero at equilibrium when the cell is not charged or discharged. 
From the cathode, in the charging reaction, electrons leave the $\mathrm{LiMn}_{2} \mathrm{O}_{4}$ and $\mathrm{Li}^{+}$-ions diffuse into the electrolyte. Thus, charge is being transferred. This reaction has a certain speed which depends on the kind of reaction, the temperature, the concentration of the reaction products and the voltage. When the overpotential, $\eta$, is very small and the electrochemical system is at equilibrium, the expression for the charge-transfer resistance can be described by:

$$
\mathrm{R}_{\mathrm{ct}}=\frac{\mathrm{RT}}{\mathrm{nFi}_{0}}
$$

Here, the charge transfer resistance $\left(R_{c t}\right.$ in $\left.[\Omega]\right)$ is determined by the gas constant $(R$ in $\left[\mathrm{J} \mathrm{mol}^{-1} \mathrm{~K}^{-1}\right]$ ), the temperature ( $\mathrm{T}$ in $[\mathrm{K}]$ ), the number of electrons (n) involved, the Faraday constant ( $\mathrm{F}$ in $\left.\left[\mathrm{C} \mathrm{mol}^{-1}\right]\right)$, and the exchange current $\left(\mathrm{i}_{\mathrm{o}}\right.$ in $\left.[\mathrm{A}]\right)[2-4]$.

The charge transfer resistance $\left(\mathrm{R}_{\mathrm{ct}} / \mathrm{R} 2\right)$ is electrically in parallel with the double layer capacitance $\left(\mathrm{C}_{\mathrm{dl}} / \mathrm{C} 2\right)$. Together with a constant resistance $(\mathrm{R} 1)$, that will be present even at high frequencies, this provides a circuit as shown in figure $1 \mathrm{~b}$ with a semi-circle like impedance response as shown in figure 1a.

4. As both anode and cathode are present in the cell, it is expected that the double layer capacity and charge-transfer resistance occur twice. Whether both can be independently resolved depends on how much their values differ. It is expected that the lithium anode's charge transfer resistance is lower, as its kinetics are faster and its surface is larger in the cells [2].

5. Finally, a Finite Space Warburg can be expected. The Warburg is a model to describe semiinfinite diffusion. It can be used for the solid-state diffusion of $\mathrm{Li}$ into the bulk of a cathode $\left(\mathrm{LiMn}_{2} \mathrm{O}_{4}\right)$. When an impermeable boundary, where the lithium-ions cannot penetrate, is present, the Finite Space Warburg describes the electrochemical behavior. As the lithiumions from the electrolyte can go into the cathode, but not further into the substrate, this finite space Warburg is a good model to fit part of the thin-film cathode [14]. 
a)

b)

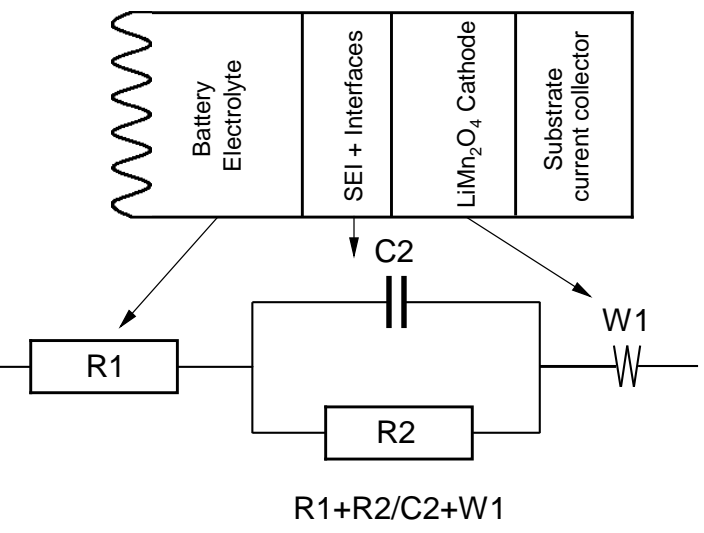

c)

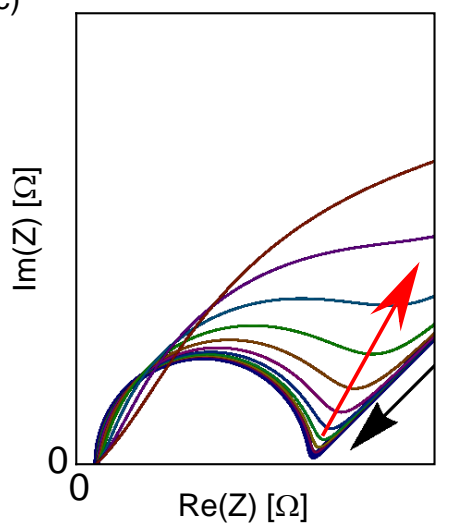

Figure 3, Describing the behavior of the $\mathrm{LiMn}_{2} \mathrm{O}_{4}$ thin film cathode. a) Physical schematic, b) circuit model, and c) impedance behavior as function of faradic and diffusion time constants. Black arrow indicates the increasing frequency direction and red arrow indicates an increasing Warburg contribution. Adapted from [13].

With the charge transfer resistances, double layer capacitances, and a finite space Warburg, a model can be made (figure 3) to fit the electrochemical behavior of the thin-film $\mathrm{LiMn}_{2} \mathrm{O}_{4}$ cathode which will provide detailed information about the internal components of the total internal resistances and the behavior of the cell and consequently the $\mathrm{LiMn}_{2} \mathrm{O}_{4}$ thin film cathode.

\subsection{Experimental}

As mentioned, thermodynamic equilibrium is important, and therefore each measurement must be performed within a limited time-scale. Therefore, the $\mathrm{LiMn}_{2} \mathrm{O}_{4}$ thin-film is charged to $4.5 \mathrm{~V}$, kept constant for an hour to reach equilibrium after which the electrochemical impedance spectroscopy (EIS) was performed. At the voltage of $4.5 \mathrm{~V}$, the cathode can be regarded as completely delithiated $\left(\lambda-\mathrm{Mn}_{2} \mathrm{O}_{4}\right)$. During EIS the impedance was measured from $1 \mathrm{MHz}$ to $1 \mathrm{mHz}$, with 10 points per decade on a log scale. For each point a perturbation 
of $10 \mathrm{mV}$ AC is applied where an average of the impedance is taken over 5 sinusoidal periods. To go through the different lithiation states of $\mathrm{Li}_{\mathrm{x}} \mathrm{Mn}_{2} \mathrm{O}_{4}(4.5-3.8 \mathrm{~V})$, steps of $10 \mathrm{mV}$ are taken while at each step the voltage is kept constant for 5 minutes to reach thermodynamic equilibrium. This is repeated until a voltage of $3.8 \mathrm{~V}$ is reached. The voltage range allows analyzing the impedance while the cathode transitions from $\lambda-\mathrm{Mn}_{2} \mathrm{O}_{4}$ to $\mathrm{LiMn}_{2} \mathrm{O}_{4}$.

\subsection{Results and Discussion}

A typical impedance result for a $\mathrm{LiMn}_{2} \mathrm{O}_{4}$ thin film is shown in figure 4 with voltages and lithiation levels shown in the legend. When the applied voltage is lowered the impedance for low frequencies $(<2 \mathrm{~Hz})$ changes drastically.

Figure $4 \mathrm{~b}$ shows the low impedance values at the high frequencies which do not change with lithation level. At first glance the graph in figure 4a seems to exhibit only two semi-circles. However, when zooming in on the high frequencies (figure 5b) a third semi-circle can be observed. The three semicircles with a substrate / electrolyte resistance and a Warburg should provide a reasonable model to fit the data.

As the impedance changes with the voltage, a good model should be able to fit the impedance for the whole voltage range. Fitting the impedance with the used model is shown in figure 5a. This model is in accordance with literature [3-5] with an extra capacitance (Q4) added to fit all voltages. This is then used to fit the $\mathrm{LiMn}_{2} \mathrm{O}_{4}$ thin film cathode in a half-cell configuration over the voltage range of 4.5 to $3.8 \mathrm{~V}$.

During fitting and simulating the EIS measurement, only a constant Warburg resulted in being able to fit over the full potential range of EIS measurements. As the low frequency tails in figure $4 \mathrm{a}$ show an incline of more than $45^{\circ}$ and the Q4 value in figure $5 \mathrm{c}$ is fluctuating with the tails, it is clear that the added capacity (Q4) overshadows any change in Warburg through the voltages resulting in a constant value during fitting. 
a)

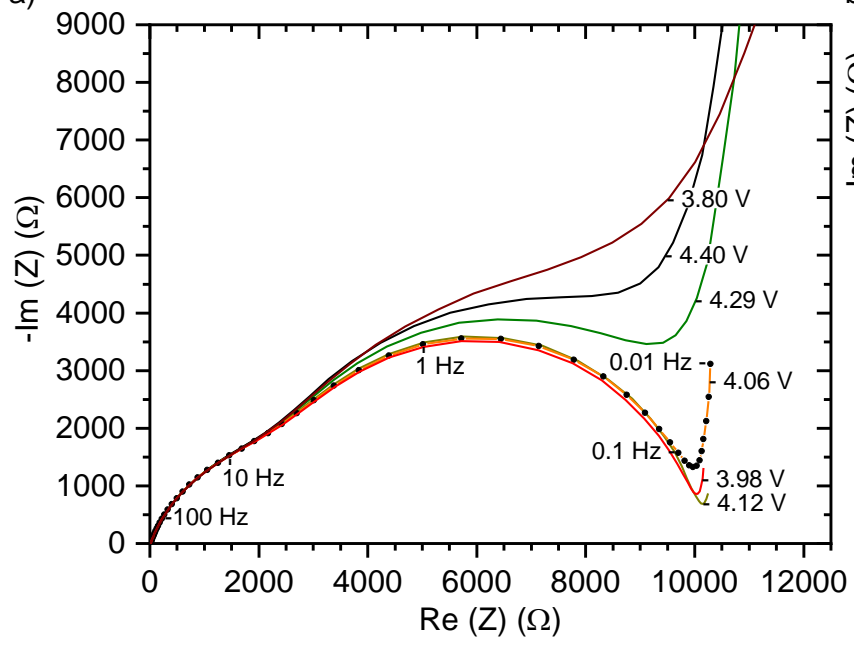

b)

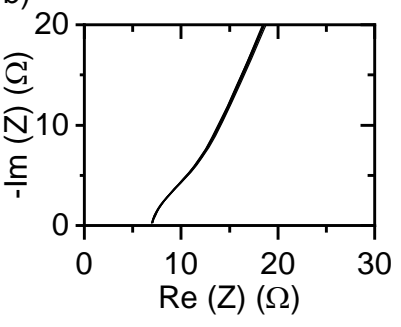

$-4.40 \mathrm{~V} \mathrm{\textrm {Li } _ { 0 . 0 0 }} \mathrm{Mn}_{2} \mathrm{O}_{4}$ $4.29 \mathrm{~V} \mathrm{Li}_{0.00} \mathrm{Mn}_{2} \mathrm{O}_{4}$ $4.12 \mathrm{~V} \mathrm{Li}_{0.25} \mathrm{Mn}_{2} \mathrm{O}_{4}$ $-4.06 \mathrm{~V} \mathrm{Li}_{0.50} \mathrm{Mn}_{2} \mathrm{O}_{4}$ $3.98 \mathrm{~V} \mathrm{Li}_{0.75} \mathrm{Mn}_{2} \mathrm{O}_{4}$ $3.80 \mathrm{~V} \mathrm{Li}_{1.00} \mathrm{Mn}_{2} \mathrm{O}_{4}$

Figure 4, a) Impedance of the $\mathrm{LiMn}_{2} \mathrm{O}_{4}$ thin film cathode in Nyquist Diagram for multiple voltages. b) A zoom-in on the impedance at high frequencies (1 $\mathrm{MHz}-10 \mathrm{kHz})$.

a) $\begin{aligned} & \text { Substrate } \\ & \text { resistance }\end{aligned}$
Warburg SEI-film Li. Metal SEI-film LMO $\begin{aligned} & \text { Charge transfer resistance Capacitance behavior } \\ & \text { double layer capacitance }\end{aligned}$ resistance double layer capacitance

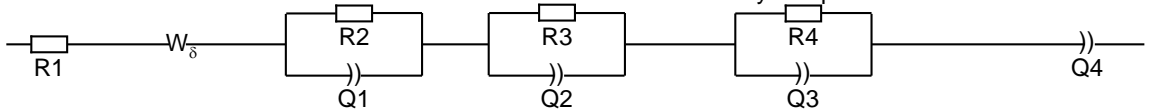

b)

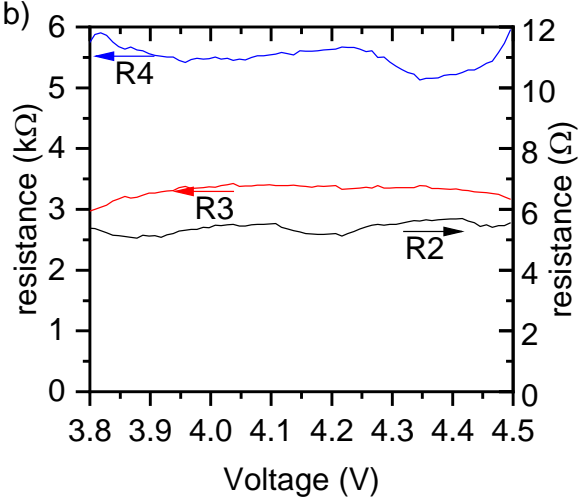

c)

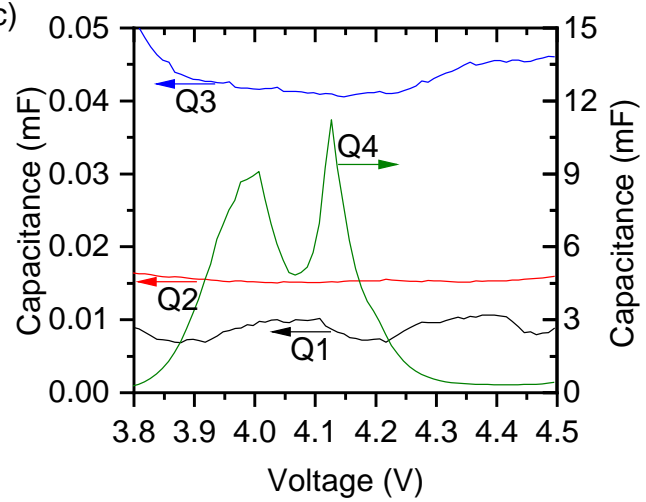

Figure 5, a) Equivalent Circuit of the fitted model with, b), the found Resistances and, $c$ ),

Capacitances. Rl and Wdl are constant over voltage and their parameters are respectively $6.407 \Omega$ and $866.97 \Omega, 2.374 \mathrm{~s}$. 
The resistance due to cables, different connections, electronic conductivity through the cell's external housing, conductivity through the substrate, and ionic conductivity through the electrolyte [2] is taken as constant and is combined in the constant R1 value of $6.407 \Omega$. Other parameters like R2, R3, R4, Q1, Q2 and Q3 are almost constant and only seem to fluctuate lightly, possibly with small changes in the temperature of the laboratory over the 2.5-day period of EIS measurement. Furthermore, small changes can also be partly attributed to SEI layer growth, and depletion or changes in the Electrolyte and/or dissolution of Mn.

During the discharging of the battery cell, it is observed that Q4 (figure 5c) follows as certain trend to allow a fit of the low frequencies of the EIS measurement, resulting in the tail observed in figure 4a. This 'tail' for the low frequencies starts around $10 \mathrm{k} \Omega$ on the real impedances and seems to encompass the capacity of the thin film. Plotting the real and imaginary impedances for 0.01 and $0.1 \mathrm{~Hz}$ (figure 6) it is observed that they are lower in the range where lithiation of $\mathrm{Li}_{x} \mathrm{Mn}_{2} \mathrm{O}_{4}$ takes place and therefore in the region of plateaus in the discharging of the $\mathrm{LiMn}_{2} \mathrm{O}_{4}$ thin film cathode.

a)

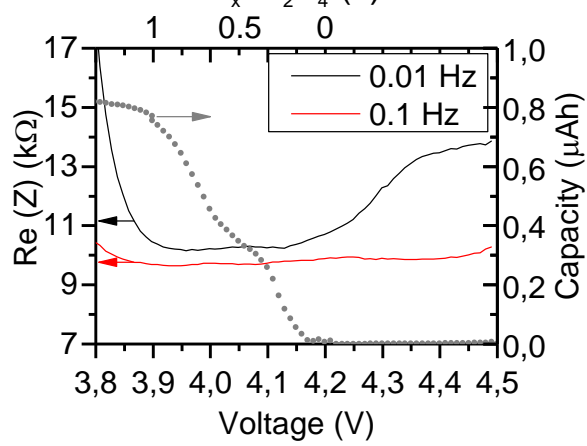

b)

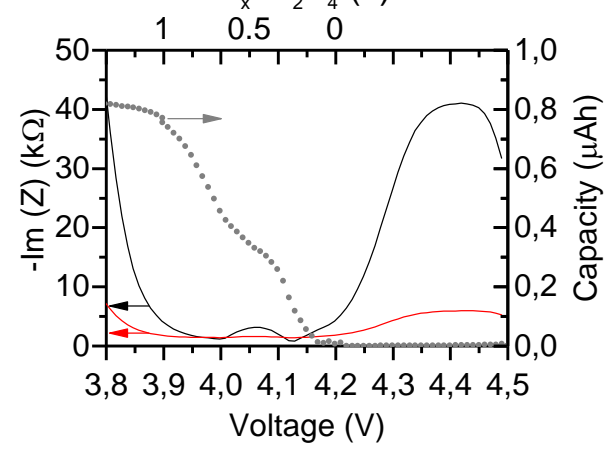

Figure 6, a) Real and, b), imaginary impedances as function of voltage and lithiation level in $\mathrm{Li}_{x} \mathrm{Mn}_{2} \mathrm{O}_{4}$. In grey the capacity as a function of voltage is shown. 
This is in agreement with the classical equation for the charge transfer resistance [6, 7]:

$$
R_{c t}=1 / f F k_{0} A c_{o}^{0.5} c_{R}^{0.5}
$$

Where the charge-transfer resistance (Rct) equals 1 over (combined) the electrochemical constant (f), times the Faraday constant $(\mathrm{F})$, the rate constant $\left(\mathrm{k}_{0}\right)$, the area $(\mathrm{A})$ and the square root of the concentration of available oxidation $\left(c_{o}\right)$ as well as reduction sites $\left(c_{R}\right)$. The total amount of intercalation sites $\left(c_{T}\right)$ is constant $\left(c_{o}+c_{R}=c_{T}\right)$. When the concentration of reduction $\left(c_{R}\right)$ or oxidation sites $\left(c_{o}\right)$ approaches the total amount of intercalation sites (i.e. at discharged or charged state) the resistance rapidly increases. This is observed in figure $6 \mathrm{a}$ and $6 \mathrm{~b}$ when the voltage is $<3.9$ or $>4.2 \mathrm{~V}$.

As Q4 changes over voltage with a certain trend as shown in figure 5c it was tried to link this parameter to the actual capacity of the layer. The trend closely resembles the peaks observed in the derivative (dQ/dE) of a discharge over voltage measurement (figure 7).

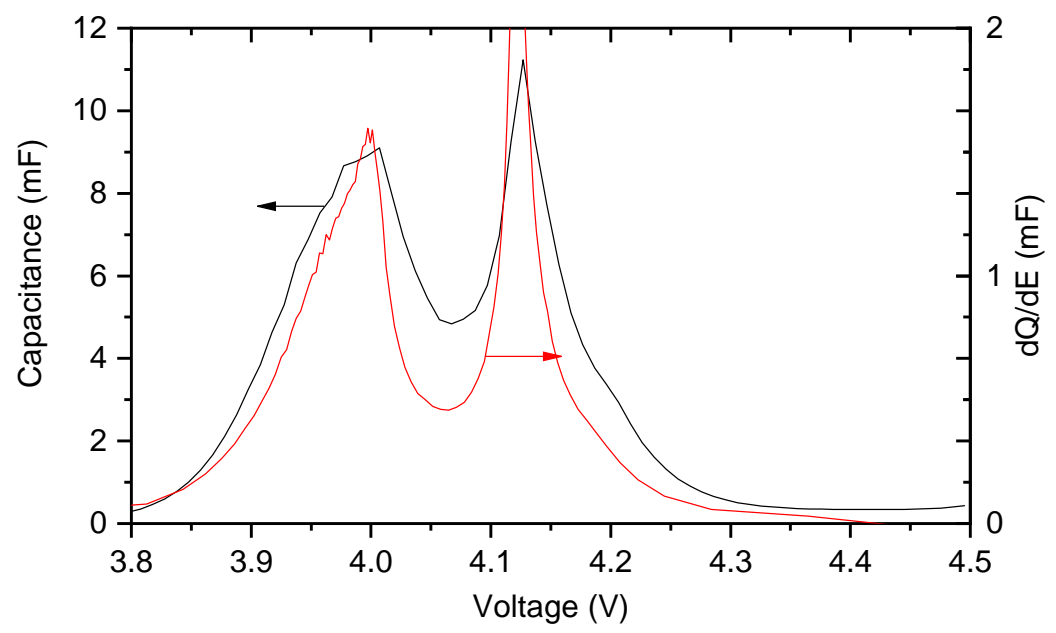

Figure 7, Fitted Capacitance Q4 (black) and measured derivative of a discharge voltage profile $(d Q / d E)$ (red) over voltage. 
Both $\mathrm{Q} 4$ and $\mathrm{dQ} / \mathrm{dE}$ have an increasing slope around $3.9 \mathrm{~V}$, a peak at $4 \mathrm{~V}$, a trough at 4.06 $\mathrm{V}$, another peak at $4.12 \mathrm{~V}$ and a downwards slope around 4.2 V. Due to their resemblance the capacity was determined by the area under the curve. Here, Q4 overestimates the capacity by about a factor of seven. It is possible that this overestimation arises from thermodynamic non-equilibrium due to the time-scale of the experiment. When more time is taken to reach a better equilibrium this overestimation should diminish.

\subsection{Calculating the diffusion coefficient}

Determining values for the Lithium diffusion kinetics are important in order to be able to compare the electrochemical response of the thin films to literature. The Warburg component in the model describes the solid-state diffusion of Li into the bulk of $\mathrm{LiMn}_{2} \mathrm{O}_{4}$. This allows, with correct simulation and fitting, one to use it to extract the diffusion coefficient. The 'Warburg slope' has a linear response and can be described as [4]:

$$
A_{w}=\left(\frac{d E}{d x}\right)\left(\frac{V_{m}}{\sqrt{2 D} z F A}\right)
$$

Where the slope of the electrode potential $\left(\frac{\mathrm{dE}}{\mathrm{dx}}\right)$ is the voltage curve vs. [ $\left.\mathrm{Li}\right]$ in $\mathrm{Li}_{\mathrm{x}} \mathrm{Mn}_{2} \mathrm{O}_{4}$, the molar volume of $\mathrm{LiMn}_{2} \mathrm{O}_{4}\left(\mathrm{~V}_{\mathrm{m}}\right)$ is in $\left[\mathrm{cm}^{3} \mathrm{~mol}^{-1}\right]$, the chemical diffusion coefficient (D) is in $\left[\mathrm{cm}^{2} \mathrm{~s}^{-1}\right]$, the charge-transfer number $(\mathrm{z})$ of the lithium is +1 , the Faraday constant $(\mathrm{F})$ is in $\left[\mathrm{Ah} \mathrm{mol}{ }^{-1}\right]$, and lastly the electrode area (A) is in $\left[\mathrm{cm}^{2}\right]$

The Warburg slope as shown above has a linear response to the change in one over the square root of the angular frequency $\left(\Delta \omega^{-1 / 2}\right)[4]$ :

$$
\mathrm{A}_{\mathrm{w}}=\left(\frac{\mathrm{dE}}{\mathrm{dx}}\right)\left(\frac{\mathrm{V}_{\mathrm{m}}}{\sqrt{2 \mathrm{D} z \mathrm{FA}}}\right)=\frac{\Delta \mathrm{Re}}{\Delta \omega^{-1 / 2}}=\frac{\Delta \mathrm{Im}}{\Delta \omega^{-1 / 2}}
$$

Where the change in real impedance $(\Delta \mathrm{Re})$ is equal to the change in imaginary impedance $(\Delta \mathrm{Im})$ for a change of the angular frequency $\left(\Delta \omega^{-1 / 2}\right)$. 
The diffusivity (D) can then be calculated. However, as a correct fit or simulation of the Warburg component can be difficult, and $\mathrm{dE} / \mathrm{dx}$ is dependent on the current used, large errors are expected. Using the formula, the diffusivity for the voltages and lithiation levels given in figure 4 are shown in table 2. Although large errors are expected, the diffusivity trend follows the conductivity [6] and diffusivity [8] trend observed in literature.

\begin{tabular}{|l|l|l|l|l|l|l|}
\hline Voltage & {$[\mathrm{V}]$} & 4.29 & 4.12 & 4.06 & 3.98 & 3.8 \\
\hline $\mathrm{Li}_{\mathrm{x}} \mathrm{Mn}_{2} \mathrm{O}_{4}$ & {$[\mathrm{x}]$} & 0 & 0.25 & 0.5 & 0.75 & 1 \\
\hline Diffusivity & {$\left[\mathrm{cm}^{2} / \mathrm{s}\right]$} & $7.1210^{-15}$ & $1.0110^{-15}$ & $1.8810^{-15}$ & $1.3310^{-15}$ & $4.3310^{-16}$ \\
\hline
\end{tabular}

Table 2, Diffusivity determined through EIS for voltages and lithiation levels.

The diffusivity can also be calculated through Cyclic Voltammetry (CV) and Potentiostatic Intermitted Titration Technique (PITT). In contrast to the thermodynamic equilibrium during EIS, the system is dynamic during Cyclic Voltammetry, while during PITT the system is in transient mode. To compare the diffusivity results obtained through EIS, PITT was used.

\subsection{PITT}

Potentiostatic Intermitted Titration Technique (PITT) allows to calculate the diffusivity through the current behavior after very small steps in the potential are taken. The current can be described by Fick's first law:

$$
I(t)=-\left.D \frac{d C_{L i}(x, t)}{d x}\right|_{x=0}
$$

Where the chemical diffusion coefficient (D) is in $\left[\mathrm{cm}^{2} \mathrm{~s}^{-1}\right]$ and the Li-ion concentration $\left(\mathrm{C}_{\mathrm{li}}\right)$ is at distance $(\mathrm{x})$ into the solid thin film from the electrode / electrolyte interface in $[\mathrm{cm}]$ and at time $(\mathrm{t})[\mathrm{s}]$. 
After each step the current behavior is measured for a fixed period. The diffusion of lithium can be modeled as a transport based on Fick's second law

$$
\frac{\partial C_{L i}(x, t)}{\partial t}=D \frac{\partial^{2} C_{L i}(x, t)}{\partial x^{2}}
$$

The boundary condition for $x \rightarrow \infty$ is $\lim _{x \rightarrow \infty} C(x, t)=C^{0}$ where $C^{0}$ is the equilibrium concentration.

The small potential step in PITT gives a current transient I(t) (figure 8) with a relationship to $\mathrm{t}[9]$ :

$$
I(t)=\frac{2 Q D}{L^{2}} \sum_{n=0}^{\infty} \exp \left(-\frac{(2 n+1)^{2} \pi^{2} D t}{2 L^{2}}\right)
$$

Where the total charge transferred during the potential step (Q) is in $[\mathrm{C}]$ and the thickness of the electrode $(\mathrm{L})$ is in $[\mathrm{cm}]$.

At long times (where $t \gg L^{2} D$ ) the $\mathrm{I}(\mathrm{t})$ can be approximated by [10]:

$$
I(t)=\frac{2 Q D}{L^{2}} \exp \left(-\frac{\pi^{2} D t}{4 L^{2}}\right)
$$

One can then derive the chemical diffusion coefficients (D) from the slope of $\ln (\mathrm{I}(\mathrm{t}))$ :

$$
D=-\frac{4 L^{2}}{\pi^{2}} \frac{d \ln (I(t))}{d t}
$$

Using potential steps of $10 \mathrm{mV}$ the current is measured for 10 minutes with a range from 4.5 $\mathrm{V}-3.8 \mathrm{~V}$, using the last 5 minutes of current for the slope of $\ln (\mathrm{I}(\mathrm{t}))$ gives the diffusivity of lithium for the $4 \mathrm{~V}$ plateaus as shown in figure 10 . 


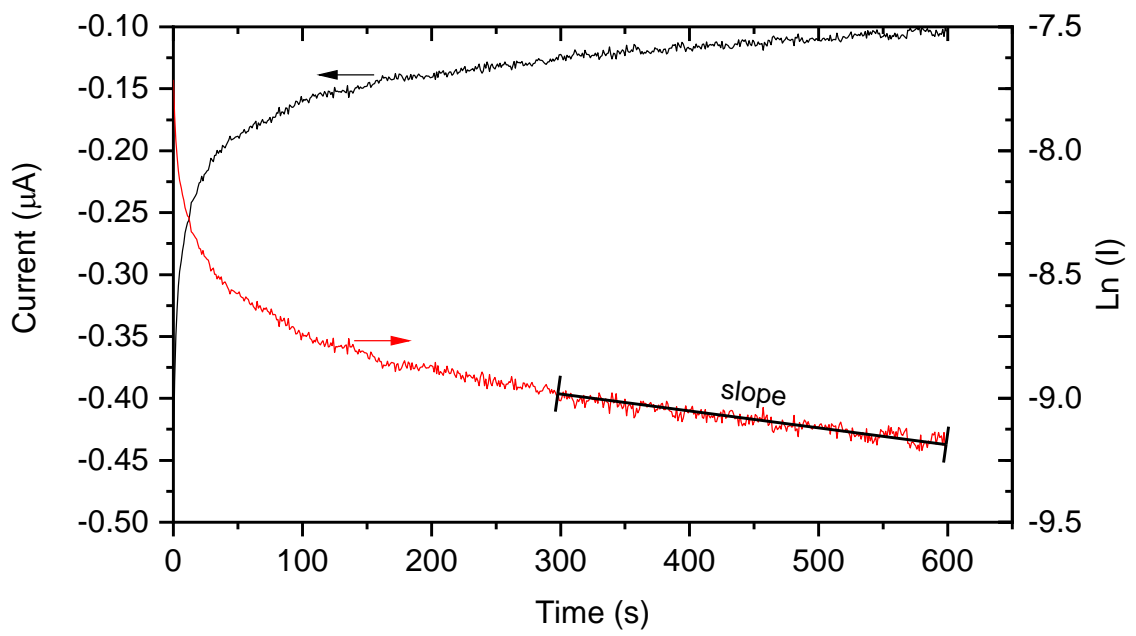

Figure 8, Current behavior after $10 \mathrm{mV}$ potential step and $\ln (\mathrm{I}(\mathrm{t}))$ at $3.8 \mathrm{~V}$.

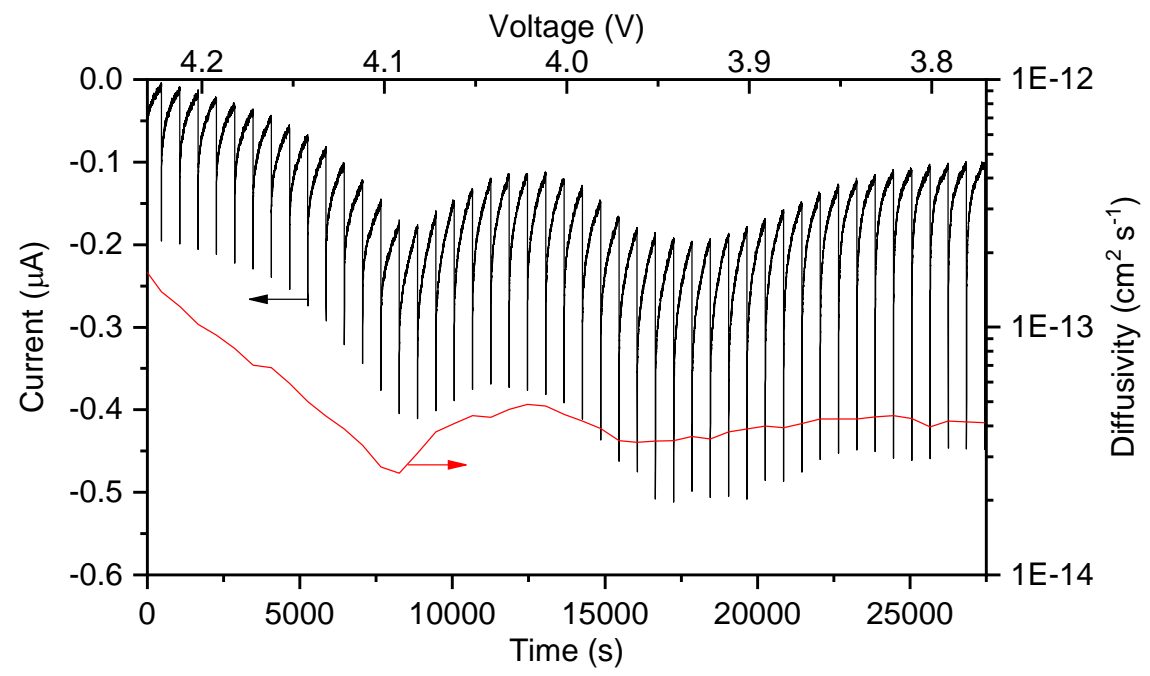

Figure 9, PITT (black) and calculated diffusivity (red) over time and voltage.

The diffusivity throughout discharging varies over voltage but is around $410^{-14} \mathrm{~cm}^{2} \mathrm{~s}^{-1}$. The diffusivity value found through EIS $\left(\sim 10^{-15}\right)$ is about an order of magnitude lower than that through PITT $\left(\sim 410^{-14}\right)$, however in accordance with the variations found in literature [3, 4]. The large difference between EIS and PITT is attributed to the large error in the capacity 
found in EIS. This error effects the Warburg slope. PITT is therefore expected to give a more representative diffusivity of the thin film cathode.

Bulk diffusivity of $\mathrm{LiMn}_{2} \mathrm{O}_{4}$ is in the order of $10^{-11}-10^{-9} \mathrm{~cm}^{2} \mathrm{~s}^{-1}$ [11]. This higher bulk diffusivity is explained through the large impedances found for the charge transfer to the electron conductor. Looking back to the values attributed to the SEI film on the $\mathrm{LiMn}_{2} \mathrm{O}_{4}$ thin film cathode and its charge transfer (R3 and R4 in figure 5) both are an order of magnitude higher with respect to polycrystalline thin films on a gold substrate [3] and a stainless steel substrate [4]. The SEI layer resistance might be lowered by improvements to the electrolyte, which is outside the scope of this research / thesis. It is known that the band alignment of the $\mathrm{LiMn}_{2} \mathrm{O}_{4}$ with respect to its current collector is crucial which has led to the introduction of a $\mathrm{SrRuO}_{3}$ current collector layer for $\mathrm{Nb}: \mathrm{SrTiO}_{3}$ substrates [12]. As a large charge transfer resistance still exists this either suggests further optimization of $\mathrm{SrRuO}_{3}$ is needed or $\mathrm{SrRuO}_{3}$ (alone) is insufficient to decrease the internal resistance and allow improved charge- discharge rates needed for high power density applications.

\subsection{Conclusion}

The model fitted to the performed EIS measurements gives insight into the components of the internal resistance as well as the capacity of the cathode. A large resistance to charge transfer indicates improvements to the current collector needs to be made. The capacity is overestimated by a factor of 7 , possibly due to non-equilibrium. A longer time to stabilize the voltage should diminish this. The $\mathrm{LiMn}_{2} \mathrm{O}_{4}$-electrolyte interface is second in determining the rate performance, the high charge transfer resistance influences the rate performance most. As only (100)-oriented thin film is measured, solely a start is made into the analysis of the different orientations and $\mathrm{LiMn}_{2} \mathrm{O}_{4}$-electrolyte interphase, and their effect on the rate performance, degradation over cycling and observed capacity. The Warburg slope used to calculate the diffusivity of the thin film gives a diffusivity following a similar trend to that 
found in literature. By means of PITT the Li-diffusivity was also calculated and compared. EIS gives an order lower diffusivity than that calculated through PITT. The found diffusivity through PITT for epitaxial thin films of $\mathrm{LiMn}_{2} \mathrm{O}_{4}$ is an order of magnitude lower compared to polycrystalline thin films on a gold and stainless steel substrate. The high resistance for charge transfer is largely responsible for this, again suggesting improvements to the current collector are needed to allow decreased internal resistance of the thin film. 


\subsection{References:}

[1] M. Hirayama, N. Sonoyama, M. Ito, M. Minoura, D. Mori, A. Yamada, K. Tamura, J. Mizuki, and R. Kanno, "Characterization of Electrode/Electrolyte Interface with $\mathrm{X}$-Ray Reflectometry and Epitaxial-Film $\mathrm{LiMn}_{2} \mathrm{O}_{4}$ Electrode," J. Electrochem. Soc., vol. 154, no. 11, p. A1065, 2007, DOI: 10.1149/1.2778853.

[2] T. B. Reddy, Linden's Handbook of Batteries, 4th ed. New York: McGraw-Hill, 2011.

[3] J. Xie, K. Kohno, T. Matsumura, N. Imanishi, A. Hirano, Y. Takeda, and O. Yamamoto, "Li-ion diffusion kinetics in $\mathrm{LiMn}_{2} \mathrm{O}_{4}$ thin films prepared by pulsed laser deposition," Electrochim. Acta, vol. 54, no. 2, pp. 376-381, 2008, DOI: 10.1016/j.electacta.2008.07.067.

[4] S. B. B. Tang, M. O. O. Lai, and L. Lu, "Study on $\mathrm{Li}^{+}$-ion diffusion in nanocrystalline $\mathrm{LiMn}_{2} \mathrm{O}_{4}$ thin film cathode grown by pulsed laser deposition using CV, EIS and PITT techniques," Mater. Chem. Phys., vol. 111, no. 1, pp. 149-153, Sep. 2008, DOI: 10.1016/j.matchemphys.2008.03.041.

[5] G. Pistoia, D. Zane, and Y. Zhang, "Some Aspects of $\mathrm{LiMn}_{2} \mathrm{O}_{4}$ Electrochemistry in the 4 Volt Range," J. Electrochem. Soc., vol. 142, no. 8, p. 2551, 1995, DOI: 10.1149/1.2050052.

[6] X. Fan, Q. Zhuang, S. Sun, J. Xu, L. Huang, Q. Dong, and Y. Jiang, "An electrochemical impedance spectroscopic study of the electronic and ionic transport properties of $\mathrm{LiCoO}_{2}$ cathode," Chinese Sci. Bull., vol. 52, no. 9, pp. 1187-1195, 2007, DOI: 10.1007/s11434-007-0169-1.

[7] M. Levi, K. Gamolsky, D. Aurbach, U. Heider, and R. Oesten, "On electrochemical impedance measurements of $\mathrm{Li}_{\mathrm{x}} \mathrm{Co}_{0.2} \mathrm{Ni}_{0.8} \mathrm{O}_{2}$ and $\mathrm{Li}_{\mathrm{x}} \mathrm{NiO}_{2}$ intercalation electrodes," Electrochim. Acta, vol. 45, no. 11, pp. 1781-1789, Feb. 2000, DOI: 10.1016/S00134686(99)00402-8.

[8] H. Kanoh, Q. Feng, T. Hirotsu, and K. Ooi, "AC Impedance Analysis for $\mathrm{Li}^{+}$ Insertion of a Pt $\lambda-\mathrm{MnO}_{2}$ Electrode in an Aqueous Phase," J. Electrochem. Soc., vol. 143, no. 8, p. 2610, 1996, DOI: 10.1149/1.1837056.

[9] Y. H. Rho and K. Kanamura, "Li+-Ion Diffusion in $\mathrm{LiCoO}_{2}$ Thin Film Prepared by the Poly(vinylpyrrolidone) Sol-Gel Method," J. Electrochem. Soc., vol. 151, no. 9, p. A1406, 2004, DOI: 10.1149/1.1779333.

[10] Y.-I. Jang, B. J. Neudecker, and N. J. Dudney, "Lithium Diffusion in $\mathrm{Li}_{\mathrm{x}} \mathrm{CoO}_{2}(0.45$ $<\mathrm{x}<0.7)$ Intercalation Cathodes," Electrochem. Solid-State Lett., vol. 4, no. 6, p. A74, 2001, DOI: 10.1149/1.1368717.

[11] M. Park, X. Zhang, M. Chung, G. B. Less, and A. M. Sastry, "A review of conduction phenomena in Li-ion batteries," J. Power Sources, vol. 195, no. 24, pp. 7904-7929, 2010, DOI: 10.1016/j.jpowsour.2010.06.060.

[12] K. Suzuki, K. Kim, S. Taminato, M. Hirayama, and R. Kanno, "Fabrication and electrochemical properties of $\mathrm{LiMn}_{2} \mathrm{O}_{4} / \mathrm{SrRuO}_{3}$ multi-layer epitaxial thin film electrodes," J. Power Sources, vol. 226, no. March 2013, pp. 340-345, 2013, DOI: 10.1016/j.jpowsour.2012.11.008. 
[13] Atlas of Electrochemical Nyquist Diagrams, Bio-Logic, Sept 282011

[14] B. A. Boukamp, "Advanced Methods in Electrochemical Impedance Spectroscopy”, Tutorial, Solid State Ionics-19, Kyoto, Japan, June 2nd, 2013 
4 Electrochemical behavior of $\mathrm{LiMn}_{2} \mathrm{O}_{4}$ thin film cathode during different loads, and through time 


\subsection{Introduction}

Due to the continuously growing demand for enhanced performance of batteries, scientific and technological efforts have been focused on electrode materials with larger capacity, higher energy- and power density, reversibility and structural stability during charge/discharge cycles, faster ionic diffusion and electronic transfer at high charge/discharge rates, lower costs, higher safety, and usage of more environmental friendly materials and processes $[1,2,3]$.

Furthermore, recent progression in electric and hybrid vehicles $((\mathrm{H}) \mathrm{EVs})$ demands high power densities of the current battery systems [4] combined with high mileage and longevity. Existing battery applications in electric mobility and stationary storage are limited by their inadequate cycle-life and inherently poor safety features [5]. The cycle-life and lifetime depend on the used materials and their interfaces, with safety being a function of the stability of the electrode materials and their interfaces with electrolyte [6-8].

Spinel $\mathrm{LiMn}_{2} \mathrm{O}_{4}$ has emerged as a promising cathode material for next generation lithium batteries $[9,10]$ due to its relatively high operating voltage (4.1 V vs $\mathrm{Li})$ and good energy density (theoretically $148 \mathrm{mAh} / \mathrm{g}$, and $120 \mathrm{mAh} / \mathrm{g}$ typically) as compared to $140 \mathrm{mAh} / \mathrm{g}$ typically achieved for $\mathrm{LiCoO}_{2}$. Its energy density can be further increased by partially replacing $\mathrm{Mn}$ by $\mathrm{Ni}$ to get the higher voltage cathode $\mathrm{LiNi}_{0.5} \mathrm{Mn}_{1.5} \mathrm{O}_{4}(\sim 4.7 \mathrm{~V})$. An overview of common cathode materials and their capacities, average potentials and energy densities is given in table 1 .

As mentioned and shown in figure 4 and 5 of chapter 1 , the edge-shared octahedral $\mathrm{Mn}_{2} \mathrm{O}_{4}$ host framework provides structural stability and interconnects lithium and empty sites (figure 5b Ch.1). These pathways allow three-dimensional diffusion of lithium ions within the framework, making $\mathrm{LiMn}_{2} \mathrm{O}_{4}$ suitable for high power applications. 
Electrochemical behavior of $\mathrm{LiMn}_{2} \mathrm{O}_{4}$ thin film cathode during different loads, and ...

\begin{tabular}{|l|l|l|l|l|}
\hline Framework & Compound & $\begin{array}{l}\text { Specific } \\
\text { Capacity } \\
{\left[\mathbf{m A h} \mathbf{g}^{-1}\right]}\end{array}$ & $\begin{array}{l}\text { Average } \\
\text { Potential } \\
{\left[\mathbf{V} \text { vs } \mathbf{L i}^{\mathbf{0}} / \mathbf{L i}^{+}\right]}\end{array}$ & $\begin{array}{l}\text { Energy Density } \\
{\left[\mathbf{W h} \mathbf{~ k g}^{-1}\right)}\end{array}$ \\
\hline Layered & $\mathrm{LiCoO}_{2}$ & $272(140)$ & 4.0 & $1088(560)$ \\
\hline & $\mathrm{LiNi}_{1 / 3} \mathrm{Mn}_{1 / 3} \mathrm{Co}_{1 / 3} \mathrm{O}_{2}$ & $272(200)$ & 4.0 & $1088(800)$ \\
\hline Spinel & $\mathrm{LiMn}_{2} \mathrm{O}_{4}$ & $148(125)$ & 4.1 & $607(513)$ \\
\hline & $\mathrm{LiNi}_{0.5} \mathrm{Mn}_{1.5} \mathrm{O}_{4}$ & $148(125)$ & 4.7 & $696(588)$ \\
\hline Olivine & $\mathrm{LiFePO}_{4}$ & $170(160)$ & 3.45 & $587(552)$ \\
\hline & $\mathrm{LiFe}_{1 / 2} \mathrm{Mn}_{1 / 2} \mathrm{PO}_{4}$ & $170(160)$ & $3.4 / 4.1$ & $638(600)$ \\
\hline
\end{tabular}

Table 1, Overview of common cathode materials by their capacities, potentials and energy densities. Specific capacity between brackets (capacities) are values achieved in practice. Adapted from [11].

Despite these advantageous structural properties, $\mathrm{LiMn}_{2} \mathrm{O}_{4}$ cathodes suffer from capacity fading and poor cycle life performance [12], which is mostly attributed to dissolution of Mnions from the $\mathrm{Mn}_{2} \mathrm{O}_{4}$ framework in the $4 \mathrm{~V}$ region [13]. This dissolution causes continuous loss of active material and consequently blocking of 3D lithium diffusion pathways, thereby impeding the overall cell performance. This, therefore, remains the key limitation for using $\mathrm{LiMn}_{2} \mathrm{O}_{4}$ cathodes in commercial applications [3]. On the other hand, significant enhancement in $\mathrm{LiMn}_{2} \mathrm{O}_{4}$ performance has been shown by controlling the specific crystal facet in contact with the electrolyte. It plays an important role in the electrochemical reactions occurring at the cathode surface for single crystalline nanowires, [14] truncated structures [15] and thin films [4]. Therefore, as shown in Chapter 2, long cycle life is achievable for $\mathrm{LiMn}_{2} \mathrm{O}_{4}$ cathodes through control over the interface towards the electrolyte.

To achieve high power densities, it is important to study and compare the electronic and ionic conductivities.

As lithium needs to intercalate faster, the amount of spots it can reach in a certain time is limited by the ionic transport diffusion coefficients. 


\begin{tabular}{|l|l|l|l|}
\hline Framework & Compound & $\begin{array}{l}\text { Electronic } \\
\text { Conductivity } \\
{\left[\mathbf{S ~ c m}^{-1}\right]}\end{array}$ & $\begin{array}{l}\text { Ionic diffusion } \\
\text { coefficient } \\
{\left[\mathbf{c m}^{\mathbf{2}} \mathbf{~ s}^{-1}\right]}\end{array}$ \\
\hline Layered & $\mathrm{LiCoO}_{2}$ & $\sim 10^{-4}$ & $\sim 10^{-9}$ \\
\hline & & & $\sim 10^{-10}$ \\
\hline Spinel & $\mathrm{LiMn}_{2} \mathrm{O}_{4}$ & $\sim 10^{-6}$ & \\
\hline & & & $\sim 10^{-14}$ \\
\hline Olivine & $\mathrm{LiFePO}_{4}$ & $\sim 10^{-9}$ & \\
\hline & & & m \\
\hline
\end{tabular}

Table 2, Electronic conductivity and ionic diffusion coefficient of multiple cathode materials in bulk and at room temperature. Adapted from [11,16]

When operating a cell, its voltage $(E)$ is usually lower than the standard voltage $\left(\mathrm{E}_{0}\right)$ due to potential drops caused by several factors such as thermodynamics, polarizations, and the internal resistance of a cell. Mathematically this is stated as:

$$
E=E_{0}-\left[\left(\eta_{c t}\right)_{a}+\left(\eta_{c t}\right)_{c}\right]-\left[\left(\eta_{c}\right)_{a}+\left(\eta_{c}\right)_{c}\right]-i R_{i}=i R
$$

Where the standard cell potential $\left(\mathrm{E}_{\mathrm{o}}\right)$ is in $[\mathrm{V}]$, the activation polarizations (charge-transfer overvoltage) at the anode and cathode (respectively $\left(\eta_{\mathrm{ct}}\right)_{\mathrm{a}}$ and $\left.\left(\eta_{\mathrm{ct}}\right)_{\mathrm{c}}\right)$ are in $[\mathrm{V}]$, the concentration polarizations at the anode and cathode (respectively $\left.\left(\eta_{c}\right)_{a},\left(\eta_{c}\right)_{c}\right)$ are in $[V]$, the cell operating current (i) is in [A], the internal resistance of the cell $\left(\mathrm{R}_{\mathrm{i}}\right)$ is in $[\Omega]$, and the apparent cell resistance $(\mathrm{R})$ is in $[\Omega]$.

The higher the apparent resistance, the larger the drop in voltage and the less the cell is suitable for high power densities. Therefore, it is important to measure the internal resistance (and its components) as done by Electrochemical Impedance Spectroscopy (EIS) in chapter 3, as well as to monitor the discharge capacity when cycling at different rates and over time. This will provide the needed information on the rate-dependent part of the capacity, and the capacity degradation over time with respect to capacity fade due to Mn-dissolution. 


\subsection{Experimental}

Thin $\mathrm{LiMn}_{2} \mathrm{O}_{4}$ films with a thickness of about $100 \mathrm{~nm}$ were fabricated on (100)-oriented $\mathrm{Nb}: \mathrm{SrTiO}_{3}$ substrates through PLD and assembled in a glovebox as described in chapter 2 . After a first charge to $4.5 \mathrm{~V}$ at $3 \mu \mathrm{A}$ and cyclic voltammetry between 4.5 and $3.3 \mathrm{~V}$ the samples undergo 10 charge-discharge cycles between 4.5 and $3.6 \mathrm{~V}$ at $5 \mu \mathrm{A}$. After these initial cycles the samples are cycled at multiple currents to study shifts in voltage plateaus and capacities. The applied currents are in the sequence 5-10-2-1-5-10-20-50 $\mu \mathrm{A}$ with each current applied for 10 cycles. Most samples exhibit a capacity of about $1 \mu \mathrm{Ah}$ which corresponds to C-rates of 5-10-2-1-5-10-20-50 C.

After the rate tests, the samples are measured at currents of 5-10-2-1 $\mu \mathrm{A}$ with 50 cycles per step, to measure the cycle life. Several samples were extensively cycled at a single current of $5 \mu \mathrm{A}$ to study the cycle life over a thousand cycles. Details on the electrochemical setup have been described in the Experimental Methods of Chapter 2.

\subsection{Effect of current on potential plateaus of $\mathrm{LiMn}_{2} \mathrm{O}_{4}$ around 4V}

As observed in chapter 2 the $4 \mathrm{~V}$ plateaus of $\mathrm{LiMn}_{2} \mathrm{O}_{4}$ shift at increasing currents. Similarly, a voltage drop during sequential discharging is observed when the discharging is done at higher currents (figure 1a). Furthermore, an increase of the voltage of the $4 \mathrm{~V}$ charge plateaus is observed for higher charge currents. These shifts are reversible and respond linear due to the internal resistance through Ohm's law. As the voltage and capacity during charge and discharge varies due to changes in the chemical potential upon (de)lithiation the relation between voltage and applied current is non-linear. However, using the first derivative of the discharge voltage plateaus where it is closest to zero, as well as a local maximum in the first derivative in between the two distinctive voltage-plateaus of $\mathrm{LiMn}_{2} \mathrm{O}_{4}$, a linear trend can be fitted (figure 1a and $1 \mathrm{~b}$ ). 

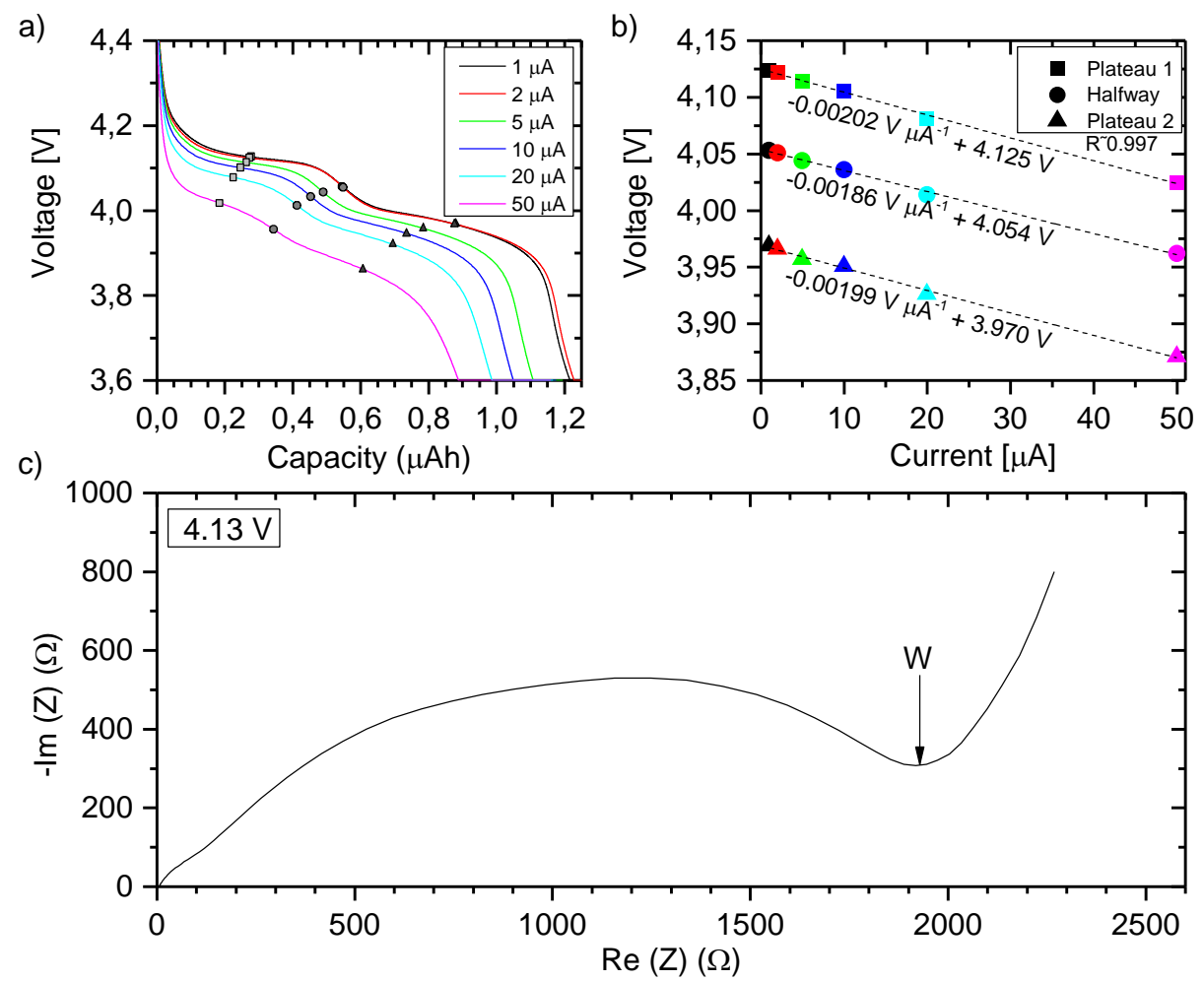

Figure 1, a) Discharge curves of epitaxial thin film of $\mathrm{LiMn}_{2} \mathrm{O}_{4}$ at different currents.

Using the first derivative, squares note a minimum for Plateau 1, circles a local maximum for the Halfway points, and triangles a $2^{\text {nd }}$ minimum for Plateau 2. b) Plateau 1, Halfway, and Plateau 2 voltage points versus current graph with a linear fit. c) Electrochemical Impedance measurement of a $\mathrm{LiMn}_{2} \mathrm{O}_{4}$ thin film at $4.13 \mathrm{~V}$ with an indication for the Warburg resistance point.

The first derivative points correspond roughly with the 25,50 and $75 \%$ points in the state of discharge of $\mathrm{LiMn}_{2} \mathrm{O}_{4}$. A linear fit through these points has an $\mathrm{R}$ value of 0.997 indicating a

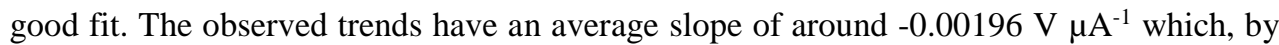
applying Ohm's law, amounts to a resistance of $1960 \Omega$. Furthermore, when no current is applied the voltages (plateau 1: $4.124 \mathrm{~V}$, halfway: $4.054 \mathrm{~V}$, plateau 2: $3.969 \mathrm{~V}$ ) correspond 
to the intercalation voltages of respectively $\lambda-\mathrm{Mn}_{2} \mathrm{O}_{4}$ to $\mathrm{Li}_{0.5} \mathrm{Mn}_{2} \mathrm{O}_{4}$, pure $\mathrm{Li}_{0.5} \mathrm{Mn}_{2} \mathrm{O}_{4}$, and $\mathrm{Li}_{0.5} \mathrm{Mn}_{2} \mathrm{O}_{4}$ to $\mathrm{LiMn}_{2} \mathrm{O}_{4}[17-19]$.

During Electrochemical Impedance Spectroscopy the Warburg (see also Chapter 3 and figure 1c) sets in around $2000 \Omega$, this allows to link the modeled resistances $\left(R_{\text {substrate }}+\right.$ $\left.\mathrm{R}_{\mathrm{SEI} \text {-films }}+\mathrm{R}_{\mathrm{ct}}\right)$ to the observed total internal resistance of $1960 \Omega$.

With the resistance known, the resistivity can be calculated through:

$$
\rho=R \frac{A}{l}
$$

Where the resistivity $(\rho)$ is in $[\Omega \mathrm{cm}]$, the resistance $(\mathrm{R})$ is in $[\Omega]$, the area $(\mathrm{A})$ is in $\left[\mathrm{cm}^{2}\right]$ and the length of the sample (l) is in [cm]. With the known values (resistance (1960 $\Omega$ ), area $\left(5 \times 5 \mathrm{~mm}^{2}\right)$ and length $(117 \mathrm{~nm})$ (specific thickness of the measured thin film cathode) ) are known, the resistivity can be calculated to be $4.1810^{7} \Omega \mathrm{cm}$.

The conductivity can then be calculated by taking the inverse of the resistivity:

$$
\sigma=\frac{1}{\rho}
$$

This leads to a conductivity of $2.3910^{-8} \mathrm{~S} \mathrm{~cm}^{-1}$, which is close to that found literature for polycrystalline $\mathrm{LiMn}_{2} \mathrm{O}_{4}$ thin films:

(100 nm, Au substrate of $10 \times 8 \mathrm{~mm}^{2}, 600-900 \Omega, 2.08 \cdot 10^{-8} \mathrm{~S} \mathrm{~cm}^{-1}$ ) [20]

(330 nm, stainless steel substrate, $10 \mathrm{~mm}$ diameter, $500 \Omega, 8.35 \cdot 10^{-8} \mathrm{~S} \mathrm{~cm}^{-1}$ ) [21]

whereas the bulk conductivity of $\mathrm{LiMn}_{2} \mathrm{O}_{4}$ is around $110^{-6} \mathrm{~S} \mathrm{~cm}^{-1}[16,22]$. Looking back at the Impedance Spectroscopy in the previous chapter the difference in the conductivity with 
literature can be mostly explained by the charge-transfer resistance $\left(\mathrm{SrRuO}_{3}-\mathrm{LiMn}_{2} \mathrm{O}_{4}\right)$ and the SEI-film $\left(\mathrm{LiMn}_{2} \mathrm{O}_{4}-\right.$ electrolyte $)$.

The large charge-transfer resistance could indicate a high resistance for the Li-ions and/or electrons to reach a suitable intercalation spot which could be attributed to grain boundaries or, in the case of high electronic resistance, a problem at the interface between $\mathrm{SrRuO}_{3}$ and $\mathrm{LiMn}_{2} \mathrm{O}_{4}$. Although $\mathrm{SrRuO}_{3}$ was already introduced to reduce the barrier between $\mathrm{Nb}: \mathrm{SrTiO}_{3}$-substrate and $\mathrm{LiMn}_{2} \mathrm{O}_{4}$ [23], its quality will still influence the measured resistance. Furthermore, during Pulsed Laser Deposition there is a possibility of interfacial intermixing. The $\mathrm{Mn}_{2} \mathrm{O}_{3}$-impurity phase as observed in chapter 2 could have partial intermixing of $\mathrm{Ru}$ from the $\mathrm{SrRuO}_{3}$ into $\mathrm{Li}_{\mathrm{y}} \mathrm{Ru}_{\mathrm{x}} \mathrm{Mn}_{2-\mathrm{x}} \mathrm{O}_{3}$, a phase that would also be electrochemically active $[24,25]$. Although such interfacial layer would probably be very thin, it might influence the electronic conduction between the thin $\mathrm{LiMn}_{2} \mathrm{O}_{4}$ film and the substrate. This, therefore, requires more detailed investigation in future research and, in addition, demonstrates the importance of interface engineering.

\subsection{Effect of current on the capacity}

As the voltage plateaus drop for higher currents, and a cell exhibits higher internal resistances, the discharging of the cell is hindered. With a cut-off voltage of $3.6 \mathrm{~V}$, the discharge plateaus of $\mathrm{LiMn}_{2} \mathrm{O}_{4}$ can fall below this voltage and the battery cannot be regarded as fully discharged $\left(\mathrm{x}<1\right.$ for $\left.\mathrm{Li}_{\mathrm{x}} \mathrm{Mn}_{2} \mathrm{O}_{4}\right)$.

Also, due to increased voltage plateaus upon charging at higher rates the cell might not be fully charged ( $x>0$ for $\left.\mathrm{Li}_{\mathrm{x}} \mathrm{Mn}_{2} \mathrm{O}_{4}\right)$ at the cut-off voltage of $4.5 \mathrm{~V}$. However, due to a constant voltage period of 5 minutes after charging, the cell should be fully charged before subsequent discharging. The same applies upon discharging, however, current due to a continued lithium intake during the constant voltage period is not taken into account. 
Figure 2 gives, for a sequence of currents, an overview of the capacity, as well as the voltage and current behaviors over the capacity. For figure $2 \mathrm{a}$ the voltage profile as function of capacity for a sequence of currents can be observed, as well as an increase in the capacity $(\Delta \mathrm{C})$ during the voltage hold period of 5 minutes. As higher currents are used, the voltage plateaus shift below the $3.6 \mathrm{~V}$ cut-off voltage, decreasing the capacity with Vcut-off as shown in $2 \mathrm{c}$.

a)

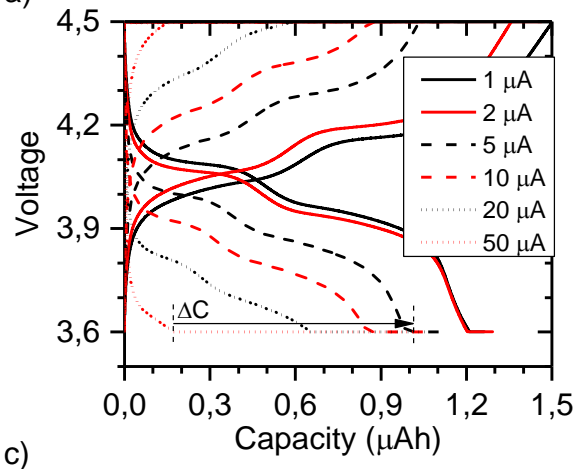

b)

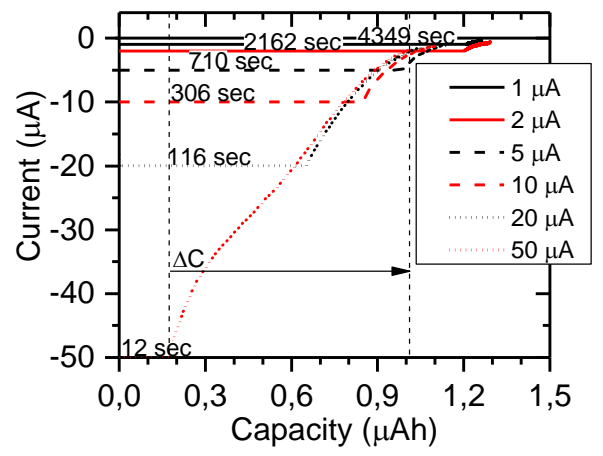

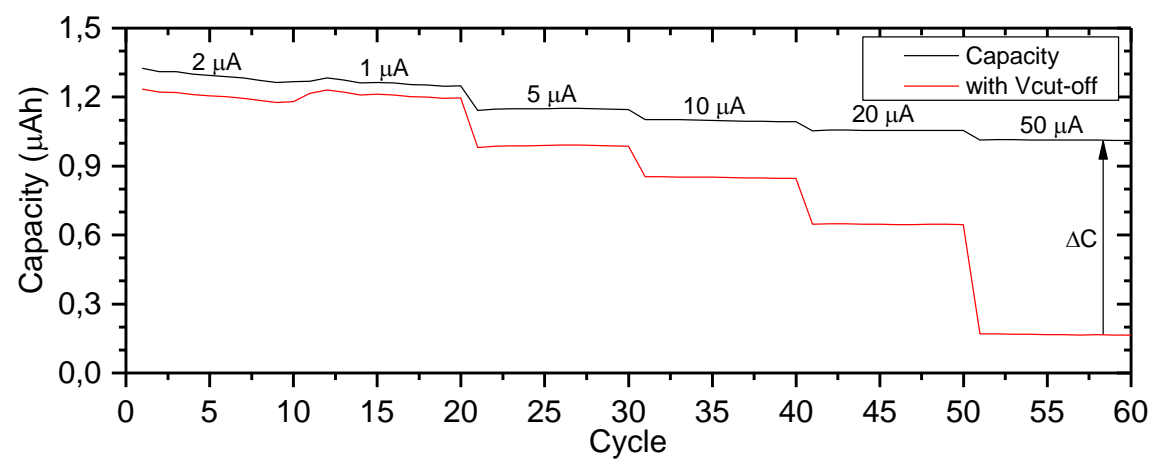

Figure 2, a) (Dis)charge profiles for a sequence of currents. b) Current behavior after $V_{\text {cut-off }}$ is reached. c) Capacities as function of cycle for the current sequence.

The increase in capacity during the voltage hold period becomes clearer in $2 b$, where the current over capacity is shown. Here the current is constant until the lower cut-off voltage is 
reached. The period until $3.6 \mathrm{~V}$ is reached is shown in seconds, after this period the current decreases during the voltage hold of 5 minutes. Here, still some effect of the two voltage plateaus of $\mathrm{LiMn}_{2} \mathrm{O}_{4}$ can be observed as a change in current slope around $0.4 \mu \mathrm{Ah}$ takes place.

During the voltage hold nearly all the lithium is either inserted into (discharge) or extracted out of (charge) the thin $\mathrm{LiMn}_{2} \mathrm{O}_{4}$ film showing that the voltage hold period is nearly sufficient to obtain a full charge before subsequent discharge. The lower discharge capacity at high currents with $\mathrm{V}_{\text {cut-off }}$ is, therefore, mostly due to the cut-off voltage in combination with the high internal resistance.

\subsection{Electrochemical response through time}

As not only the energy density but also the cycle life of a battery is important, the progressive decline of the electrochemical response over time while cycling the cell is measured. In the previous section the cycle life was measured while changing currents. However, as the charge and discharge rates might influence the degradation processes due to different internal resistances between samples, in this study the current was kept constant at $5 \mu \mathrm{A}$ from the first cycle onwards. Four samples with equal thin $\mathrm{LiMn}_{2} \mathrm{O}_{4}$ films, synthesized at the same moment by Pulsed Laser Deposition, were used to, furthermore, check reproducibility. This is shown in figure 3 . Here, both capacity and coulombic efficiency (the difference between the amounts of current that goes into the cell versus that which can be extracted) are shown for a thousand cycles, showing long cycle-life.

The four samples show some capacity degradation over their thousand cycles while their capacity over cycle graphs mostly overlap. Furthermore, after the first 20 cycles the coulombic efficiency is above $90 \%$. This shows excellent reproducibility as well as good cyclability of the epitaxial thin $\mathrm{LiMn}_{2} \mathrm{O}_{4}$ films. 


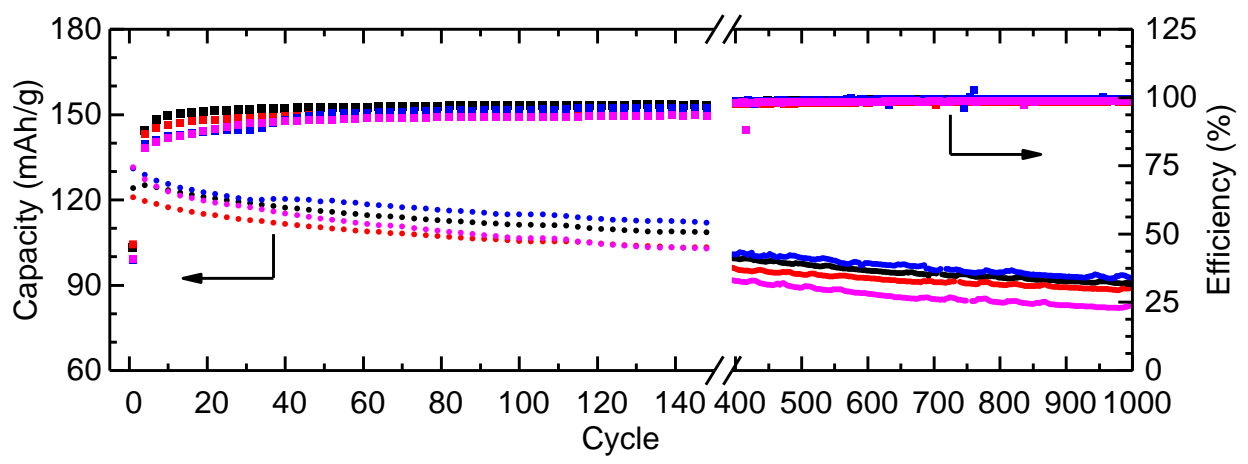

Figure 3, Capacity over cycles for four thin $\mathrm{LiMn}_{2} \mathrm{O}_{4}$ films grown on (100)-oriented $\mathrm{Nb}: \mathrm{SrTiO}_{3}$ substrates as well as their Coulombic efficiency of cycling.

The cycle-life performance of the synthesized thin $\mathrm{LiMn}_{2} \mathrm{O}_{4}$ films is compared to previous studies in bulk, as well as thin films, in figure 4.

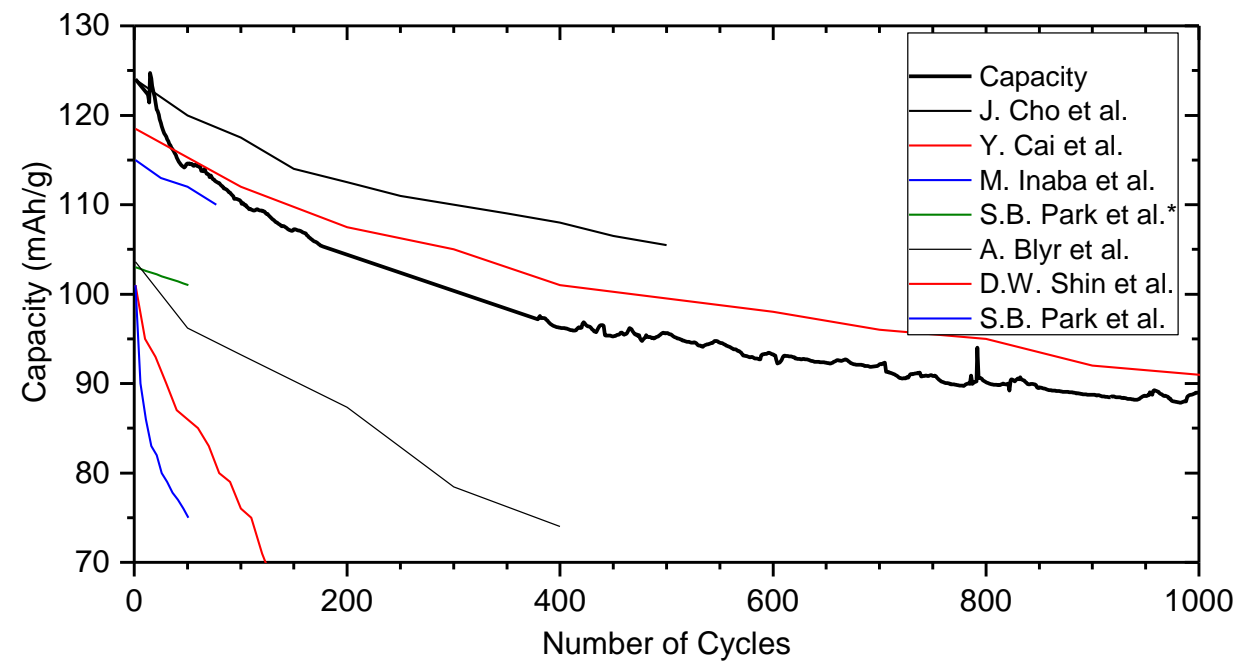

Figure 4, Capacity over cycles for multiple $\mathrm{LiMn}_{2} \mathrm{O}_{4}$ cathodes from literature and this study's thin film (thick black line). * A coating was used to improve cycle-life. Please refer to table 3 (next page) for the cycling conditions used in these previous studies. 
A clear decrease over cycles for all $\mathrm{LiMn}_{2} \mathrm{O}_{4}$ cathodes becomes apparent in the literature comparison in figure 4. The samples of J. Choa et al. [26] and Y. Cai et al. [27] are able to maintain higher capacity over cycles in the range 0-1000 cycles. However, these are for $\mathrm{LiMn}_{2} \mathrm{O}_{4}$ in particle form, not thin film. As particles have a reduced surface to bulk ratio, the dissolution of $\mathrm{Mn}$ is slower, adding to a slower decay of capacity over cycles. Furthermore, as the particles are usually sintered, they, too, exhibit mostly the energetically favored $\{111\}$-facets. The thin film by M. Inaba et al. [28] has a lower starting capacity, but seems to have a lower capacity loss slope. As they do not show more than 100 cycles, however, the capacity retention over a longer period cannot be compared. Polycrystalline samples suffer more from internal stresses than large single crystalline particles, which can be observed for the capacity degradation of the samples of D.W. Shin et al. [29]. Discharge to lower voltages combined with higher rates both increase the existence of localized $\mathrm{Li}_{2} \mathrm{Mn}_{2} \mathrm{O}_{4}$. Due to $\mathrm{Li}_{2} \mathrm{Mn}_{2} \mathrm{O}_{4}$ 's larger size, this induces more stress on the particles, and increased concentration of $\mathrm{Mn}^{3+}$ leads to increased Mn dissolution, leading to a quicker degradation [26].

A summary of the cycling conditions for the results shown in figure 4 is shown in table 3 . From this it is concluded that the cycling conditions alone do not determine the capacity fade over cycles. Instead, due to the nature of the Mn dissolution through mainly the $\langle 110\rangle$ surface as indicated in $[4,14,15,32]$ the capacity fade over cycles is expected to be lower as more of the <111> facet is exposed to the electrolyte [26]. Structurally engineered thin films mostly exhibit their $<111>$ surface, as well as particles sintered at high temperatures [26,27]. Polycrystalline particles [28,29] and particles that have a truncated shape [30] show multiple facets and, thereby, suffer more from the Mn dissolution. 
Electrochemical behavior of $\mathrm{LiMn}_{2} \mathrm{O}_{4}$ thin film cathode during different loads, and $\ldots$

\begin{tabular}{|c|c|c|c|c|c|c|}
\hline Electrolyte & Ratio & Voltage range & C-rate & Cathode build-up & & [ref.] \\
\hline $\begin{array}{l}1 \mathrm{M} \mathrm{LiPF}_{6} \\
\mathrm{EC}: \mathrm{DMC}\end{array}$ & $1: 1$ & $3.6-4.5$ & 3.3 & $\begin{array}{l}105 \mathrm{~nm}(100) \mathrm{LiMn}_{2} \mathrm{O}_{4} \\
\text { on } \mathrm{SrRuO}_{3} / \mathrm{SrTiO}_{3}\end{array}$ & This study & \\
\hline $\begin{array}{l}1 \mathrm{M} \mathrm{LiPF} 6 \\
\mathrm{EC}: \mathrm{DMC}\end{array}$ & $1: 1$ & $3.4-4.5$ & 1 & $15 \mu \mathrm{m}$ particles & J. Choa & [26] \\
\hline $\begin{array}{l}1 \mathrm{M} \mathrm{LiPF} 6 \\
\mathrm{EC}: \mathrm{DMC}\end{array}$ & $1: 1$ & $3.5-4.3$ & 10 & $\begin{array}{l}\text { Crystalline } \\
\text { nanoparticles } 150 \mathrm{~nm}\end{array}$ & Y. Cai & [27] \\
\hline 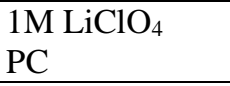 & 1 & $3.5-4.25$ & $\sim 10$ & $\begin{array}{l}300 \mathrm{~nm} \text { polycrystalline } \\
\text { by PLD on } \mathrm{Au}\end{array}$ & M. Inaba & [28] \\
\hline $\begin{array}{l}\text { 1M LiPF} 6 \\
\text { EC:DMC:EMC }\end{array}$ & $1: 1: 1$ & $3.5-4.5$ & 0.5 & $\begin{array}{l}2-5 \mu \mathrm{m} \text { particles } \\
* \mathrm{ZnO} \text { coating }\end{array}$ & S.B. Park & [30] \\
\hline $\begin{array}{l}1 \mathrm{M} \mathrm{LiPF}_{6} \\
\mathrm{EC}: \mathrm{DMC}^{-}\end{array}$ & $2: 1$ & $\begin{array}{c}2.5-4.5 \\
\text { (only } 4 \mathrm{~V} \text { peaks) }\end{array}$ & 0.2 & $\sim 10 \mu \mathrm{m}$ particles & A. Blyr & [31] \\
\hline $\begin{array}{l}1 \mathrm{M} \mathrm{LiPF} 6 \\
\mathrm{EC}: \mathrm{DMC}\end{array}$ & $1: 1$ & $3.0-4.5$ & 4 & $\begin{array}{l}\text { Polycrystalline by PLD } \\
\text { on } \mathrm{Pt} / \mathrm{Ti} / \mathrm{SiO}_{2} / \mathrm{Si}(100)\end{array}$ & D.W. Shin & [29] \\
\hline
\end{tabular}

Table 3, Electrolytes, solvents, solvent ratios, voltage ranges, $C$-rates, and cathode build-

ups of the graphs shown in figure 4 with their respective references.

Furthermore, $\mathrm{Li}_{2} \mathrm{Mn}_{2} \mathrm{O}_{4}$ stresses cathode material to the point of fractures, due to the JahnTeller distortion [9]. Cracking of the particles can lead to a loss of connection to the current collector, further contributing to capacity fade.

Structurally engineered epitaxial thin films might suffer less from the distortions caused by the Jahn-Teller transition due to their limited thickness and single-crystal nature, making it interesting to investigate the overlithiated $\mathrm{Li}_{2} \mathrm{Mn}_{2} \mathrm{O}_{4}$.

\subsection{Conclusion}

In conclusion, as the current rate increases, the voltage drop of the discharge plateaus is more severe. A linear trend can be used to calculate the internal resistance of the cell. To get the components of this internal resistance one has to resort to methods like Electrochemical Impedance Spectroscopy as shown in chapter 3. There, that technique is employed to hypothesize on why the conductivity of the thin-films is 50 times lower than that for bulk $\mathrm{LiMn}_{2} \mathrm{O}_{4}$. 
As the current rate increases, the capacity decreases. This is attributed to the high internal resistance causing the voltage plateaus to drop below the cut-off voltage. When including the capacity gained during the $5 \mathrm{~min}$. voltage hold, the difference is much less severe and the voltage hold is therefore nearly enough.

The large resistance to charge-transfer could indicate a high resistance for the Li-ions and/or electrons to reach a suitable intercalation spot, which could be attributed to grain boundaries, or, in the case of high electronic resistance, a problem at the interface between $\mathrm{SrRuO}_{3}$ and $\mathrm{LiMn}_{2} \mathrm{O}_{4}$. Currently, the thin films are capable of high current rates which could further be improved when the large charge-transfer resistance is decreased. $\mathrm{SrRuO}_{3}$ was already introduced to do so [23], however, the quality of the deposited $\mathrm{SrRuO}_{3}$ layer could greatly influence the measured resistance. Furthermore, during pulsed laser deposition there is a possibility of intermixing. $\mathrm{Li}_{\mathrm{y}} \mathrm{Ru}_{\mathrm{x}} \mathrm{Mn}_{2-\mathrm{x}} \mathrm{O}_{3}$ 's crystal structure is similar to that of $\mathrm{Mn}_{2} \mathrm{O}_{3}$ and might have therefore been overlooked. Although probably very thin, it might influence the electronic conduction between the thin film $\mathrm{LiMn}_{2} \mathrm{O}_{4}$ and its substrate. This requires more detailed investigation in future research.

The discharge capacity over cycles shows low degradation over extensive cycling and is comparable to that of bulk $\mathrm{LiMn}_{2} \mathrm{O}_{4}$ when mostly its $<111>$ facet is shown. It outperforms polycrystalline thin films found in literature, indicating the importance of interface engineering of the $\mathrm{LiMn}_{2} \mathrm{O}_{4}$ cathode. Although capacity fade is still present, it is currently attributed to Mn-dissolution even though hardly any interface except the $<111>$ is in contact with the electrolyte. 


\subsection{References}

[1] F. Cheng, J. Liang, Z. Tao, and J. Chen, "Functional materials for rechargeable batteries," Adv. Mater., vol. 23, no. 15, pp. 1695-1715, 2011, DOI: 10.1002/adma.201003587.

[2] T. B. Reddy, Linden's Handbook of Batteries, 4th ed. New York: McGraw-Hill, 2011.

[3] N. Nitta, F. Wu, J. T. Lee, and G. Yushin, "Li-ion battery materials: Present and future," Mater. Today, vol. 18, no. 5, pp. 252-264, 2015, DOI: 10.1016/j.mattod.2014.10.040.

[4] M. Hirayama, N. Sonoyama, M. Ito, M. Minoura, D. Mori, A. Yamada, K. Tamura, J. Mizuki, and R. Kanno, "Characterization of Electrode/Electrolyte Interface with X-Ray Reflectometry and Epitaxial-Film $\mathrm{LiMn}_{2} \mathrm{O}_{4}$ Electrode," J. Electrochem. Soc., vol. 154, no. 11, p. A1065, 2007, DOI: 10.1149/1.2778853.

[5] F. Lin, I. M. Markus, D. Nordlund, T.-C. Weng, M. D. Asta, H. L. Xin, and M. M. Doeff, "Surface reconstruction and chemical evolution of stoichiometric layered cathode materials for lithium-ion batteries," Nat. Commun., vol. 5, pp. 1-9, 2014, DOI: $10.1038 /$ ncomms 4529 .

[6] A. C. Luntz, J. Voss, and K. Reuter, "Interfacial Challenges in Solid-State Li Ion Batteries," J. Phys. Chem. Lett., vol. 6, no. 22, pp. 4599-4604, 2015, DOI: 10.1021/acs.jpclett.5b02352.

[7] K. X. Wang, X. H. Li, and J. S. Chen, "Surface and interface engineering of electrode materials for lithium-ion batteries," Adv. Mater., vol. 27, no. 3, pp. 527545, 2015, DOI: 10.1002/adma.201402962.

[8] Y. Yuan, K. Amine, J. Lu, and R. Shahbazian-Yassar, "Understanding materials challenges for rechargeable ion batteries with in situ transmission electron microscopy," Nat. Commun., vol. 8, no. May, pp. 1-14, 2017, DOI: 10.1038/ncomms 15806 .

[9] M. M. Thackeray, "Manganese oxides for lithium batteries," Prog. Solid State Chem., vol. 25, no. 1-2, pp. 1-71, 1997, DOI: 10.1016/S0079-6786(97)81003-5.

[10] M. J. Lee, S. Lee, P. Oh, Y. Kim, and J. Cho, "High performance $\mathrm{LiMn}_{2} \mathrm{O}_{4}$ cathode materials grown with epitaxial layered nanostructure for Li-Ion batteries," Nano Lett., vol. 14, no. 2, pp. 993-999, 2014, DOI: 10.1021/nl404430e.

[11] C. M. Julien, A. Mauger, K. Zaghib, and H. Groult, "Comparative Issues of Cathode Materials for Li-Ion Batteries," Inorganics, vol. 2, pp. 132-154, 2014, DOI: 10.3390/inorganics2020132.

[12] R. J. Gummow, A. de Kock, and M. M. Thackeray, "Improved capacity retention in rechargeable 4 V lithium/lithium-manganese oxide (spinel) cells," Solid State Ionics, vol. 69, no. 1, pp. 59-67, 1994, DOI: 10.1016/0167-2738(94)90450-2.

[13] J. C. Hunter, "Preparation of a new crystal form of manganese dioxide: $\lambda-\mathrm{MnO}_{2}, " J$. Solid State Chem., vol. 39, no. 2, pp. 142-147, 1981, DOI: 10.1016/00224596(81)90323-6. 
[14] E. Hosono, T. Kudo, I. Honma, H. Matsuda, and H. Zhou, "Synthesis of Single Crystalline Spinel $\mathrm{LiMn}_{2} \mathrm{O}_{4}$ Nanowires for a Lithium Ion Battery with High Power Density," 2009, DOI: 10.1021/nl803394v.

[15] J. S. Kim, K. Kim, W. Cho, W. H. Shin, R. Kanno, and J. W. Choi, "A truncated manganese spinel cathode for excellent power and lifetime in lithium-ion batteries," Nano Lett., vol. 12, no. 12, pp. 6358-6365, 2012, DOI: 10.1021/nl303619s.

[16] M. Park, X. Zhang, M. Chung, G. B. Less, and A. M. Sastry, "A review of conduction phenomena in Li-ion batteries," J. Power Sources, vol. 195, no. 24, pp. 7904-7929, 2010, DOI: 10.1016/j.jpowsour.2010.06.060.

[17] A. Rougier, K. A. Striebel, S. J. Wen, and E. J. Cairns, "Cyclic Voltammetry of Pulsed Laser Deposited $\mathrm{Li}_{\mathrm{x}} \mathrm{Mn}_{2} \mathrm{O}_{4}$ Thin Films," J. Electrochem. Soc., vol. 145, no. 9, pp. 2975-2980, 1998.

[18] C. Julien, E. Haro-Poniatowski, M. A. Camacho-Lopez, L. Escobar-Alarcon, and J. Jimenez-Jarquin, "Growth of $\mathrm{LiMn}_{2} \mathrm{O}_{4}$ thin films by pulsed-laser deposition and their electrochemical properties in lithium microbatteries," Mater. Sci. ..., vol. 72, pp. 36-46, 2000, DOI: dx.doi.org/10.1016/S0921-5107(99)00598-X.

[19] N. Sonoyama, K. Iwase, H. Takatsuka, T. Matsumura, N. Imanishi, Y. Takeda, and R. Kanno, "Electrochemistry of $\mathrm{LiMn}_{2} \mathrm{O}_{4}$ epitaxial films deposited on various single crystal substrates," J. Power Sources, vol. 189, no. 1, pp. 561-565, Apr. 2009, DOI: 10.1016/j.jpowsour.2008.10.037.

[20] J. Xie, K. Kohno, T. Matsumura, N. Imanishi, A. Hirano, Y. Takeda, and O. Yamamoto, "Li-ion diffusion kinetics in $\mathrm{LiMn}_{2} \mathrm{O}_{4}$ thin films prepared by pulsed laser deposition," Electrochim. Acta, vol. 54, no. 2, pp. 376-381, 2008, DOI: 10.1016/j.electacta.2008.07.067.

[21] S. B. B. Tang, M. O. O. Lai, and L. Lu, "Study on $\mathrm{Li}^{+}$-ion diffusion in nanocrystalline $\mathrm{LiMn}_{2} \mathrm{O}_{4}$ thin film cathode grown by pulsed laser deposition using CV, EIS and PITT techniques," Mater. Chem. Phys., vol. 111, no. 1, pp. 149-153, Sep. 2008, DOI: 10.1016/j.matchemphys.2008.03.041.

[22] G. Pistoia, D. Zane, and Y. Zhang, "Some Aspects of $\mathrm{LiMn}_{2} \mathrm{O}_{4}$ Electrochemistry in the 4 Volt Range," J. Electrochem. Soc., vol. 142, no. 8, p. 2551, 1995, DOI: 10.1149/1.2050052.

[23] K. Suzuki, K. Kim, S. Taminato, M. Hirayama, and R. Kanno, "Fabrication and electrochemical properties of $\mathrm{LiMn}_{2} \mathrm{O}_{4} / \mathrm{SrRuO}_{3}$ multi-layer epitaxial thin film electrodes," J. Power Sources, vol. 226, no. March 2013, pp. 340-345, 2013, DOI: 10.1016/j.jpowsour.2012.11.008.

[24] M. Sathiya, K. Ramesha, G. Rousse, D. Foix, D. Gonbeau, A. S. Prakash, M. L. Doublet, K. Hemalatha, and J. M. Tarascon, "High performance $\mathrm{Li}_{2} \mathrm{Ru}_{1-\mathrm{y}} \mathrm{Mn}_{\mathrm{y}} \mathrm{O}_{3}(0.2$ $\leq \mathrm{y} \leq 0.8$ ) cathode materials for rechargeable lithium-ion batteries: Their understanding," Chem. Mater., vol. 25, no. 7, pp. 1121-1131, 2013, DOI: $10.1021 / \mathrm{cm} 400193 \mathrm{~m}$.

[25] C. Liu, Z. G. Neale, and G. Cao, "Understanding electrochemical potentials of cathode materials in rechargeable batteries," Mater. Today, vol. 19, no. 2, pp. 109- 
123, Mar. 2016, DOI: 10.1016/j.mattod.2015.10.009.

[26] J. Choa and M. M. Thackeray, "Structural Changes of $\mathrm{LiMn}_{2} \mathrm{O}_{4}$ Spinel Electrodes during Electrochemical Cycling," J. Electrochem. Soc., vol. 146, no. 10, p. 3577, 1999, DOI: 10.1149/1.1392517.

[27] Y. Cai, Y. Huang, X. Wang, D. Jia, W. Pang, Z. Guo, Y. Du, and X. Tang, "Facile synthesis of $\mathrm{LiMn}_{2} \mathrm{O}_{4}$ octahedral nanoparticles as cathode materials for high capacity lithium ion batteries with long cycle life," J. Power Sources, vol. 278, pp. 574-581, Mar. 2015, DOI: 10.1016/j.jpowsour.2014.12.082.

[28] T. Doi, M. Inaba, Y. Iriyama, T. Abe, and Z. Ogumi, "Electrochemical STM Observation of $\mathrm{Li}_{1+\mathrm{x}} \mathrm{Mn}_{2-\mathrm{x}} \mathrm{O}_{4}$ Thin Films Prepared by Pulsed Laser Deposition," $J$. Electrochem. Soc., vol. 155, no. 1, p. A20, 2008, DOI: 10.1149/1.2799076.

[29] D. W. Shin, J.-W. Choi, J.-P. Ahn, W.-K. Choi, Y. S. Cho, and S.-J. Yoon, " $\mathrm{ZrO}_{2}-$ Modified $\mathrm{LiMn}_{2} \mathrm{O}_{4}$ Thin-Film Cathodes Prepared by Pulsed Laser Deposition," $J$. Electrochem. Soc., vol. 157, no. 5, p. A567, 2010, DOI: 10.1149/1.3332745.

[30] S. Bin Park, H. C. Shin, W. G. Lee, W. Il Cho, and H. Jang, "Improvement of capacity fading resistance of $\mathrm{LiMn}_{2} \mathrm{O}_{4}$ by amphoteric oxides," J. Power Sources, vol. 180, no. 1, pp. 597-601, 2008, DOI: 10.1016/j.jpowsour.2008.01.051.

[31] A. Blyr, "Self-Discharge of $\mathrm{LiMn}_{2} \mathrm{O}_{4} / \mathrm{C}$ Li-Ion Cells in Their Discharged State," J. Electrochem. Soc., vol. 145, no. 1, p. 194, 2006, DOI: 10.1149/1.1838235.

[32] M. Hirayama, H. Ido, K. Kim, W. Cho, K. Tamura, J. Mizuki, and R. Kanno, "Dynamic structural changes at $\mathrm{LiMn}_{2} \mathrm{O}_{4}$ /electrolyte interface during lithium battery reaction," J. Am. Chem. Soc., vol. 132, no. 43, pp. 15268-15276, 2010, DOI: $10.1021 / \mathrm{ja105389t.}$ 
5 Electrochemical response of overlithiated $\mathrm{Li}_{2} \mathrm{Mn}_{2} \mathrm{O}_{4}$ thin film cathode 


\subsection{Introducing $\mathrm{Li}_{2} \mathrm{Mn}_{2} \mathrm{O}_{4}$}

High energy density, power density and longevity are the key requirements of a good battery, as mentioned in chapter 1 . Spinel $\mathrm{LiMn}_{2} \mathrm{O}_{4}$ is a promising cathode material for next generation lithium batteries $[1,2]$ due to its relatively high operating voltage $(4.1 \mathrm{~V}$ vs $\mathrm{Li})$ and energy density (theoretically $148 \mathrm{mAh} / \mathrm{g}$, typical $125 \mathrm{mAh} / \mathrm{g}$ ) combined with low cost and absence of direct environmental or safety hazards. In chapter 2 control over the interface and orientation of the cathode layers was demonstrated allowing good cyclability with longevity over a thousand cycles at a C-rate of 3.3.

The $\lambda-\mathrm{Mn}_{2} \mathrm{O}_{4}$ framework can host extra lithium (beyond 1) into empty octahedral (16c) sites, resulting in a $3 \mathrm{~V}$ voltage plateau [3]. By discharging the cell below the $3 \mathrm{~V}$ plateau, an almost twofold increase in capacity can be achieved as the theoretical specific capacity goes from 148 to $288 \mathrm{mAh} / \mathrm{g}$ and the practical specific capacity goes from 125 to $245 \mathrm{mAh} / \mathrm{g}$ [4]. Compensating for the added weight of the lithium not 148 but $140 \mathrm{mAh} / \mathrm{g}$ is added, resulting in a combined specific capacity of $288 \mathrm{mAh} / \mathrm{g}$. This increases the energy density of the $\lambda$ $\mathrm{Mn}_{2} \mathrm{O}_{4}$ framework to $1027 \mathrm{Wh} / \mathrm{kg}$ theoretically, or $873 \mathrm{Wh} / \mathrm{kg}$ in practice [4].

The reaction scheme for discharging the $\lambda-\mathrm{Mn}_{2} \mathrm{O}_{4}$ framework is shown below in table 1:

$$
\begin{aligned}
& \text { Charged } \stackrel{\text { Discharge }}{\longrightarrow} \text { Discharged } 1 \stackrel{\text { further discharge }}{\longrightarrow} \text { Discharged } 2 \\
& \lambda-\mathrm{Mn}_{2}^{4+} \mathrm{O}_{4} \quad \stackrel{\mathrm{Li}^{+}+e^{-}}{\longrightarrow} \quad \mathrm{Li}^{+}\left(\mathrm{Mn}^{3+}+\mathrm{Mn}^{4+}\right) \mathrm{O}_{4} \quad \stackrel{\mathrm{Li}^{+}+e^{-}}{\longrightarrow} \quad \mathrm{Li}_{2}^{+} \mathrm{Mn}_{2}^{3+} \mathrm{O}_{4}
\end{aligned}
$$

Table 1, Reaction scheme for discharging $\mathrm{Li}_{x} \mathrm{Mn}_{2} \mathrm{O}_{4}$ cathode $(0<x<2)$.

Here the first discharge happens with the two distinct plateaus around $4 \mathrm{~V}$ after which another discharge happens around $3 \mathrm{~V}$. The discharge graph is shown in figure 1. 
This extra lithium-ion, per unit cell, incorporated at the $3 \mathrm{~V}$ plateau, induces a Jahn-Teller distortion in the $\lambda-\mathrm{Mn}_{2} \mathrm{O}_{4}$ framework $[1,3,5]$. The cubic-spinel crystal structure with a lattice parameter of $8.25 \AA$ undergoes a transition to a $9.24 \AA \cdot(5.65 \AA)^{2}$ tetragonal spinel structure $[1,3,5]$. This change in crystal structure, with a $16 \%$ increase in the a/c ratio (and $5 \%$ in volume), creates large stresses within the material, often cracking it and causing loss of connection to the current collector, which causes loss of capacity $[1,3]$.

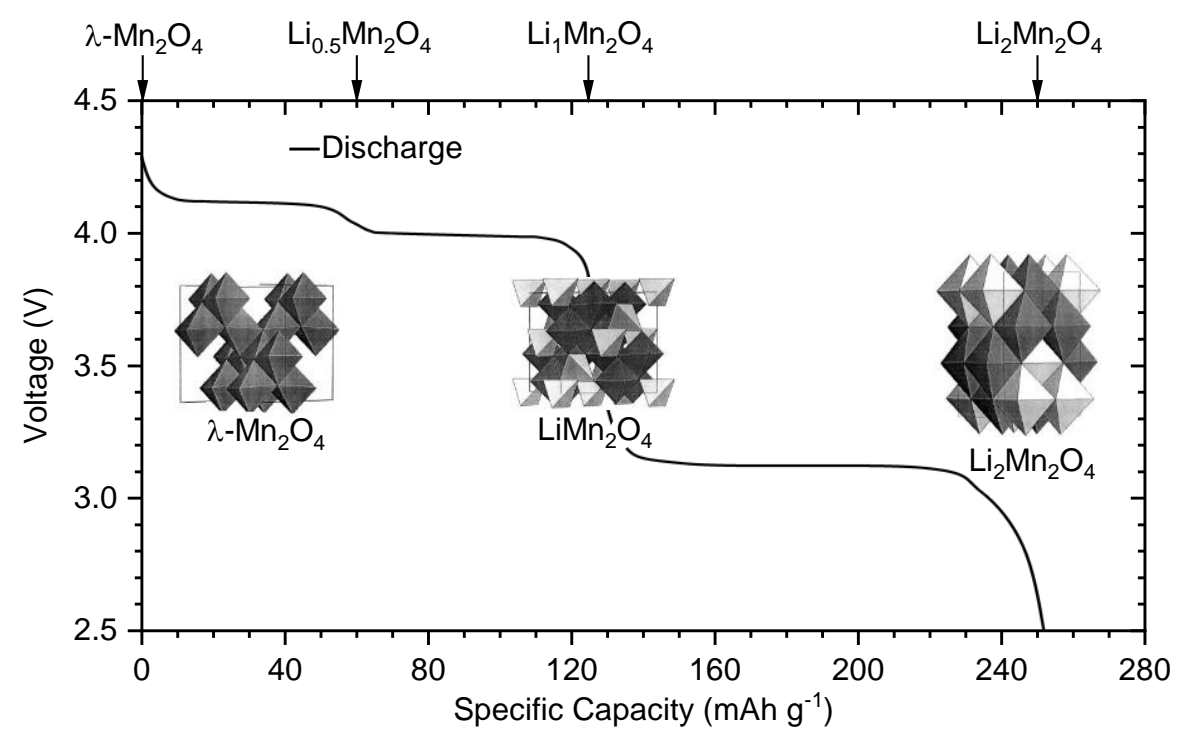

Figure 1, Discharge profile for $\mathrm{Li}_{x} \mathrm{Mn}_{2} \mathrm{O}_{4}$ cathode $(0<x<2)$. Insets show the crystal structure throughout lithiation [3].

Therefore, most studies in literature avoid using the $3 \mathrm{~V}$ plateau and limit the discharge voltage to the $4.5-3.4 \mathrm{~V}$ range [6]. Thin film studies on $\mathrm{LiMn}_{2} \mathrm{O}_{4}$ that do include it, report a severe capacity fade of 50\% within 50 cycles, $4.3-2 \mathrm{~V}$ range [7] and $15 \%$ within 10 cycles, $4.45-2.7 \mathrm{~V}$ range [8]. However, these are usually not epitaxial thin films as used in this study, but polycrystalline. 
In a study by Y.-I. Jang et al. [9] it was shown that by starting with orthorhombic $\mathrm{LiMnO}_{2}$ the characteristic plateaus at $3 \mathrm{~V}$ and $4 \mathrm{~V}$ are achieved through consecutive cycling. Orthorhombic $\mathrm{LiMnO}_{2}$ is stoichiometrically similar to $\mathrm{Li}_{2} \mathrm{Mn}_{2} \mathrm{O}_{4}$-tetragonal-spinel. Through this process their capacity starts low $(40 \mathrm{mAh} / \mathrm{g}, 1 / 4 \mathrm{C}, 2-4.4 \mathrm{~V}$ range) and increases over cycling to $130 \mathrm{mAh} / \mathrm{g}$ in 40 cycles after which it stabilizes [9]. While it is debatable if this stability is maintained over longer cycling periods, they propose a suppression of the JahnTeller distortion due to cation disorder and the formation of nanodomains. At a rate of $1 / 4 \mathrm{C}$ they achieve only $130 \mathrm{mAh} / \mathrm{g}$, however, they are able to achieve almost the theoretical capacity of $\mathrm{Li}_{2} \mathrm{Mn}_{2} \mathrm{O}_{4}(270$ of $285 \mathrm{mAh} / \mathrm{gram})$ at a low current rate $(3.33 \mathrm{~mA} / \mathrm{g}-1 / 40 \mathrm{C})$.

Even though orthorhombic $\mathrm{LiMnO}_{2}$ is only able to achieve the high specific capacity at very low currents, it is still very interesting to see the large impact on the total (practical) energy density. Compared to other cathode compounds, mentioned in table 1 of chapter 1 , the $\mathrm{Li}_{2} \mathrm{Mn}_{2} \mathrm{O}_{4}$ has the second highest theoretical energy density, and the highest practical energy density. As the formation of nanodomains was proposed to suppress the Jahn-Teller distortion, epitaxial thin films might also exhibit suppressed Jahn-teller distortion. To research this suppression and the impact on the capacity over cycles, the electrochemical response of samples with single $\{111\}$-facets and high crystallinity are investigated.

\subsection{Experimental results on 100 -oriented $\mathrm{Li}_{x} \mathrm{Mn}_{2} \mathrm{O}_{4}$ thin film cathodes} 100-Oriented $\mathrm{Li}_{x} \mathrm{Mn}_{2} \mathrm{O}_{4}$ thin films were synthesized following the synthesis route as described in chapter 2 . When discharging to voltages below $3 \mathrm{~V}$ a charge and discharge peak can be observed in the $3 \mathrm{~V}$ plateau region during cyclic voltammetry (indicating $\mathrm{Li}_{2} \mathrm{Mn}_{2} \mathrm{O}_{4}$ ), and two charge and discharge peaks can be observed in the $4 \mathrm{~V}$ plateaus region $\left(\mathrm{Li}_{1} \mathrm{Mn}_{2} \mathrm{O}_{4}\right)$, see figure 2. Additionally, when discharging to voltages below $3 \mathrm{~V}$, a peak around $3.8 \mathrm{~V}$ appears, which does not when discharging till $3 \mathrm{~V}$. The peak at $3.8 \mathrm{~V}$ seems irreversible (no direct discharge counterpart), however, remains present during consecutive cycling. It is not 
well known where this peak comes from [10], however, an indication for its origin is found in [11] where a sudden volume contraction (possible tetragonal to cubic spinel) occurred. It is hypothesized that $\mathrm{Li}-\mathrm{Mn}$ defect clusters are formed in which $\mathrm{Li}$ is stabilized, therefore requiring a higher voltage to extract this lithium [12]. Similarly to the peak positions in cyclic voltammetry, charge-discharge shows plateaus around the same voltages. Two plateaus can be observed in the $4 \mathrm{~V}$ region, one plateau in the $3 \mathrm{~V}$ region, and a small plateau at $3.8 \mathrm{~V}$ corresponding with the different peaks observed in cyclic voltammetry.

a)

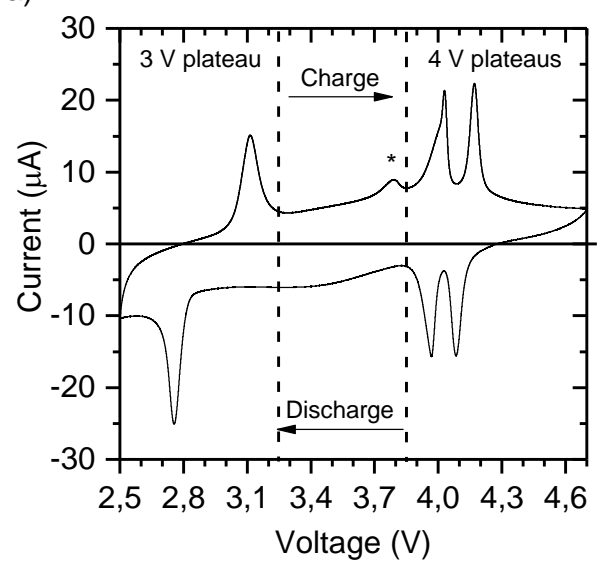

b)

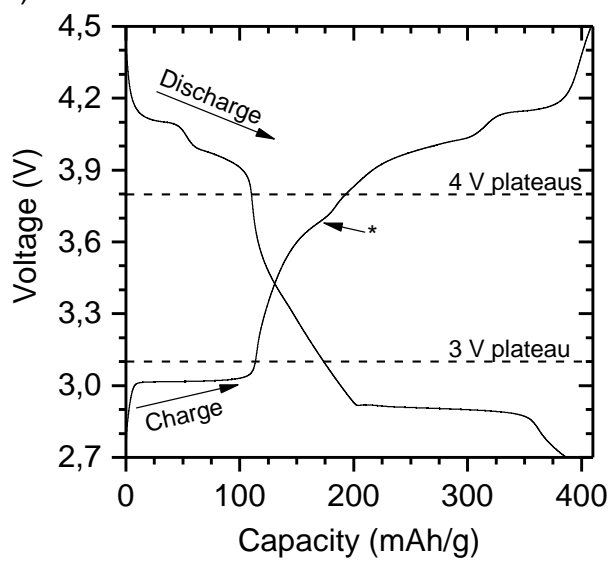

Figure 2, a) Cyclic voltammetry for a thin $\mathrm{Li}_{x} \mathrm{Mn}_{2} \mathrm{O}_{4}$ film at $1 \mathrm{mV} / \mathrm{sec}$. b) Charge Discharge curve at $1 \mu \mathrm{A}$ in the voltage range of $4.5-2.7 \mathrm{~V}$. At (*) a peak/plateau around $3.8 \mathrm{~V}$ is observed which is hypothesized to be Li-Mn defect clusters.

From figure 2 the observed specific capacity for the thin film is much larger (almost 380 $\mathrm{mAh} / \mathrm{g})$ than what is theoretically possible $(288 \mathrm{mAh} / \mathrm{g})$. Looking at the discharge graph in figure $2 \mathrm{~b}$ a capacity of about $120 \mathrm{mAh} / \mathrm{g}$ for the $4 \mathrm{~V}$ plateaus can be observed, as is also achieved in practice. For the $3 \mathrm{~V}$ plateau however, the discharge capacity $(3.1-2.7 \mathrm{~V})$ is over $200 \mathrm{mAh} / \mathrm{g}$, much higher than the theoretically predicted value of $140 \mathrm{mAh} / \mathrm{g}$. On the other hand, the discharge between $3.8-3 \mathrm{~V}$ shows a capacity of almost $80 \mathrm{mAh} / \mathrm{gram}$ as a 
certain "tail". This extra capacity cannot be explained by capacity of the $\mathrm{Li}_{2} \mathrm{Mn}_{2} \mathrm{O}_{4}$ layer alone, as it would require a layer of almost $40 \mathrm{~nm}$ thicker $(\sim 1 / 3)$ or a higher lithiation level. A possible explanation is given when the solid electrolyte interphase (SEI) acts as an extra charge reservoir which can significantly contribute to the capacity as was recently suggested by [13].

Moreover, surface effect contributions have been shown to occur for $\mathrm{Li}_{4} \mathrm{Ti}_{5} \mathrm{O}_{12}$ spinel causing a similar tail [14 - 16]. As for thin films the surface capacity can have a significant contribution to the electrochemical behavior with respect to the limited volume of the film, it is therefore proposed that this large surface area causes the capacity contribution. The surface is furthermore enhanced for the 100 -oriented $\mathrm{Li}_{\mathrm{x}} \mathrm{Mn}_{2} \mathrm{O}_{4}$ thin film cathodes as observed as the pyramidal structures in chapter 2 .

To minimize the surface contributions, cycling was performed close to either the $4 \mathrm{~V}$ plateaus $(4.5-3.6 \mathrm{~V})$ or the $3 \mathrm{~V}$ plateau $(3.2-2.7 \mathrm{~V})$. The $4 \mathrm{~V}$ plateaus are cycled for 30 times with a current of $5 \mu \mathrm{A}$ giving a capacity of almost $120 \mathrm{mAh} / \mathrm{g}$ (figure $3 \mathrm{a}$ ). Subsequent cycling of only the $3 \mathrm{~V}$ plateau for 30 times with $1 \mu \mathrm{A}$ gives a capacity of around $115 \mathrm{mAh} / \mathrm{g}$ (figure 3b). These capacities are more in line with the expected practical capacities for $\mathrm{Li}_{\mathrm{x}} \mathrm{Mn}_{2} \mathrm{O}_{4}$.

Cycling the $3 \mathrm{~V}$ plateau is known to quickly degrade the $\mathrm{LiMn}_{2} \mathrm{O}_{4}$ cathode material due to the Jahn-Teller distortion $[1,3,6-8]$. To observe the effect of the distortion or possible suppression, the $3 \mathrm{~V}$ region was cycled for epitaxially engineered thin films of $\mathrm{Li}_{\mathrm{x}} \mathrm{Mn}_{2} \mathrm{O}_{4}$ in (100)-orientation. The capacity exhibits a rate dependence and indeed cycling the $3 \mathrm{~V}$ plateau with $5 \mu \mathrm{A}$ (figure 4), instead of the $1 \mu \mathrm{A}$ (figure $3 \mathrm{~b}$ ), reduces the capacity from 116 to $93 \mathrm{mAh} / \mathrm{g}$. During cycling for 300 cycles (figure 4), the capacity is nearly constant. 

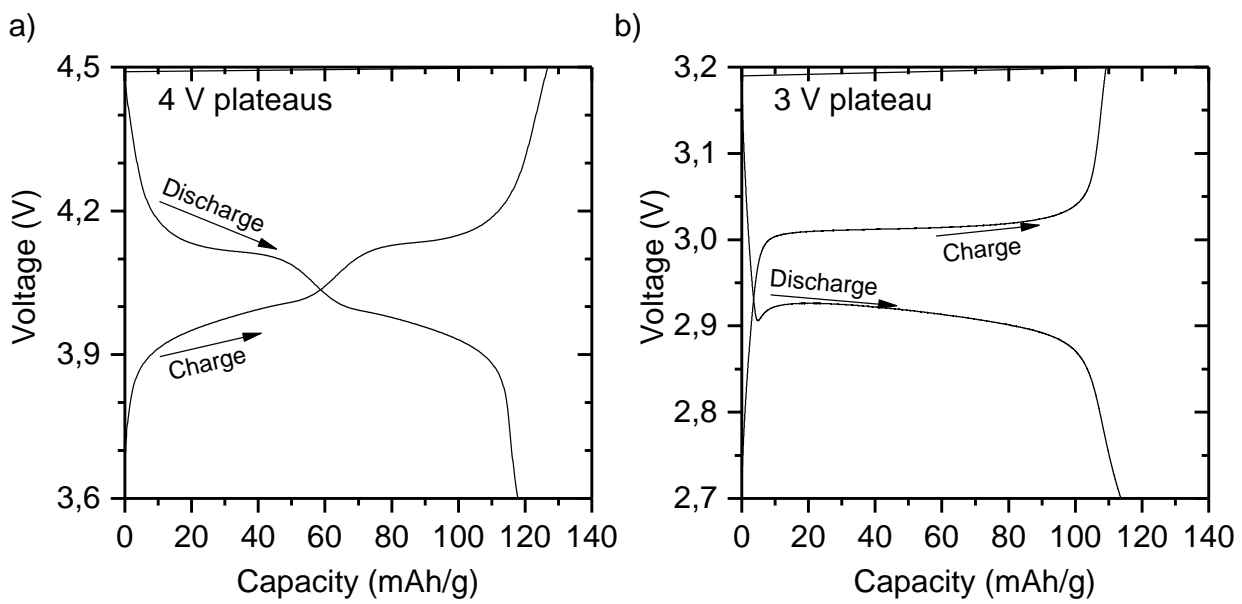

Figure 3, a) Charge-discharge capacity for the $4 V$ plateaus at $5 \mu A$ and, b), chargedischarge for the $3 \mathrm{~V}$ plateau at $1 \mu \mathrm{A}$. The specific capacities achieved are respectively $119 \mathrm{mAh} / \mathrm{g}$ and $116 \mathrm{mAh} / \mathrm{g}$.

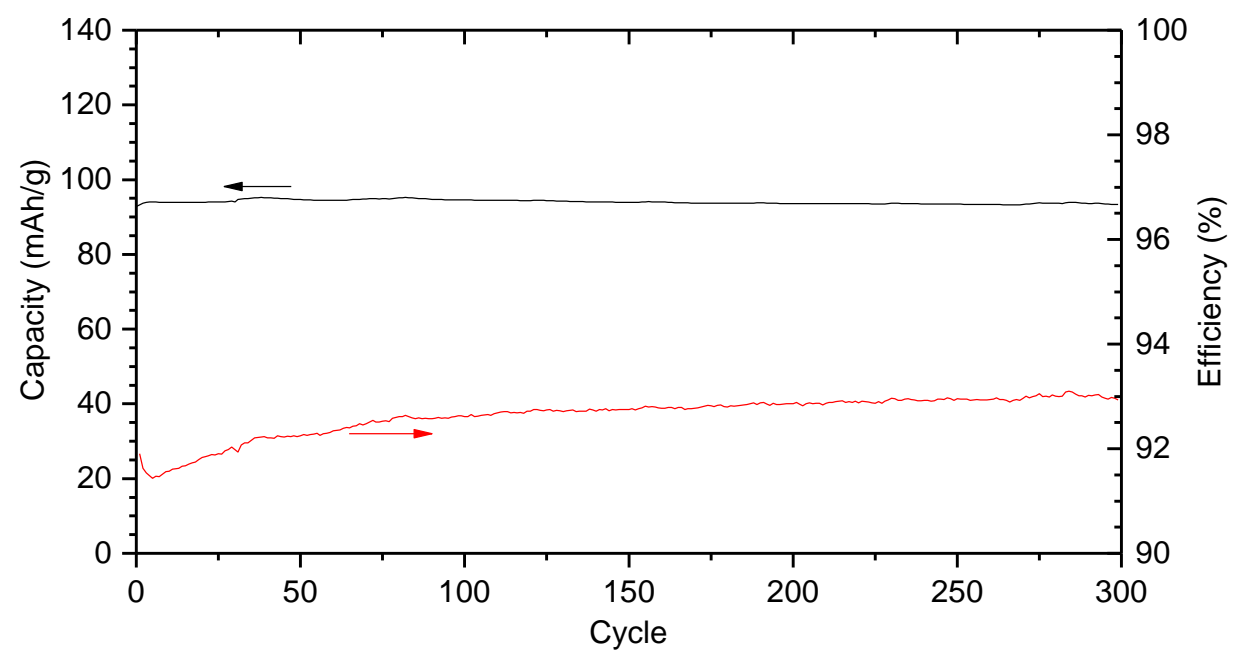

Figure 4, Capacity and efficiency over cycles for a thin film of $\mathrm{LiMn}_{2} \mathrm{O}_{4}$ between a voltage range of $2.7-3.2 \mathrm{~V}$ at a current of $5 \mu \mathrm{A}$. The capacity is around $94 \mathrm{mAh} / \mathrm{gram}$ with an efficiency between $91-93 \%$. 
Although small variations are visible, these can be attributed to fluctuations in temperature of the lab during the long cycling period.

As discussed, even the best performing $\mathrm{LiMn}_{2} \mathrm{O}_{4}$ cathodes show a decrease in their capacity over cycling (chapter 4, figure 4). It was previously suggested that increasing the nanodomains in powders through the process of ball-milling for an extensive period of time severely reduces the capacity fade at the $3 \mathrm{~V}$ plateau due to strain compensation of the nanograins [17]. As the deformation of particles with smaller grains is less anisotropic, there is less possibility of particle fracture due to the Jahn-Teller distortion. However, it has not been shown before that thin films of $\mathrm{Li}_{\mathrm{x}} \mathrm{Mn}_{2} \mathrm{O}_{4}$ can be cycled around the $3 \mathrm{~V}$ plateau with negligible loss in capacity.

As the coulombic efficiency of the charge-discharge is between 91 and 93\%, not all lithium that has been extracted can be inserted due to parasitic processes such as SEI-layer growth on the surfaces of metallic lithium anode and $\mathrm{Li}_{x} \mathrm{Mn}_{2} \mathrm{O}_{4}$ cathode in the $1 \mathrm{M} \mathrm{LiPF}, 1: 1$, EC:DMC electrolyte. However, as metallic lithium is present in excess, Li loss due to SEIlayer growth is expected to be negligible in the measurements.

The reversible electrochemical process taking place around $3 \mathrm{~V}$ is expected to be the insertion of a $\mathrm{Li}$-ion into $\mathrm{LiMn}_{2} \mathrm{O}_{4}$ cubic spinel to obtain $\mathrm{Li}_{2} \mathrm{Mn}_{2} \mathrm{O}_{4}$, a tetragonal spinel. The out-of-plane lattice parameter for (001)-oriented thin films should increase from $(8.25 \AA$ to $9.24 \AA$ ) for the transition of cubic- to tetragonal spinel $\mathrm{Li}_{2} \mathrm{Mn}_{2} \mathrm{O}_{4}[12,18]$. Therefore, this structural change was studied by XRD (figure 5). Samples were discharged to various voltages and taken out of their cell to observe the out-of-plane lattice parameter change. A pristine sample that has not been cycled nor been in contact with electrolyte is added for comparison. 


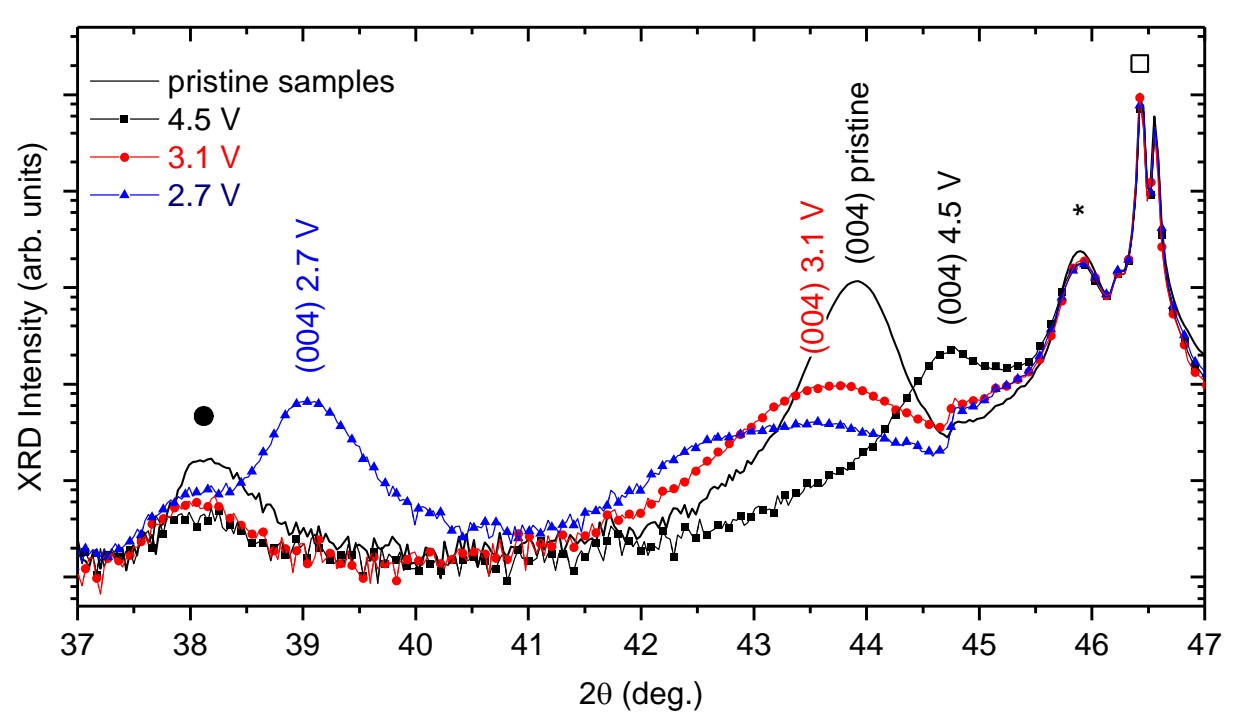

Figure 5, Out-of-plane XRD intensity over 2Theta angle for (100)-oriented thin $\mathrm{Li}_{x} \mathrm{Mn}_{2} \mathrm{O}_{4}$ films. For comparison a thin film before cycling (pristine) is added. Contributions by the

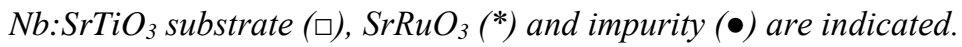

All samples show a peak around $38^{\circ}$ which is contributed to the impurity phase: $\mathrm{Mn}_{2} \mathrm{O}_{3}$. This phase might be present due to lithium deficiency during synthesis at elevated temperatures, as discussed in Chapter 2. Around $46.5^{\circ}$ the substrate peaks for $\mathrm{Nb}: \mathrm{SrTiO}_{3}$ and around $46^{\circ}$ the $\mathrm{SrRuO}_{3}$ buffer layer peaks are visible. Between 38.5 till $45.5^{\circ}$ peaks can be observed representing various (004)-peaks at different lithiation levels of $\mathrm{Li}_{\mathrm{x}} \mathrm{Mn}_{2} \mathrm{O}_{4}$. At a voltage of $4.5 \mathrm{~V}$ it is expected that $\mathrm{x}$ within $\mathrm{Li}_{\mathrm{x}} \mathrm{Mn}_{2} \mathrm{O}_{4}$ is 0 (or $\lambda-\mathrm{Mn}_{2} \mathrm{O}_{4}$ ). Similarly, for 3.1 $\mathrm{V}, x=1\left(\mathrm{Li}_{1} \mathrm{Mn}_{2} \mathrm{O}_{4}\right)$ and at $2.7 \mathrm{~V}, x=2\left(\mathrm{Li}_{2} \mathrm{Mn}_{2} \mathrm{O}_{4}\right)$. The peaks for the different voltages and thereby linked lithiation levels in $\mathrm{Li}_{x} \mathrm{Mn}_{2} \mathrm{O}_{4}$ correspond with the lattice parameters found in literature: for $\lambda-\mathrm{Mn}_{2} \mathrm{O}_{4}$ the lattice parameter is $8.03 \AA$, for $\mathrm{Li}_{1} \mathrm{Mn}_{2} \mathrm{O}_{4}(3.1 \mathrm{~V})$ it is $8.25 \AA$ and for $\mathrm{Li}_{2} \mathrm{Mn}_{2} \mathrm{O}_{4}(2.7 \mathrm{~V})$ it is $9.24 \AA[12,18-20]$. 
This is a strong indication that the cubic to tetragonal-spinel transition takes place without much loss of capacity. With the enhanced energy density of $\mathrm{Li}_{2} \mathrm{Mn}_{2} \mathrm{O}_{4}$ it is very interesting to further research as to why there is minimal capacity fade in epitaxial thin films. It is hypothesized that the stability is partly due to the film thickness and its epitaxial growth. As shown in chapter 4 , figure 4 , other thin films grown by RF / magnetron sputtering show more severe capacity degradation $[21,22]$ where, even with a coating [8], a clear degradation is still visible. As the epitaxial growth results in mostly $\{111\}$-facets interfacing the electrolyte, the amount of dissolution of Mn is limited as this occurs mostly through the $\{110\}$ facet [23].

For (100)-oriented $\mathrm{Li}_{\mathrm{x}} \mathrm{Mn}_{2} \mathrm{O}_{4}$ films the out-of-plane lattice parameter during the Jahn-Teller distortion goes from $8.25 \AA(x=1)$ to $9.24 \AA(x=2)[12,18-20]$ whereas the in-plane lattice parameter changes from $8.25 \AA(x=1)$ to $5.65 \AA(x=2)$. Due to this, strains caused by the cubic- to tetragonal-spinel transition at the $3 \mathrm{~V}$ plateau could cause a reordering of the $\mathrm{Mn}$ to take place [24]. During the reordering from tetragonal to monoclinic or orthorhombic transition it was suggested that both result in a structure that is energetically favorable under in-plane stress as opposed to the tetragonal phase. The applied strain leads to redistribution of $\mathrm{Mn}$ ions within the oxygen framework. This changes the Mn distribution ratio from 1:3 in alternating layers of the tetragonal phase to a $2: 2$ distribution in the monoclinic or orthorhombic phase as shown in the figure on the right.

This transition due to the strain could explain the longevity of the cycling at the $3 \mathrm{~V}$ plateau. When the strain can be accommodated for by the material, it will not break or lose connection to the current collector, and, therefore, there will be no loss of capacity. X. Chen et al. unfortunately only shows five Cyclic Voltammetry cycles taken at $0.5 \mathrm{mV} / \mathrm{sec}$ and no results for extensive cycling [24]. 


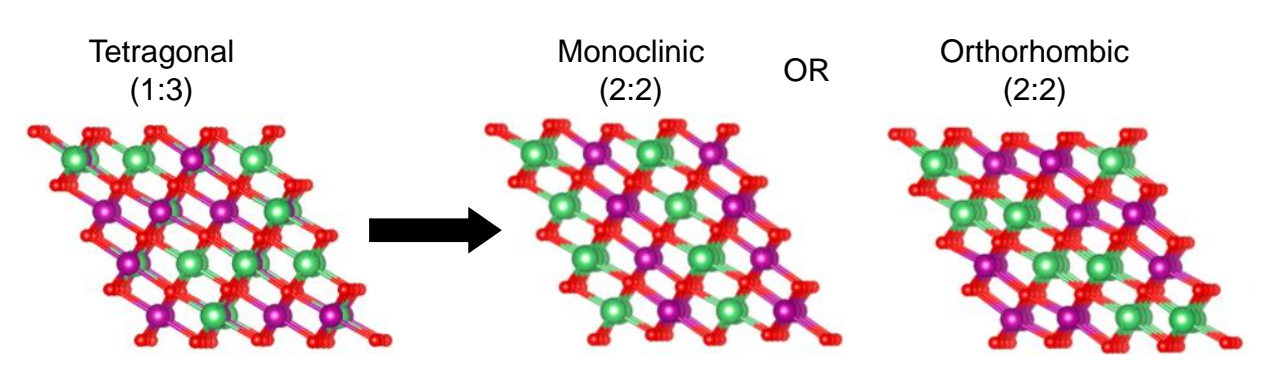

Figure 6, Transition of $\mathrm{Li}_{2} \mathrm{Mn}_{2} \mathrm{O}_{4}$ from tetragonal to monoclinic or orthorhombic due to strain. Adapted from [24].

Upon discharging the $3 \mathrm{~V}$ plateau, the average Mn-valence state changes from $3.5+$ to $3+$ :

$$
\mathrm{Li}^{+}\left(\mathrm{Mn}^{3+} \mathrm{Mn}^{4+}\right) \mathrm{O}_{4}{ }^{8-}+\mathrm{Li}^{+}+\mathrm{e}^{-} \quad \rightarrow \quad \mathrm{Li}^{+} \mathrm{Li}^{+}\left(\mathrm{Mn}^{3+} \mathrm{Mn}^{3+}\right) \mathrm{O}_{4}{ }^{8-}
$$

Looking at the dissolution reaction, including the $3 \mathrm{~V}$ plateau should increase the $\mathrm{Mn}^{3+}$ concentration and therefore increase the Mn-dissolution:

$$
4 \mathrm{H}^{+}+2 \mathrm{Li}\left(\mathrm{Mn}^{3+} \mathrm{Mn}^{4+}\right) \mathrm{O}_{4} \rightarrow 3 \lambda-\mathrm{Mn}^{4+} \mathrm{O}_{2}+\mathrm{Mn}^{2+}+2 \mathrm{Li}^{+}+2 \mathrm{H}_{2} \mathrm{O}
$$

To investigate enhanced dissolution and thereby capacity fade due to including the $3 \mathrm{~V}$ plateau, more charge-discharge cycles are done. After an initial 1000 cycles of solely the $4 \mathrm{~V}$ plateau (shown in chapters 2 and 4) a cycling period of 300 times at $5 \mu \mathrm{A}$ between 2.7 $-3.2 \mathrm{~V}$ (figure 4$)$ is employed. Thereafter, the $4 \mathrm{~V}$ region is cycled again $(3.6-4.5 \mathrm{~V}$ at $5 \mu \mathrm{A}$ ) for 250 times. Even though the capacity does not seem to decrease when the $3 \mathrm{~V}$ plateau is cycled, it is clear capacity fade does occur for the $4 \mathrm{~V}$ plateaus. Mn-dissolution is therefore not enhanced or even stopped when both manganese reside in the $3+$ valence state.

However, the capacity $(4.5-3.6 \mathrm{~V}$ at $5 \mu \mathrm{A})$, when cycling the $4 \mathrm{~V}$ region again after a period of cycling the $3 \mathrm{~V}$ plateau $(3.2-2.7 \mathrm{~V}$ at $5 \mu \mathrm{A}$ ), has returned to (or slightly above) the capacity $(4.5-3.6 \mathrm{~V}$ at $5 \mu \mathrm{A})$ of the very first cycle before cycling the $3 \mathrm{~V}$ plateau. When 
Mn-dissolution is the factor for loss of capacity, the capacity cannot return to its initial value.

With dissolution the material goes into the electrolyte causing an irreversible loss of capacity.

To elucidate the process behind the possible rejuvenation of the cathode by including the $3 \mathrm{~V}$ plateau, the cell was first cycled for 50 times around the $3 \mathrm{~V}$ plateau (not shown) after which the cell was further cycled between the $4 \mathrm{~V}$ plateaus $(4.5-3.6 \mathrm{~V})$ and $3 \mathrm{~V}$ and $4 \mathrm{~V}$ plateaus $(4.5-2.7 \mathrm{~V})$. In figure 7 (in blue) this is visible as periodically 50 cycles of capacity fade, followed by 10 cycles of both the $3 \mathrm{~V}$ and $4 \mathrm{~V}$ plateaus.

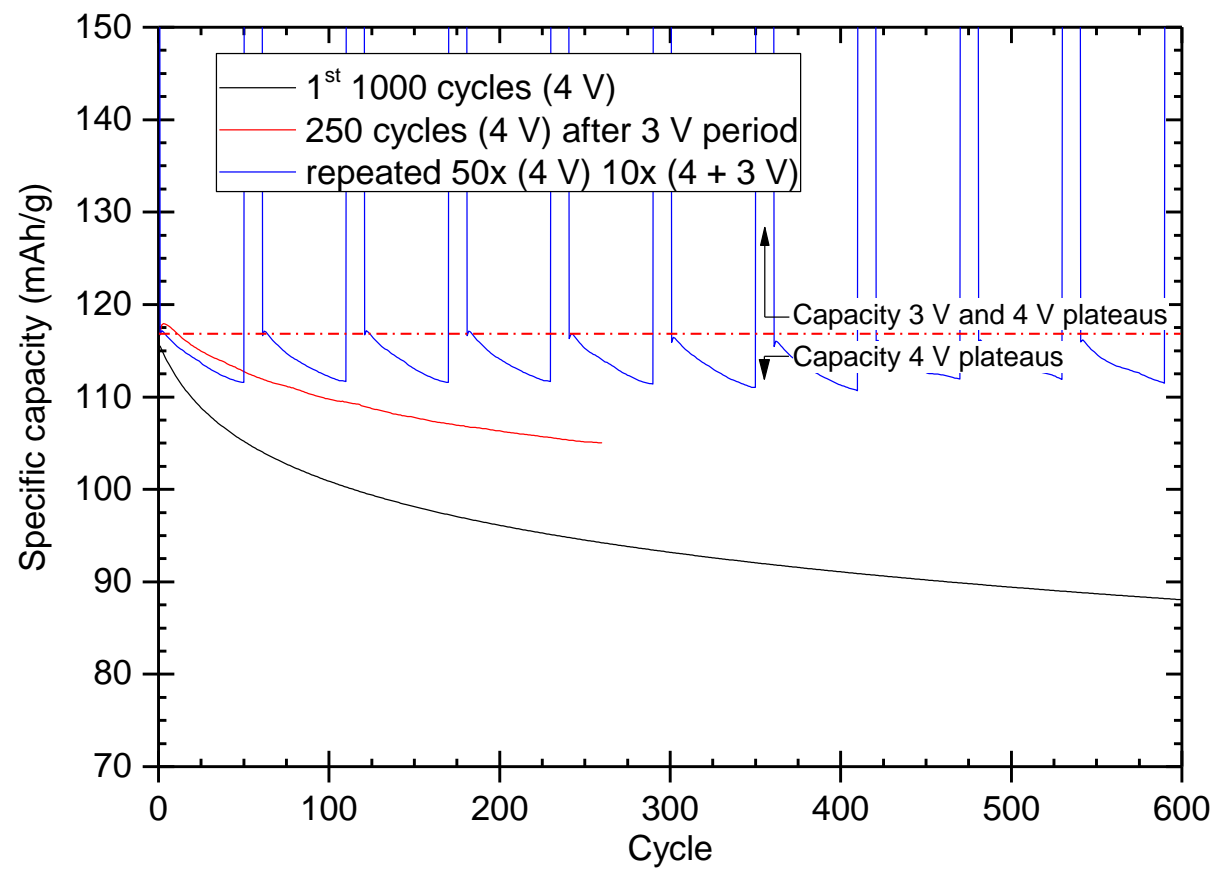

Figure 7, Capacity over cycles for an epitaxial thin film of $\mathrm{LiMn}_{2} \mathrm{O}_{4}$ at $3.3 \mathrm{C}(5 \mu \mathrm{A})$.

After 10 cycles of both the $3 \mathrm{~V}$ and $4 \mathrm{~V}$ plateaus the capacity is apparently rejuvenated and starts to fade again during the 50 cycles at the $4 \mathrm{~V}$ plateaus period. This is repeated ten times to observe possible capacity fade of the first cycle after each period of cycling both the $3 \mathrm{~V}$ and $4 \mathrm{~V}$ plateaus. It is observed that the capacity of the $4 \mathrm{~V}$ plateau is continuously brought 
back to the initial $\sim 120 \mathrm{mAh} / \mathrm{g}$ capacity when a period of cycling the $3 \mathrm{~V}$ plateau was included. No significant decrease in capacity of the first cycle of only the $4 \mathrm{~V}$ plateaus is observed. To analyze possible fades and the increases of the $4 \mathrm{~V}$ capacity an analysis of the voltage profile is shown in figure 8 .

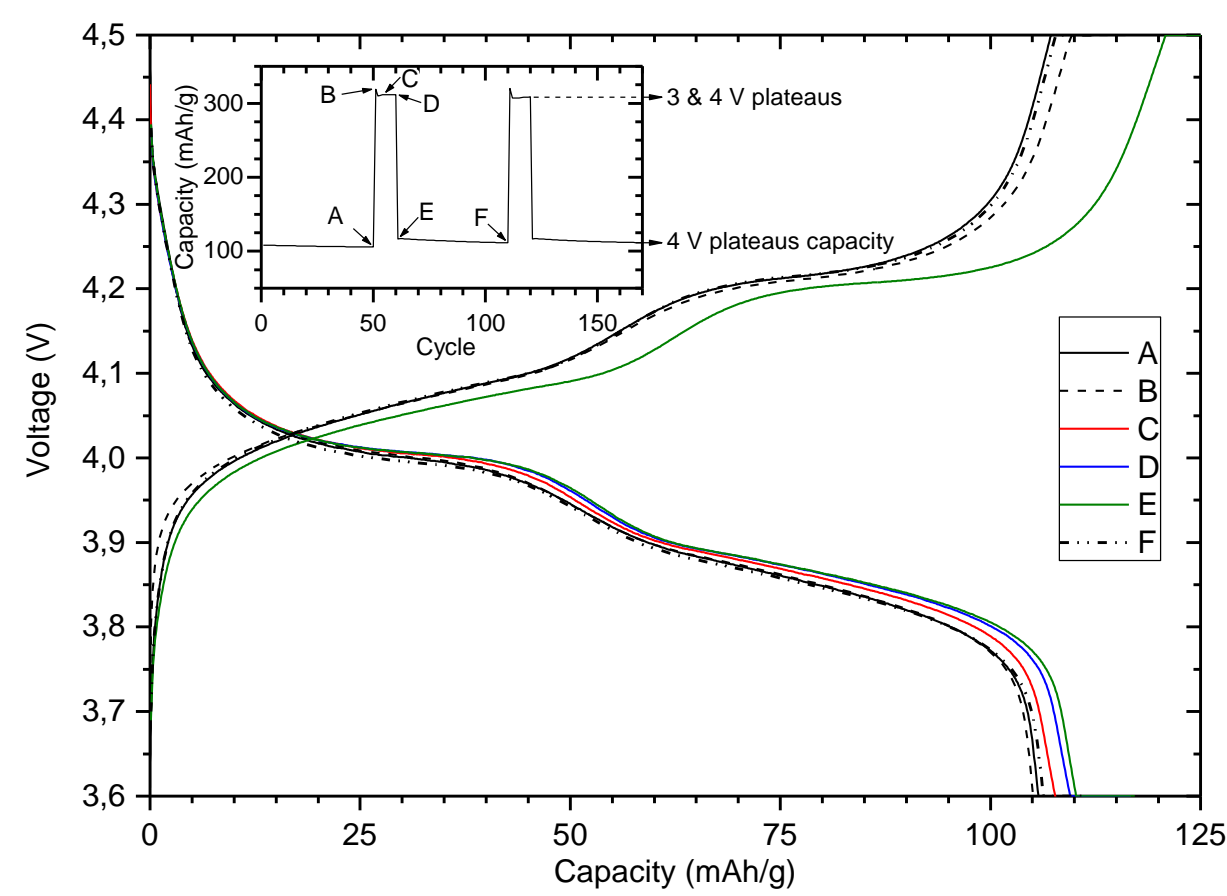

Figure 8, Voltage profile over capacity for an epitaxial thin film of $\mathrm{LiMn}_{2} \mathrm{O}_{4}$ at 3,3 C (5 $\mu$ A). Inset shows discharge capacity over cycles with A through $F$ denoting different points in the cycling process.

Above, the voltage profile over capacity at different points in the cycling between the two voltage ranges $(10 \mathrm{x} 4.5-2.7 \mathrm{~V}$ followed by $50 \mathrm{x} 4.5-3.6 \mathrm{~V})$ can be observed. The points in the inset have different discharge over capacity profiles:

A. Voltage profile after fifty cycles of only the $4 \mathrm{~V}$ plateaus (aging). 
B. Charge after A) and discharge till 3.6 V. A small capacity fade is visible at $3.6 \mathrm{~V}$. The discharge continues down to $2.7 \mathrm{~V}$ leading to a high discharge capacity (above $300 \mathrm{mAh} / \mathrm{g}$ ) as shown in the inset.

C. Halfway point of cycling both the $3 \mathrm{~V}$ and $4 \mathrm{~V}$ plateaus. Discharge capacity at $3.6 \mathrm{~V}$ has slightly increased.

D. Last point in cycling both the $3 \mathrm{~V}$ and $4 \mathrm{~V}$ plateaus. Discharge capacity at $3.6 \mathrm{~V}$ has further increased. Discharge continues for the last time down to $2.7 \mathrm{~V}$.

E. First cycle of only the $4 \mathrm{~V}$ plateaus. Discharge capacity at $3.6 \mathrm{~V}$ has increased through C, D till $\mathrm{E}$ as can be observed from the voltage graph.

F. Voltage profile after fifty cycles of only the $4 \mathrm{~V}$ plateaus showing capacity fade.

The charge profiles of $\mathrm{C}$ and $\mathrm{D}$ cannot be observed as they are outside the capacity range as their charging starts at $2.7 \mathrm{~V}$.

It is clear that cycling the $4 \mathrm{~V}$ plateau leads to the capacity fade that is associated in literature by the Mn dissolution. The shown revival of capacity is only possible if either the structure of $\mathrm{LiMn}_{2} \mathrm{O}_{4}$ has a reversible Mn-dissolution (i.e. dissolved $\mathrm{Mn}$ can reconstruct the $\lambda-\mathrm{Mn}_{2} \mathrm{O}_{4}$ framework) or the capacity fade has a different origin. It is hypothesized that one such origin could be insufficient charge and discharge, which accumulates into a fade. However, this would mean an increasing difficulty (voltage fade) in the extraction of lithium which is not observed. One other explanation could be that during charge and discharge at the $4 \mathrm{~V}$ plateaus, small amounts of $\mathrm{Mn}$ reorganization takes place. The proposed $\mathrm{Mn}$ reorganization by X. Chen et al. [24] would then already take place at higher voltages, slowly blocking the pathways for lithium diffusion and therefore decreasing the amount of capacity. As the material is then discharged to $2.7 \mathrm{~V}$ the material fully converts and upon charge it changes 
back. Doing this several times revives the material, unblocking the lithium pathways and returning the capacity to its original value.

The question then arises if there is any capacity fade at all as the capacity of the $4 \mathrm{~V}$ plateau is continuously brought back. As increased temperatures are known to make the Mndissolution more severe $[25,26]$, experiments at elevated temperatures would elucidate if and how severe Mn dissolution takes place in the epitaxial thin films of $\mathrm{LiMn}_{2} \mathrm{O}_{4}$.

\subsection{Conclusion}

Epitaxial thin films with single $\{111\}$-facets and high crystallinity are overlithiated from $\mathrm{LiMn}_{2} \mathrm{O}_{4}$ to $\mathrm{Li}_{2} \mathrm{Mn}_{2} \mathrm{O}_{4}$ by discharging below $3 \mathrm{~V}$. Due to surface effect contributions a large "tail" is visible in the charge-discharge, giving rise to capacities above theoretical values. Contrary to most literature studies on $\mathrm{Li}_{\mathrm{x}} \mathrm{Mn}_{2} \mathrm{O}_{4}$, cycling the $3 \mathrm{~V}$ plateau did not result in capacity degradation. Out-of-plane structural characterization by XRD shows the lattice parameter of the thin film does change with lithiation, indicating the Jahn-Teller distortion has taken place for $\mathrm{Li}_{2} \mathrm{Mn}_{2} \mathrm{O}_{4}$. Strain compensation is suggested to prevent particle fractures upon Jahn-Teller distortion, therefore, no loss of material and therefore capacity occurs. A structural transition due to in-plane strain could explain the strain compensation of the thin films, where $\mathrm{Li}_{2} \mathrm{Mn}_{2} \mathrm{O}_{4}$ is not tetragonal, but monoclinic or orthorhombic. The Jahn-teller distortion is thus present, but its effect is suppressed to the point where no effect on the capacity over cycles is visible. Furthermore, limited or no Mn-dissolution takes place in the thin films as cycling the $3 \mathrm{~V}$ plateaus for 10 cycles is sufficient to rejuvenate the $4 \mathrm{~V}$ region capacity to its original value.

This allows for $\mathrm{LiMn}_{2} \mathrm{O}_{4}$ cathodes which can both 1), cycle deeper to allow the use of 288 $\mathrm{mAh} /$ gram instead of the currently only $148 \mathrm{mAh} /$ gram used, and 2), cycle for extensive lifetimes as the capacity is able to be rejuvenated. 


\subsection{References}

[1] M. M. Thackeray, "Manganese oxides for lithium batteries," Prog. Solid State Chem., vol. 25, no. 1-2, pp. 1-71, 1997, DOI: 10.1016/S0079-6786(97)81003-5.

[2] M. J. Lee, S. Lee, P. Oh, Y. Kim, and J. Cho, "High performance $\mathrm{LiMn}_{2} \mathrm{O}_{4}$ cathode materials grown with epitaxial layered nanostructure for Li-Ion batteries," Nano Lett., vol. 14, no. 2, pp. 993-999, 2014, DOI: 10.1021/nl404430e.

[3] J. E. Greedan, “Geometrically frustrated magnetic materials," J. Mater. Chem., vol. 11, no. 1, pp. 37-53, 2001, DOI: 10.1039/b003682j.

[4] C. M. Julien, A. Mauger, K. Zaghib, and H. Groult, "Comparative Issues of Cathode Materials for Li-Ion Batteries,” Inorganics, vol. 2, pp. 132-154, 2014, DOI: 10.3390/inorganics2020132.

[5] T. Okumura, Y. Yamaguchi, M. Shikano, and H. Kobayashi, "Further findings of $\mathrm{X}$-ray absorption near-edge structure in lithium manganese spinel oxide using firstprinciples calculations," J. Mater. Chem. A, vol. 2, no. 21, pp. 8017-8025, 2014, DOI: $10.1039 / \mathrm{c} 3$ ta15412b.

[6] J. Choa and M. M. Thackeray, "Structural Changes of $\mathrm{LiMn}_{2} \mathrm{O}_{4}$ Spinel Electrodes during Electrochemical Cycling," J. Electrochem. Soc., vol. 146, no. 10, p. 3577, 1999, DOI: 10.1149/1.1392517.

[7] B. Put, P. M. Vereecken, N. Labyedh, A. Sepulveda, C. Huyghebaert, I. P. Radu, and A. Stesmans, "High Cycling Stability and Extreme Rate Performance in Nanoscaled $\mathrm{LiMn}_{2} \mathrm{O}_{4}$ Thin Films," ACS Appl. Mater. Interfaces, vol. 7, no. 40, pp. 22413-22420, 2015, DOI: 10.1021/acsami.5b06386.

[8] R. J. Gummow, A. de Kock, and M. M. Thackeray, "Improved capacity retention in rechargeable $4 \mathrm{~V}$ lithium/lithium-manganese oxide (spinel) cells," Solid State Ionics, vol. 69, no. 1, pp. 59-67, 1994, DOI: 10.1016/0167-2738(94)90450-2.

[9] Y.-I. Jang, "Electrochemical Cycling-Induced Spinel Formation in High-ChargeCapacity Orthorhombic $\mathrm{LiMnO}_{2}$," J. Electrochem. Soc., vol. 146, no. 9, p. 3217, 1999, DOI: $10.1149 / 1.1392457$.

[10] L. Yunjian, L. Xinhai, G. Huajun, W. Zhixing, H. Qiyang, P. Wenjie, and Y. Yong, "Electrochemical performance and capacity fading reason of $\mathrm{LiMn}_{2} \mathrm{O}_{4} /$ graphite batteries stored at room temperature," J. Power Sources, vol. 189, no. 1, pp. 721725, 2009, DOI: 10.1016/j.jpowsour.2008.08.044.

[11] K. Y. Chung, J. H. Kim, W.-S. Yoon, H. S. Kim, B. W. Cho, and K.-B. Kim, "The condition for the evolution of extra current peak in the cyclic voltammogram of $\mathrm{Li}_{\mathrm{x}} \mathrm{Mn}_{2} \mathrm{O}_{4}$ investigated by in situ bending beam method," Electrochem. commun., vol. 11, no. 1, pp. 212-215, Jan. 2009, DOI: 10.1016/j.elecom.2008.11.008.

[12] K. West, G. Vitins, and R. Koksbang, "Synthesis and host properties of tetragonal $\mathrm{Li}_{2} \mathrm{Mn}_{2} \mathrm{O}_{4}$ and $\mathrm{Li}_{2} \mathrm{Co}_{0.4} \mathrm{Mn}_{1.6} \mathrm{O}_{4}$," Electrochim. Acta, vol. 45, no. 19, pp. 3141-3149, Jun. 2000, DOI: 10.1016/S0013-4686(00)00395-9.

[13] S. J. Rezvani, R. Gunnella, A. Witkowska, F. Mueller, M. Pasqualini, F. Nobili, S. Passerini, and A. Di Cicco, "Is the Solid Electrolyte Interphase an Extra-Charge 
Reservoir in Li-Ion Batteries?,” ACS Appl. Mater. Interfaces, vol. 9, no. 5, pp. 45704576, Feb. 2017, DOI: 10.1021/acsami.6b12408.

[14] W. J. H. Borghols, D. Lützenkirchen-Hecht, U. Haake, E. R. H. van Eck, F. M. Mulder, and M. Wagemaker, "The electronic structure and ionic diffusion of nanoscale $\mathrm{LiTiO}_{2}$ anatase," Phys. Chem. Chem. Phys., vol. 11, no. 27, p. 5742, 2009, DOI: 10.1039/b823142g.

[15] H. Ge, N. Li, D. Li, C. Dai, and D. Wang, "Study on the Theoretical Capacity of Spinel Lithium Titanate Induced by Low-Potential Intercalation," J. Phys. Chem. C, vol. 113, no. 16, pp. 6324-6326, Apr. 2009, DOI: 10.1021/jp9017184.

[16] M. Hirayama, K. Kim, T. Toujigamori, W. Cho, and R. Kanno, "Epitaxial growth and electrochemical properties of $\mathrm{Li}_{4} \mathrm{Ti}_{5} \mathrm{O}_{12}$ thin-film lithium battery anodes," Dalt. Trans., vol. 40, no. 12, pp. 2882-2887, 2011, DOI: 10.1039/c0dt01477j.

[17] S. Kang, J. B. Goodenough, and L. K. Rabenberg, "Effect of Ball-Milling on 3-V Capacity of Lithium-Manganese Oxospinel Cathodes," Chem. Mater., vol. 13, no. 5, pp. 1758-1764, May 2001, DOI: 10.1021/cm000920g.

[18] Y. Liu, T. Fujiwara, H. Yukawa, and M. Morinaga, "Chemical bonding in lithium intercalation compound $\mathrm{Li}_{\mathrm{x}} \mathrm{Mn}_{2} \mathrm{O}_{4}(\mathrm{x}=0,1,2)$," Electrochim. Acta, vol. 46, pp. 11511159, 2001, DOI: 10.1016/S0013-4686(00)00692-7.

[19] T. Eriksson, A.-K. Hjelm, G. Lindbergh, and T. Gustafsson, "Kinetic Study of $\mathrm{LiMn}_{2} \mathrm{O}_{4}$ Cathodes by In Situ XRD with Constant-Current Cycling and Potential Stepping," J. Electrochem. Soc., vol. 149, no. 9, p. A1164, 2002, DOI: 10.1149/1.1497170.

[20] S. Mukerjee, T. R. Thurston, N. M. Jisrawi, X. Q. Yang, J. McBreen, M. L. Daroux, and X. K. Xing, "Structural Evolution of $\mathrm{Li}_{x} \mathrm{Mn}_{2} \mathrm{O}_{4}$ in Lithium-Ion Battery Cells Measured In Situ Using Synchrotron X-Ray Diffraction Techniques," $J$. Electrochem. Soc., vol. 145, no. 2, p. 466, 1998, DOI: 10.1149/1.1838286.

[21] T. Doi, M. Inaba, Y. Iriyama, T. Abe, and Z. Ogumi, "Electrochemical STM Observation of $\mathrm{Li}_{1+x} \mathrm{Mn}_{2-x} \mathrm{O}_{4}$ Thin Films Prepared by Pulsed Laser Deposition," $J$. Electrochem. Soc., vol. 155, no. 1, p. A20, 2008, DOI: 10.1149/1.2799076.

[22] D. W. Shin, J.-W. Choi, J.-P. Ahn, W.-K. Choi, Y. S. Cho, and S.-J. Yoon, " $\mathrm{ZrO}_{2}-$ Modified $\mathrm{LiMn}_{2} \mathrm{O}_{4}$ Thin-Film Cathodes Prepared by Pulsed Laser Deposition,” J. Electrochem. Soc., vol. 157, no. 5, p. A567, 2010, DOI: 10.1149/1.3332745.

[23] M. Hirayama, N. Sonoyama, M. Ito, M. Minoura, D. Mori, A. Yamada, K. Tamura, J. Mizuki, and R. Kanno, "Characterization of Electrode/Electrolyte Interface with X-Ray Reflectometry and Epitaxial-Film $\mathrm{LiMn}_{2} \mathrm{O}_{4}$ Electrode," J. Electrochem. Soc., vol. 154, no. 11, p. A1065, 2007, DOI: 10.1149/1.2778853.

[24] X. Chen, M. Vörös, J. C. Garcia, T. T. Fister, D. B. Buchholz, J. Franklin, Y. Du, T. C. Droubay, Z. Feng, H. Iddir, L. A. Curtiss, M. J. Bedzyk, and P. Fenter, "StrainDriven Mn-Reorganization in Overlithiated $\mathrm{Li}_{x} \mathrm{Mn}_{2} \mathrm{O}_{4}$ Epitaxial Thin-Film Electrodes," ACS Appl. Energy Mater., vol. 1, no. 6, pp. 2526-2535, 2018, DOI: 10.1021/acsaem.8b00270. 
[25] Z. Liu, H. Wang, L. Fang, J. Y. Lee, and L. M. Gan, "Improving the hightemperature performance of $\mathrm{LiMn}_{2} \mathrm{O}_{4}$ spinel by micro-emulsion coating of $\mathrm{LiCoO}_{2}$," J. Power Sources, vol. 104, no. 1, pp. 101-107, 2002, DOI: 10.1016/S03787753(01)00878-3.

[26] Y. Xia, Y. Zhou, and M. Yoshio, "Capacity Fading on Cycling of $4 \mathrm{~V} \mathrm{Li} / \mathrm{LiMn}_{2} \mathrm{O}_{4}$ Cells,” J. Electrochem. Soc., vol. 144, no. 8, p. 2593, 1997, DOI: 10.1149/1.1837870. 
6 Solid-state electrolyte $\mathrm{Li}_{3 x} \mathrm{La}_{2 / 3-x} \mathrm{TiO}_{3}$ in thin film batteries 


\subsection{Introducing solid-state electrolyte $\mathrm{Li}_{3 x} \mathrm{La}_{2 / 3-x} \mathrm{TiO}_{3}$}

Safety is an intrinsic challenge of conventional Li-ion batteries due to the high energy densities and use of flammable liquid electrolytes. While solid electrolytes are expected to exhibit enhanced safety due to higher thermal stability, absence of leakage, and higher resistance to punctures [1 - 3]. Batteries with a solid electrolyte, so-called solid-state batteries, might also be made thinner, as separator, solvents and salts are not needed, which can increase energy density. As compared to liquid electrolytes, however, the solid electrolytes have in general lower ionic conductivities, which is why research is mostly focused on increasing the ionic conductivity [2 - 4]. Furthermore, the solid-solid interface between the electrolyte and anode/cathode becomes rigid, which might cause loss of contact when large differences in temperature expansion coefficients exist or changes in the lattice parameter, during lithiation, occur. As lithium is intercalated into the electrode material, it expands (and contracts again upon de-lithiation), this process can cause loss of contact (over time and cycling) at the interface between the electrode material and the solid electrolyte, increasing the contact resistance [1]. Preferably, an electrolyte can accommodate the changes in the structure of the electrode.

Common materials that have been studied to function as solid-state electrolytes are polymers, ceramics and glass materials. A literature overview of state-of-the-art electrolytes is presented in figure 1. $\mathrm{Li}_{0.5} \mathrm{La}_{0.5} \mathrm{TiO}_{3}$ perovskite solid state electrolyte is a very promising ceramic electrolyte, showing high ionic conductivities $\left(\sim 510^{-4} \mathrm{~S} / \mathrm{cm}\right)$ around room temperature close to that of a standard liquid electrolyte like $1 \mathrm{M} \mathrm{LiPF}_{6}$ EC:DMC 1:1 $\left(10^{-2}\right.$ $\mathrm{S} / \mathrm{cm})[4,5]$. It is furthermore a perovskite material with a lattice parameter $(3.86-3.88 \AA$ $[1,6])$ close to that of our $\mathrm{Nb}: \mathrm{SrTiO}_{3}$ substrate $(3.91 \AA)$. Thereby having a high probability to grow epitaxially on both the crystalline $\mathrm{LiMn}_{2} \mathrm{O}_{4}$ cathode thin films and $\mathrm{Nb}: \mathrm{SrTiO}_{3}$ substrates. 


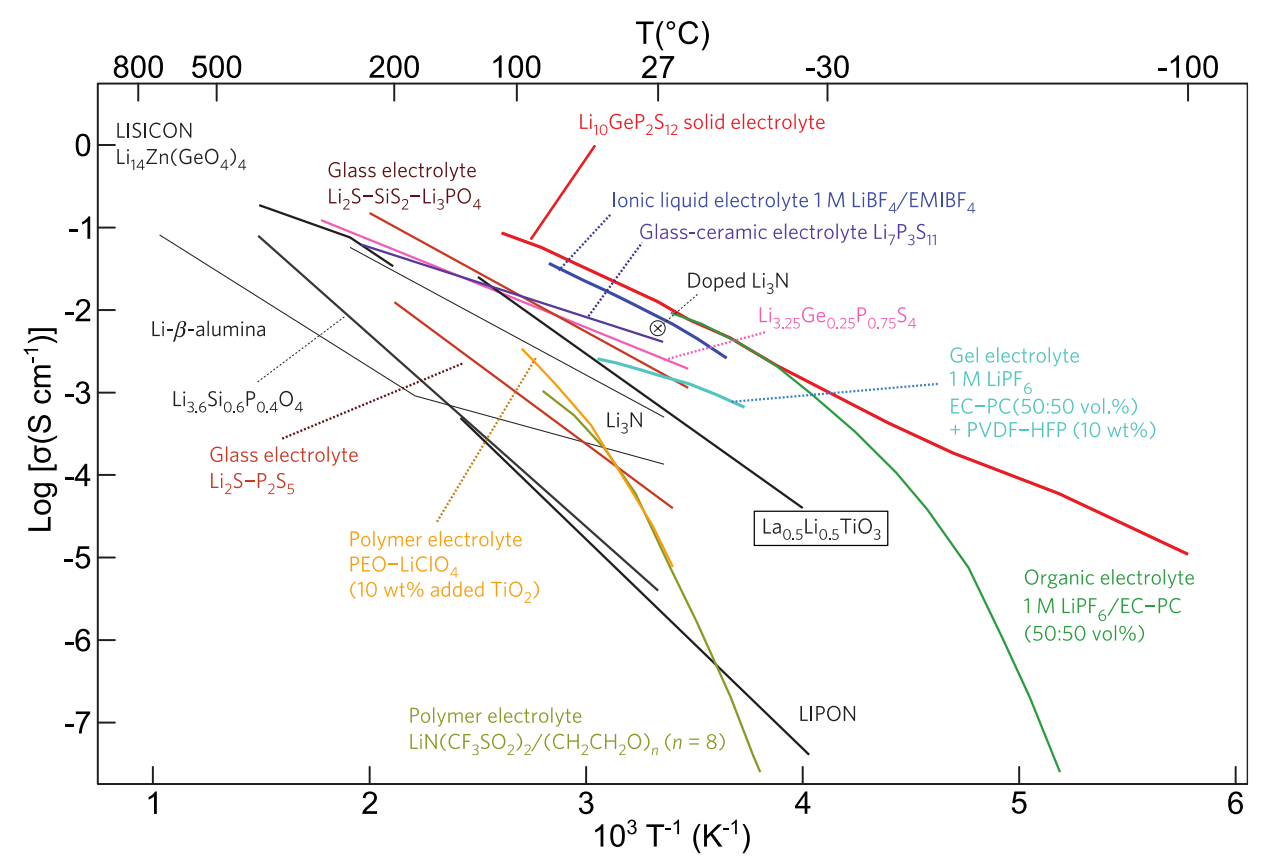

Figure 1, Overview of state-of-the-art electrolytes showing the ionic conductivity as function of temperature on a Lin-log scale. Adapted from [5]

Therefore, through pulsed laser deposition, $\mathrm{Li}_{0.5} \mathrm{La}_{0.5} \mathrm{TiO}_{3}$ is synthesized on $\mathrm{Nb}: \mathrm{SrTiO}_{3}$ substrates with different crystalline surface orientations, and at various synthesis temperatures, to determine the structural and electrochemical dependence of grown thin films on its substrate and synthesis temperature. Afterwards, the solid electrolyte will be combined with a solid anode and the $\mathrm{LiMn}_{2} \mathrm{O}_{4}$ cathode to determine the structural and electrochemical properties of an all-oxide full solid state battery. Furthermore, creating a nanocomposite could allow for increased contact area, which in turn would allow for an enhanced power density. Therefore, it is tried to synthesize a nanocomposite for solid-state batteries and characterize its structural and electrochemical properties. 


\subsection{Thin film $\mathrm{Li}_{3 x} \mathrm{La}_{2 / 3-x} \mathrm{TiO}_{3}$ solid-state electrolyte}

The crystal structure of the perovskite $\mathrm{Li}_{3 x} \mathrm{La}_{2 / 3-\mathrm{x}} \mathrm{TiO}_{3}$ (LLTO) is shown in figure $2 \mathrm{a}$. The $\mathrm{Li}_{3 \times} \mathrm{La}_{2 / 3-x} \mathrm{TiO}_{3}$ structure is often described by an orthorhombic structure of two primitive perovskite unit cells stacked on top of each other due to A-site deficiencies in the crystal structure $[7,8]$. However, when the lithium ratio (x) in $\mathrm{Li}_{3 \mathrm{x}} \mathrm{La}_{2 / 3-\mathrm{x}} \mathrm{TiO}_{3}$ is high enough $(x>$ $0.08)$, the crystal structure can be regarded as cubic $[9,10]$.

The stoichiometry of $\mathrm{Li}_{3 x} \mathrm{La}_{2 / 3-x} \mathrm{TiO}_{3}$ has a dramatic effect on the ionic conductivity, as can be seen in figure $2 \mathrm{~b}$ [11]. For $x=0.11\left(\mathrm{Li}_{0.33} \mathrm{La}_{0.56} \mathrm{TiO}_{3}\right)$ the highest ionic conductivity, due to lithium vacancy controlled diffusion through the LLTO-system, can be achieved along which Li can diffuse $[12,13]$.
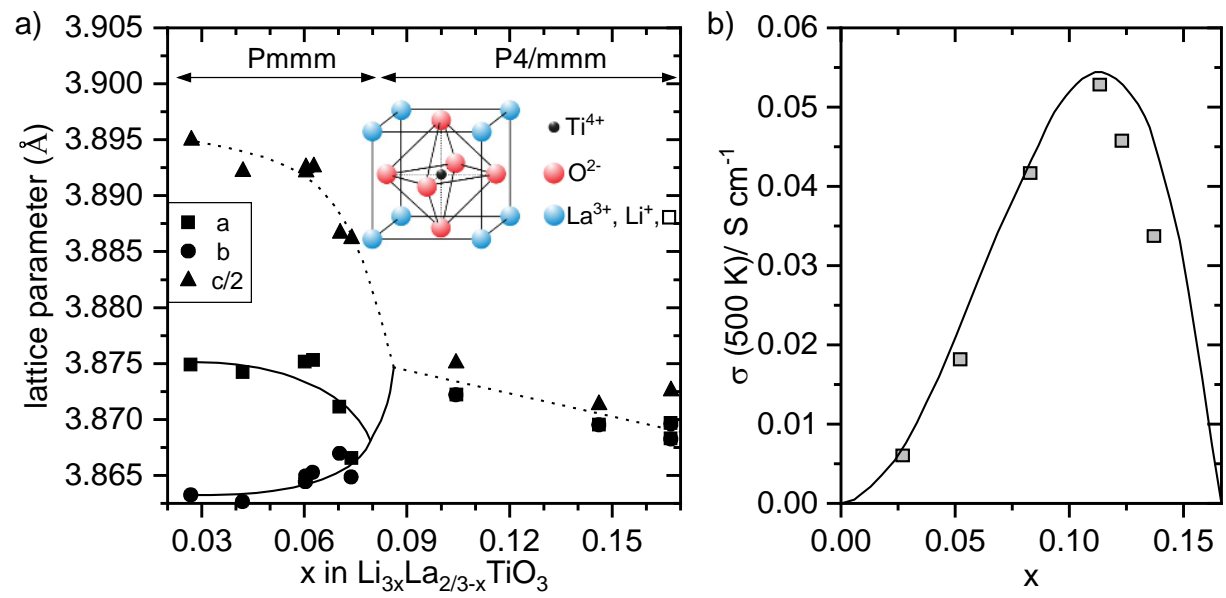

Figure 2, a) Lattice parameter of $\mathrm{Li}_{3 x} \mathrm{La}_{2 / 3-x} \mathrm{TiO}_{3}$ versus lithium ratio, adapted from [9]. Inset of a) shows $\mathrm{Li}_{3 x} \mathrm{La}_{2 / 3-x} \mathrm{TiO}_{3}$ in spacegroup $\mathrm{P} 4 / \mathrm{mmm}$. Black sphere is $\mathrm{Ti}^{4+}$, red spheres are $\mathrm{O}^{2-}$, blue spheres are either $\mathrm{La}^{3+}, \mathrm{Li}^{+}$or a vacancy. b) Ionic conductivity vs. ratio of lithium in $\mathrm{Li}_{3 x} \mathrm{La}_{2 / 3-x} \mathrm{TiO}_{3}$ adapted from [14]. Adapted from [15] 
To study the influence of the underlying crystal orientation of the substrate on the $\mathrm{Li}_{3 \mathrm{x}} \mathrm{La}_{2 / 3-\mathrm{x}} \mathrm{TiO}_{3}$ thin film crystal structure, $\mathrm{Nb}: \mathrm{SrTiO}_{3}$ substrates with (100, 110 or 111)orientation were used. Synthesis was done through pulsed laser deposition with conditions derived from both the synthesis of $\mathrm{LiMn}_{2} \mathrm{O}_{4}$ (Chapter 2) and literature $[1,6,10]$. The $\mathrm{Li}_{3 \times} \mathrm{La}_{2 / 3-x} \mathrm{TiO}_{3}$ thin films were grown at various temperatures $\left(700-900{ }^{\circ} \mathrm{C}\right)$ on $\mathrm{Nb}$-doped (0.5 wt $\%)$ single crystalline $\mathrm{SrTiO}_{3}(100,110$ or 111) substrates from a sintered $\mathrm{Li}_{0.5} \mathrm{La}_{0.5} \mathrm{TiO}_{3}$-target, using a $\mathrm{KrF}$ excimer laser operating at $248 \mathrm{~nm}$ at a repetition rate of 2 $\mathrm{Hz}$. The $\mathrm{Nb}: \mathrm{SrTiO}_{3}$ substrates were annealed at $950{ }^{\circ} \mathrm{C}$ for $1.5 \mathrm{~h}$ in an oxygen flow of 150 $\mathrm{ml} / \mathrm{min}$. The oxygen pressure during growth was $0.2 \mathrm{mbar}(20 \mathrm{~Pa})$, while the laser energy fluence was $2.3 \mathrm{~J} \mathrm{~cm}^{-2}$. After deposition, the thin films were cooled down to room temperature in an oxygen pressure of 1 bar at a rate of $10{ }^{\circ} \mathrm{C} \min ^{-1}$ to optimize the oxidation level.

X-ray diffraction was used to study the epitaxial relation between the $\mathrm{Li}_{3 x} \mathrm{La}_{2 / 3-x} \mathrm{TiO}_{3}$ thin films and the $\mathrm{Nb}: \mathrm{SrTiO}_{3}$ substrates. Firstly, the temperature was varied to observe the lowest point at which good crystallinity can be observed, to minimalize the lithium deficiency due to evaporation. In figure $3 \mathrm{a}$ clear peaks of the $\mathrm{Nb}$ :STO (100) substrate as well as peaks of $\mathrm{Li}_{3 \times} \mathrm{La}_{2 / 3-x} \mathrm{TiO}_{3}$, marked with their respective orientation, can be observed. Although $\mathrm{Li}_{3 \mathrm{x}} \mathrm{La}_{2 / 3-\mathrm{x}} \mathrm{TiO}_{3}$ is clearly present for the higher temperatures, a significant contribution of anatase and rutile $\mathrm{TiO}_{x}$ phases are still observed. Additionally, more rutile phase peaks would be expected as they are favored over anatase at these high temperatures [16], however a large anatase contribution is still present.

The rutile and anatase phases indicate lithium deficiencies, similar to the formation of $\mathrm{Mn}_{2} \mathrm{O}_{3}$ impurities as observed in the synthesis of $\mathrm{LiMn}_{2} \mathrm{O}_{4}$ shown in Chapter 2. 

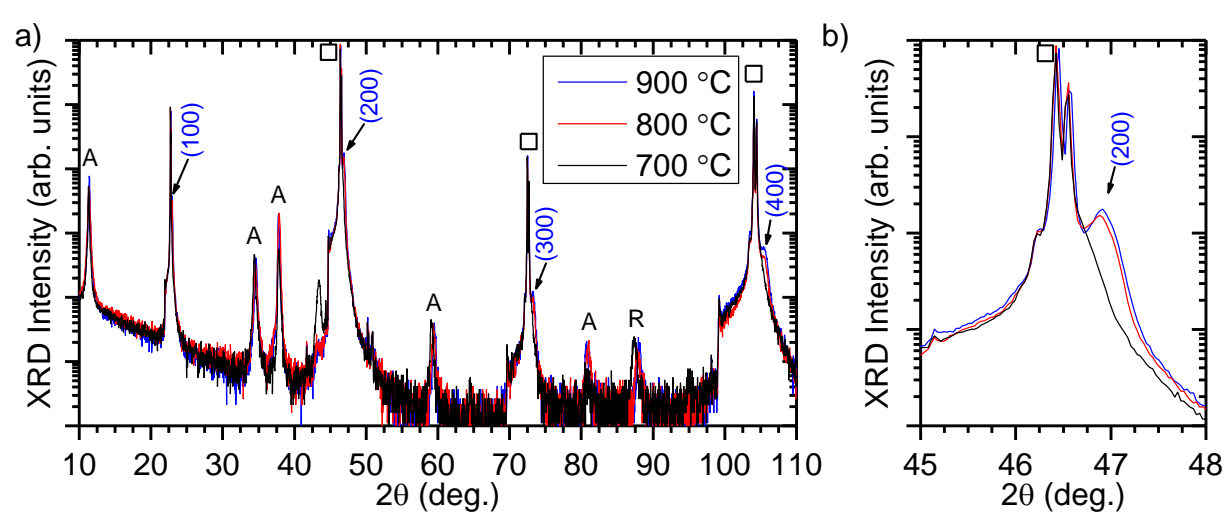

Figure 3, Out-of-plane XRD intensity over 2Theta angle for $\mathrm{Li}_{3 x} \mathrm{La}_{2 / 3-x} \mathrm{TiO}_{3}$ thin films grown on $\mathrm{Nb}$ :STO-100 at various temperatures $\left(700-900{ }^{\circ} \mathrm{C}\right)$. b) is a zoom-in between 45 - 48 degrees in $2 \Theta$ of a). Contributions by the $\mathrm{Nb}: \mathrm{SrTiO}_{3}$ substrate (口) and impurities anatase $\mathrm{TiO}_{x}(\mathrm{~A})$ and rutile $\mathrm{TiO}_{x}(\mathrm{R})$ are indicated.

In figure $3 b$ a strong intensity for the $\mathrm{Li}_{3 x} \mathrm{La}_{2 / 3-x} \mathrm{TiO}_{3}(200)$-peak at 800 and $900{ }^{\circ} \mathrm{C}$ can be observed, indicating epitaxial thin film growth.

From $3 b$, the (200)-peak position is determined by subtraction of the $\mathrm{Nb}: \mathrm{SrTiO}_{3}$ peak from a bare substrate XRD (not shown). This gives, for 800 and $900{ }^{\circ} \mathrm{C}$, a peak position of $46.9^{\circ}$ with a corresponding lattice parameter of $3.872 \AA$. Using figure $2 \mathrm{a}$, the lattice parameter is used to estimate the lithium concentration to be close to $x=0.13$ for the 800 and $900{ }^{\circ} \mathrm{C}$ samples. As for the $700{ }^{\circ} \mathrm{C}$ synthesis the $\mathrm{Li}_{3 x} \mathrm{La}_{2 / 3}-\mathrm{XTiO}_{3}$ peak is hardly visible, this indicates that this temperature is insufficient to synthesize crystalline $\mathrm{Li}_{3 \mathrm{x}} \mathrm{La}_{2 / 3-\mathrm{x}} \mathrm{TiO}_{3}$. To minimalize the lithium deficiency due to evaporation of lithium at high temperatures, the lowest temperature $\left(800{ }^{\circ} \mathrm{C}\right)$ at which crystalline $\mathrm{Li}_{3 x} \mathrm{La}_{2 / 3-} \mathrm{TiO}_{3}$ is formed is used for follow-up synthesis. 
The topography for $\mathrm{Li}_{3 x} \mathrm{La}_{2 / 3-x} \mathrm{TiO}_{3}$ thin films grown on the three different orientations of $\mathrm{Nb}: \mathrm{STO}((100),(110) \&(111))$ is shown in figure 4. Clear cubic / rectangular features are visible in the AFM images of the (100) and (110)-oriented $\mathrm{Li}_{3 \mathrm{x}} \mathrm{La}_{2 / 3-\mathrm{x}} \mathrm{TiO}_{3}$ thin films in the vertical and horizontal direction, indicating an in-plane relation to the $\mathrm{Nb}: \mathrm{SrTiO}_{3}$ substrate, while in the (111) orientation no clear shape can be distinguished. Roughness (RMS) values are 5.61, 1.38 and $2.03 \mathrm{~nm}$ for respectively the (100), (110) and (111)-oriented films which have a thickness of about $100 \mathrm{~nm}$ as determined through cross-section SEM (not shown).

In figure 5, XRD is shown of the same samples. Substrate peaks are marked as well as the peaks of $\mathrm{Li}_{3 x} \mathrm{La}_{2 / 3-x} \mathrm{TiO}_{3}$ with their respective orientations. The out-of-plane XRD gives a hint for an epitaxial relation between substrate and thin-film which in-plane XRD could prove. Due to the similarity of the growth to that of $\mathrm{LiMn}_{2} \mathrm{O}_{4}$ it is assumed to be epitaxial. All $\mathrm{Li}_{3 x} \mathrm{La}_{2 / 3-x} \mathrm{TiO}_{3}$ thin films show contributions of the rutile and anatase $\mathrm{TiO}_{x}$ phases.

The cubic / rectangular features in the AFM images are attributed to the anatase $\mathrm{TiO}_{\mathrm{x}}$-phase as the perovskite $\mathrm{Li}_{3 \mathrm{x}} \mathrm{La}_{2 / 3-\mathrm{x}} \mathrm{TiO}_{3}$ is expected to grow coherent flat layers on the perovskite $\mathrm{Nb}$ :STO substrate due to energetically favored facets $[17,18]$.
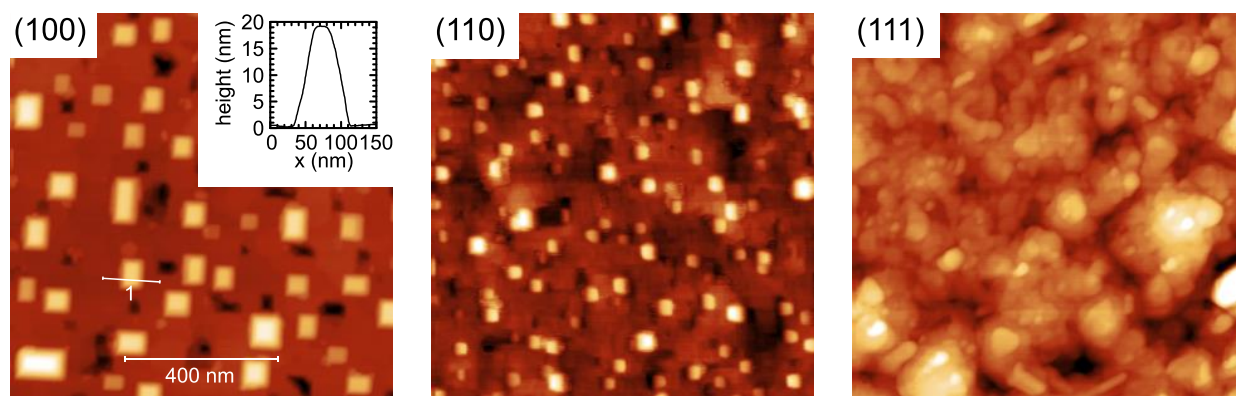

Figure 4, AFM topography of $\mathrm{Li}_{3 x} \mathrm{La}_{2 / 3-x} \mathrm{TiO}_{3}$ thin films on $\mathrm{Nb}$ :STO-((100), (110) \& (111)) at $800{ }^{\circ} \mathrm{C}$. Inset shows height profile over the (100)-oriented surface. 
a)

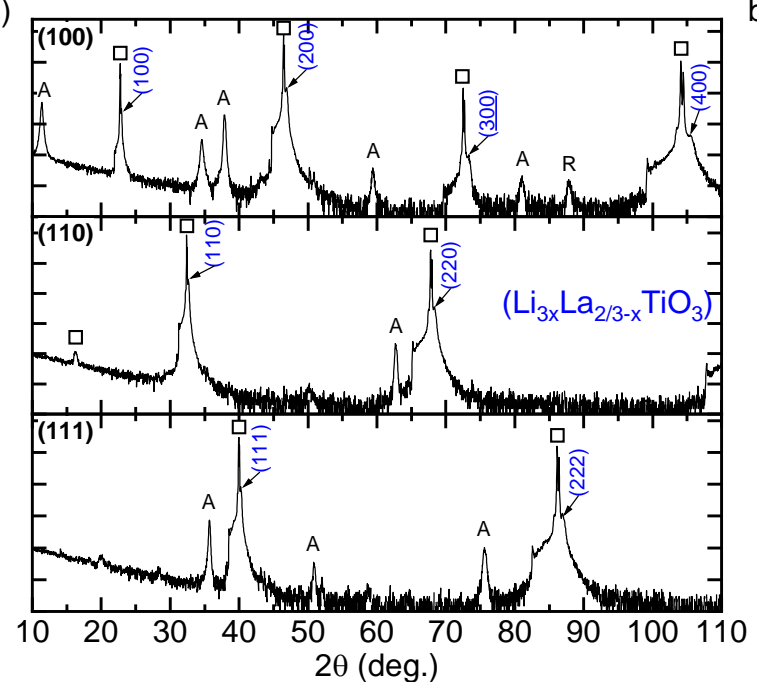

b)

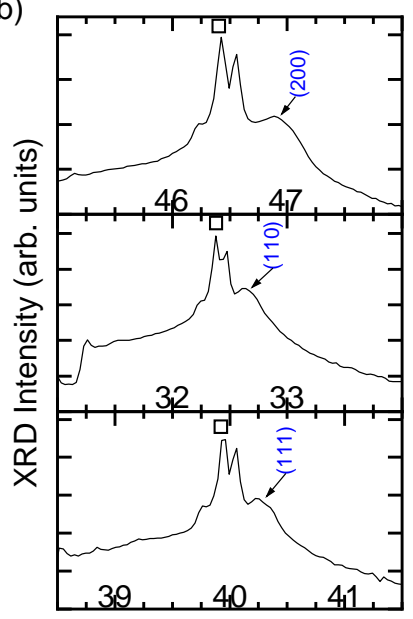

$2 \theta$ (deg.)

Figure 5, a) Out-of-plane XRD intensity over 2Theta angle for $\mathrm{Li}_{3 x} \mathrm{La}_{2 / 3-x} \mathrm{TiO}_{3}$ thin films grown on ((100), (110) \& (111))-Nb:STO at $800^{\circ} \mathrm{C}$. b) is a zoom-in of the main substrate peak with the main $\mathrm{Li}_{3 x} \mathrm{La}_{2 / 3-x} \mathrm{TiO}_{3}$ peak. Contributions by the $\mathrm{Nb}: \mathrm{SrTiO}_{3}$ substrate ( $\square$ ) and impurities anatase $\mathrm{TiO}_{x}(\mathrm{~A})$ and rutile $\mathrm{Ti}_{x}(\mathrm{R})$ are indicated

\subsection{All-oxide full solid state batteries}

Through a study on synthesizing epitaxial thin films of the anode material $\mathrm{Li}_{4} \mathrm{Ti}_{5} \mathrm{O}_{12}$ [19] it becomes possible to synthesize the three key elements of the battery: Anode $\left(\mathrm{Li}_{4} \mathrm{Ti}_{5} \mathrm{O}_{12}\right)$, Electrolyte $\left(\mathrm{Li}_{3 x} \mathrm{La}_{2 / 3-x} \mathrm{TiO}_{3}\right)$ and Cathode $\left(\mathrm{LiMn}_{2} \mathrm{O}_{4}\right)$. As mentioned in the introduction of this chapter, the advantages of a solid electrolyte are mainly enhanced safety and increased energy density with the disadvantage of low Li-ion diffusivity and difficulties in coating and maintaining interfacial connection. On the other hand, a reduced thickness of solid electrolyte could still allow for sufficient lithium diffusion. In Chapter 3 the Li-diffusivity through $\mathrm{LiMn}_{2} \mathrm{O}_{4}$ was measured to be roughly around $4 \cdot 10^{-14} \mathrm{~cm}^{2} \mathrm{~s}^{-1}$ whereas that of the electrolyte is reported to be higher than $10^{-11} \mathrm{~cm}^{2} \mathrm{~s}^{-1}$ [20]. A limited Li-conducting $\mathrm{Li}_{3 \times} \mathrm{La}_{2 / 3}-\mathrm{XTiO}_{3}$ electrolyte does not have to be the bottleneck for a full solid-state battery, 
this might actually be the diffusivity through the cathode / anode. To synthesize a full stack of the materials, some crucial limitations have to be taken into account. The deposition temperature of $\mathrm{LiMn}_{2} \mathrm{O}_{4}$ is limited to about $600{ }^{\circ} \mathrm{C}$ as higher temperatures result in a structural change that is no longer electrochemically active as shown in chapter 2 . Furthermore, $\mathrm{LiMn}_{2} \mathrm{O}_{4}$ can have interfacial reactions at higher temperatures [1]. As both the $\mathrm{Li}_{4} \mathrm{Ti}_{5} \mathrm{O}_{12}$ and $\mathrm{Li}_{3 \times} \mathrm{La}_{2 / 3-x} \mathrm{TiO}_{3}$ need higher synthesis temperatures of respectively 700 and $800{ }^{\circ} \mathrm{C}$ they have to be synthesized before $\mathrm{LiMn}_{2} \mathrm{O}_{4}$. However, as the electrolyte $\left(\mathrm{Li}_{3 x} \mathrm{La}_{2 / 3}\right.$ ${ }_{x} \mathrm{TiO}_{3}$ ) needs to be synthesized in between $\mathrm{Li}_{4} \mathrm{Ti}_{5} \mathrm{O}_{12}$ and $\mathrm{LiMn}_{2} \mathrm{O}_{4}, \mathrm{Li}_{4} \mathrm{Ti}_{5} \mathrm{O}_{12}$ needs to exceed its synthesis temperature. Luckily, in the study on $\mathrm{Li}_{4} \mathrm{Ti}_{5} \mathrm{O}_{12}$ no structural change was observed at elevated temperatures $\left(>800^{\circ} \mathrm{C}\right)$ after synthesis at $700{ }^{\circ} \mathrm{C}$. Therefore, the buildup of the all-oxide full solid-state battery will start with a layer of $\mathrm{Li}_{4} \mathrm{Ti}_{5} \mathrm{O}_{12}$ followed by $\mathrm{Li}_{3 x} \mathrm{La}_{2 / 3-x} \mathrm{TiO}_{3}$ and lastly $\mathrm{LiMn}_{2} \mathrm{O}_{4}$ : "Nb:SrTiO $3 / \mathrm{Li}_{4} \mathrm{Ti}_{5} \mathrm{O}_{12} / \mathrm{Li}_{3 \mathrm{x}} \mathrm{La}_{2 / 3-\mathrm{x}} \mathrm{TiO}_{3} / \mathrm{Li}_{\mathrm{x}} \mathrm{Mn}_{2} \mathrm{O}_{4}$ ".

The anode material $\left(\mathrm{Li}_{4} \mathrm{Ti}_{5} \mathrm{O}_{12}\right)$ has a voltage of $1.5 \mathrm{~V}$ vs. $\mathrm{Li}$ and the cathode material $\left(\mathrm{LiMn}_{2} \mathrm{O}_{4}\right)$ a voltage of $4 \mathrm{~V}$ vs. $\mathrm{Li}$, therefore a potential difference of $2.5 \mathrm{~V}$ is expected. On the one hand the energy density is increased by using solid state materials, while on the other it is decreased due to the choice of materials, which is one of the reasons to research high potential cathodes [21]. Despite this, $\mathrm{Li}_{4} \mathrm{Ti}_{5} \mathrm{O}_{12}$ is chosen, as lithium metal is very reactive, many electrolytes decompose at low voltages vs. $\mathrm{Li}[22,24]$. An $\mathrm{Li}_{4} \mathrm{Ti}_{5} \mathrm{O}_{12}$ anode provides a higher voltage and is thus not as reactive. The $\mathrm{Li}_{3 \mathrm{x}} \mathrm{La}_{2 / 3-\mathrm{x}} \mathrm{TiO}_{3}$, does not react with this anode, whereas vs. lithium metal it would undergo lithium insertion and decompose. Although, Y. Zhu et al.[23] showed that the decomposition energy for $\mathrm{Li}_{3 x} \mathrm{La}_{2 / 3-x} \mathrm{TiO}_{3}$ is very low, preventing the decomposition from occurring quickly, it could still quickly decompose the thin film. 
The voltage vs. $\mathrm{Li}$ of the $\mathrm{LiMn}_{2} \mathrm{O}_{4}$ cathode potential during cycling can rise above $4.5 \mathrm{~V}$. The stability of $\mathrm{Li}_{3 \mathrm{x}} \mathrm{La}_{2 / 3-\mathrm{x}} \mathrm{TiO}_{3}$ at high voltages (versus $\mathrm{LiMn}_{2} \mathrm{O}_{4}$ ) can become unsure [22, 24]. However, it has been shown that amorphous $\mathrm{Li}_{3 x} \mathrm{La}_{2 / 3-x} \mathrm{TiO}_{3}$ can be stable (no lithium extraction occurs) up to $12 \mathrm{~V}$ with blocking electrodes [4]. Furthermore, $\mathrm{Li}_{3 \times} \mathrm{La}_{2 / 3-x} \mathrm{TiO}_{3}$ has been shown in a previous study to work in combination with $\mathrm{LiMn}_{2} \mathrm{O}_{4}[1]$.

With a thinner electrolyte a higher energy density can be achieved, the electrolyte only has to prevent a short between cathode and anode (i.e. coat the thin layer) as well as show a sufficient Li-diffusivity. The thickness for $\mathrm{LiMn}_{2} \mathrm{O}_{4}$ is around $\sim 100 \mathrm{~nm}$ as shown in previous experiments (Chapter 2) and through the study on synthesizing epitaxial thin films of the anode material $\mathrm{Li}_{4} \mathrm{Ti}_{5} \mathrm{O}_{12}$ [19] the thickness of this anode is matched. The matching is used in order to intercalate the same amount of lithium ions that is extracted from the $\mathrm{LiMn}_{2} \mathrm{O}_{4}$ layer upon charge and vice versa upon discharge. This resulted in the all-oxide full solid state stacks shown in figure 6:

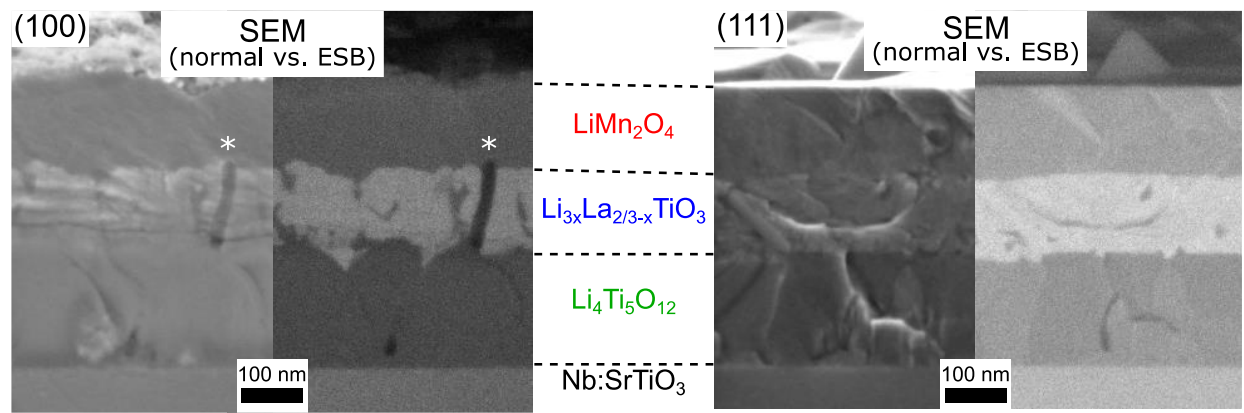

Figure 6, SEM images of All-Oxide Full Solid State Battery on (100)- (left) and (111)-

(right) oriented substrate consisting of the anode $\mathrm{Li}_{4} \mathrm{Ti}_{5} \mathrm{O}_{12}$, solid-state electrolyte $\mathrm{Li}_{3 x} \mathrm{La}_{2 / 3-x} \mathrm{TiO}_{3}$ and cathode $\mathrm{LiMn}_{2} \mathrm{O}_{4}$. 
In the SEM images, the secondary electron detector image (standard) is combined with the Energy Selective Backscattering (ESB) detector image, which shows contrast based on density / atomic mass differences of the materials. As the Lanthanum in the $\mathrm{Li}_{3 \mathrm{x}} \mathrm{La}_{2 / 3-\mathrm{x}} \mathrm{TiO}_{3}$ layer is a heavy element (similar to the Strontium in the $\mathrm{SrTiO}_{3}$ substrate) it results in a layer showing up brighter. For the (100)-oriented substrate, the first layer $\left(\mathrm{Li}_{4} \mathrm{Ti}_{5} \mathrm{O}_{12}\right)$ has a high surface area, as is common for spinel material on (100)-perovskite substrates due to the energetically favored facets of the spinel material grown on the perovskite substrate [18]. This might result in the large grains observed in the $\mathrm{Li}_{3 x} \mathrm{La}_{2 / 3-x} \mathrm{TiO}_{3}$ layer grown on top of it. The $\mathrm{Li}_{4} \mathrm{Ti}_{5} \mathrm{O}_{12}$ layer grown on the (111)-oriented substrates shows much lower surface roughness, as expected for a spinel material grown on a (111)-oriented perovskite substrate [18]. Furthermore, due to the energetically favored facet of the $\mathrm{Li}_{4} \mathrm{Ti}_{5} \mathrm{O}_{12}$-spinel material, consecutive layers can also have lower surface roughness. In the (100)-oriented stack of layers, a darker rod-like feature through the electrolyte layer can be observed. As it is darker than the anode or cathode layer in the ESB images, it is expected to be composed of light elements (such as Li. metal) connecting the cathode and anode. This could cause shorts between the anode and cathode, preventing electrochemical cycling of the full stack.

To structurally characterize the different layers, XRD is used. Again, clear peaks are visible from the substrate, together with the $\mathrm{LiMn}_{2} \mathrm{O}_{4}$ peaks, $\mathrm{Li}_{3 \mathrm{x}} \mathrm{La}_{2 / 3-\mathrm{x}} \mathrm{TiO}_{3}$ peaks and $\mathrm{Li}_{4} \mathrm{Ti}_{5} \mathrm{O}_{12}$ peaks. All three deposited layers take the orientation of the substrate and grow oriented in the same direction (figure 7). 


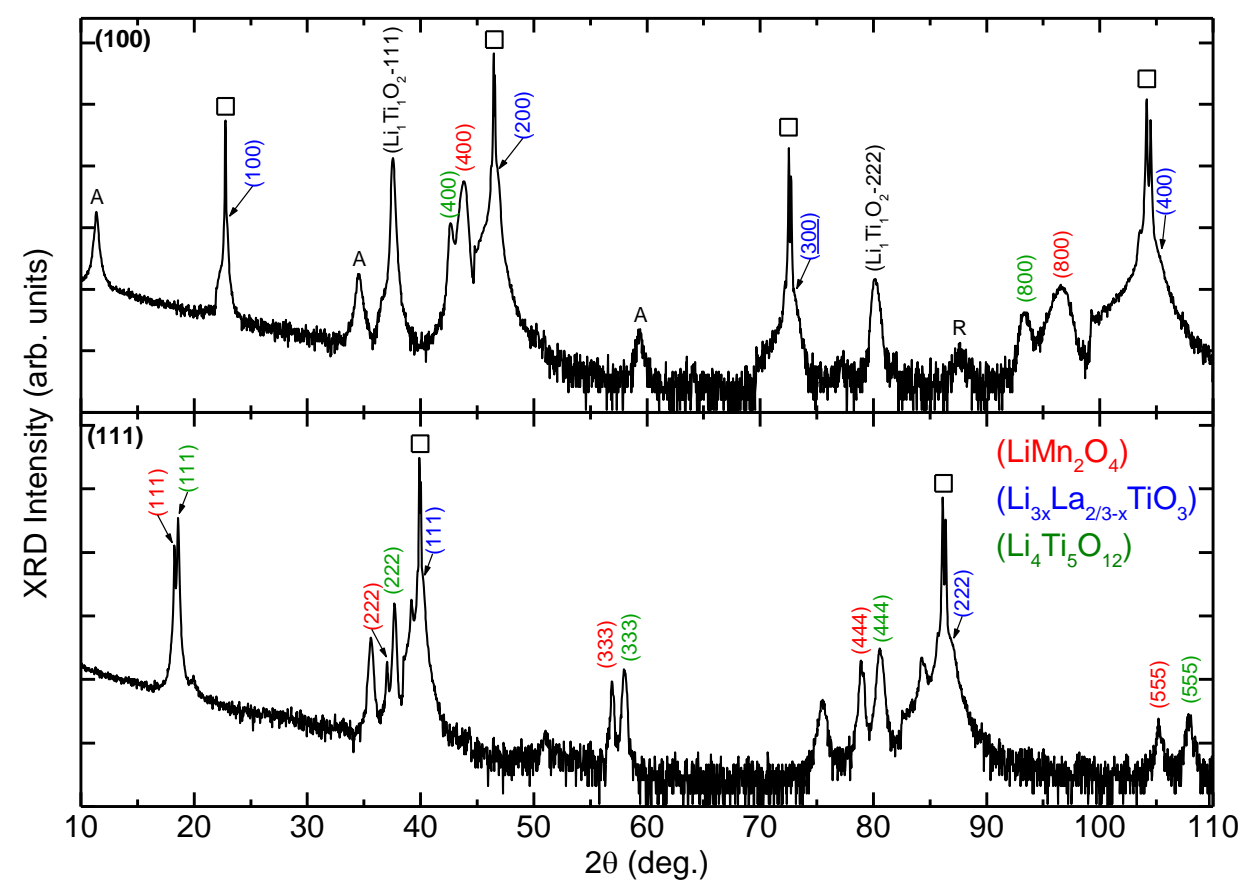

Figure 7, XRD of All-Oxide Full Solid State Battery on (100)- and (111)-oriented $\mathrm{Nb}: \mathrm{SrTiO}_{3}$ substrate consisting of the anode $\mathrm{Li}_{4} \mathrm{Ti}_{5} \mathrm{O}_{12}$, solid-state electrolyte $\mathrm{Li}_{3 x} \mathrm{La}_{2 / 3-x} \mathrm{TiO}_{3}$ and cathode $\mathrm{LiMn}_{2} \mathrm{O}_{4}$ marked in their respective color. Contributions by the $\mathrm{Nb}: \mathrm{SrTiO}_{3}$ substrate ( $\square$ ) and impurities anatase $\mathrm{TiO}_{x}(\mathrm{~A})$ and rutile $\mathrm{TiO}_{x}(\mathrm{R})$ are indicated.

Taking the peak-position of (400)- $\mathrm{Li}_{\mathrm{x}} \mathrm{Mn}_{2} \mathrm{O}_{4}$ to be $43.84^{\circ}$, results in a lattice parameter of about $8.26 \AA$, and therefore, based on [24], a lithium concentration estimated to be around 0. Based on our own measurements in chapter 5 (figure 5) the lithium concentration would be estimated to be $1\left(\mathrm{x}=1, \mathrm{Li}_{\mathrm{x}} \mathrm{Mn}_{2} \mathrm{O}_{4}\right)$ as the peak-position corresponds best to that of the pristine or $3.1 \mathrm{~V}$ (400)-orientation peak. This difference between bulk and thin film could be explained by strain from the substrate. Therefore, as the $\mathrm{Li}_{x} \mathrm{Mn}_{2} \mathrm{O}_{4}$ layer is the third of three relative thick layers, any strain induced by the substrate or through the layers below is 
expected to be negligible. The peak position, and thereby lithium concentration, is therefore more likely to coincide with that of bulk and thus 0 .

Comparing the $\mathrm{Li}_{3 x} \mathrm{La}_{2 / 3}-\mathrm{TiO}_{3}$ peak intensity here to that after synthesis on a $\mathrm{Nb}: \mathrm{SrTiO}_{3}$ substrate as shown in figure $3 \& 4$, the intensity has clearly dropped. From this it could be concluded that the $\mathrm{Li}_{3 x} \mathrm{La}_{2 / 3-x} \mathrm{TiO}_{3}$-layer is less crystalline than expected and therefore only a small shoulder with low intensity is visible next to the peaks of the (100)- and (111)oriented substrates. However, as the next layer $\left(\mathrm{Li}_{\mathrm{x}} \mathrm{Mn}_{2} \mathrm{O}_{4}\right)$ grown on top shows clear epitaxial crystallinity, it is more likely that a decrease in lithium concentration led to an increase in c-axis parameter as shown in figure $2 \mathrm{a}$ where the lattice parameter of $\mathrm{Li}_{3 \mathrm{x}} \mathrm{La}_{2 / 3-\mathrm{x}} \mathrm{TiO}_{3}$ versus lithium ratio is shown from [9]. A common suggestion would be to synthesize at a lower temperature so less lithium evaporation would take place. However, as seen in figure 3, this would reduce crystallinity. A higher pulse frequency of the PLD-laser would allow for less evaporation time for the lithium, possibly increasing its concentration, although faster deposition might also result in lower crystallinity. It is suggested to research this in a follow up study.

Additional peaks around $37^{\circ}$ and $80^{\circ}$ on the (100)-oriented substrate are observed, which are characterized as a $\mathrm{Li}_{1} \mathrm{Ti}_{1} \mathrm{O}_{2}$ phase. As the peaks of the $\mathrm{Li}_{1} \mathrm{Ti}_{1} \mathrm{O}_{2}$-phase are very strong it is expected that a large portion of the $\mathrm{Li}_{1} \mathrm{Ti}_{1} \mathrm{O}_{2}$-phase is synthesized at the cost of the $\mathrm{Li}_{3 \times} \mathrm{La}_{2 / 3-x} \mathrm{TiO}_{3}$-phase. However, looking at the stoichiometry of the target materials the Lanthanum must remain somewhere, but does not show up by XRD characterization.

Part of the presence of the $\mathrm{Li}_{1} \mathrm{Ti}_{1} \mathrm{O}_{2}$-phase in the $\mathrm{Li}_{3 \times} \mathrm{La}_{2 / 3-x} \mathrm{TiO}_{3}$-layer could be due to a change in its underlying layer. The template on which thin film growth will happen has changed as $\mathrm{Li}_{3 \times} \mathrm{La}_{2 / 3-\mathrm{x}} \mathrm{TiO}_{3}$ is grown on top of the synthesized $\mathrm{Li}_{4} \mathrm{Ti}_{5} \mathrm{O}_{12}$, instead of the 
$\mathrm{Nb}: \mathrm{SrTiO}_{3}$ substrate. The anode material $\mathrm{Li}_{1} \mathrm{Ti}_{1} \mathrm{O}_{2}$ is a good electronic but poor ionic conductor [25] and, therefore, severely hampers the effectiveness of the electrolyte layer.

Further investigation and synthesis optimizations to reduce the amount of this $\mathrm{Li}_{1} \mathrm{Ti}_{1} \mathrm{O}_{2}$ phase is critical. Reduction of the $\mathrm{TiO}_{\mathrm{x}}$-phases is advised as they can be lithiated to $\mathrm{Li}_{1} \mathrm{Ti}_{1} \mathrm{O}_{2}$ at low voltages of around $1.5 \mathrm{~V}$ [26].

While electrochemically characterizing the layers, clear resistance behavior is shown by an open-circuit-voltage of around $0 \mathrm{~V}$ and a current linearly increasing with the applied voltage. As the synthesized layers are extremely thin while the electrolyte is expected to be electronically isolating, a dark rod as seen in figure $6\left(^{*}\right)$ could lead to shorts. Furthermore, edge effects on the substrate can no longer be neglected. During synthesis also some deposition takes place on the edges of the substrate, when sufficiently thin, these can cause shorts as well. Also, due to off-stoichiometry of the electrolyte layer it might have high electronic conductivity. For $\mathrm{Li}_{3 x} \mathrm{La}_{2 / 3-x} \mathrm{TiO}_{3}$ it is observed it can become highly electronic conducting when too much lithium is inserted [2]. However, as synthesis is done through PLD, and lithium is very volatile, this higher amount of lithium compared to the target composition is very unlikely. It is more likely that the thin electrolyte layer suffers from shorts as well as edge effects that cause additional shorts. As the (111)-oriented layers showed no shorts, this sample had a part cut out from its middle with a diamond pen. This way, edges (with shorts) which developed during synthesis can no longer contribute and conduction along the edges can be dismissed. This improved the total resistivity of the layer, however subsequent cyclic voltammetry measurements still did not show battery behavior. Instead, its resistance around $0 \mathrm{~V}$ was still low with diode like behavior as the current sharply increases above $2 \mathrm{~V}$. 
Further research and optimization of the synthesis conditions is required to further investigate this all-oxide full solid state battery. The focus of future research is advised to be on both the interface between $\mathrm{Li}_{4} \mathrm{Ti}_{5} \mathrm{O}_{12}$ and $\mathrm{Li}_{3 \mathrm{x}} \mathrm{La}_{2 / 3-\mathrm{x}} \mathrm{TiO}_{3}$, as well as optimizing the growth conditions of $\mathrm{Li}_{3 \times} \mathrm{La}_{2 / 3}-\mathrm{XTiO}_{3}$ on $\mathrm{Li}_{4} \mathrm{Ti}_{5} \mathrm{O}_{12}$.

\subsection{Nanocomposites of $\mathrm{LiMn}_{2} \mathrm{O}_{4}$ and $\mathrm{Li}_{3 x} \mathrm{La}_{2 / 3-x} \mathrm{TiO}_{3}$}

The ability to synthesize a 3D structured battery allows enhanced surface area, as well as more control over this surface area, which enables the exploration of batteries with increased power densities. As the schematic in figure 8 shows, a 2D thick film allows for high specific energy densities due to high loading (high percentage of active material in the anode/cathode part) and relatively large thickness of the anode/cathode. A 2D thin film allows for relatively high power densities by using lower levels of loading (relatively lower amount of active material) and a relatively thin thickness enabling fast lithium transport to the electrolyte. A 3D structure allows use of both advantages, as it combines the large lithium loading with fast lithium transport.

As mentioned in chapter 5, volume expansion of the active anode/cathode material can cause cracking of the material, losing connection to the current collector [27, 28]. When the electrolyte is no longer a liquid but a solid, also loss of connection to the electrolyte can occur, causing an increasing interface resistance over cycling. When an epitaxial film is grown layer-by-layer, on a single crystalline substrate allowing alignment of the crystal orientations, reductions in the resistance to ionic diffusion within both the solid electrolyte and the electrode/solid electrolyte interface can be expected [1].

When a 3D architecture is used, the surface is further increased and the diffusion distance from within the electrode to and from the electrolyte is decreased allowing for faster lithium- 
ion exchange. Furthermore, thicker electrode layers are allowed without significant increase in internal resistance as now the electronic transport becomes limiting, which is much faster than the ionic transport [28]. This also allows for higher loadings, both of which contribute to an increase in both specific power and energy density [28] (figure 8).

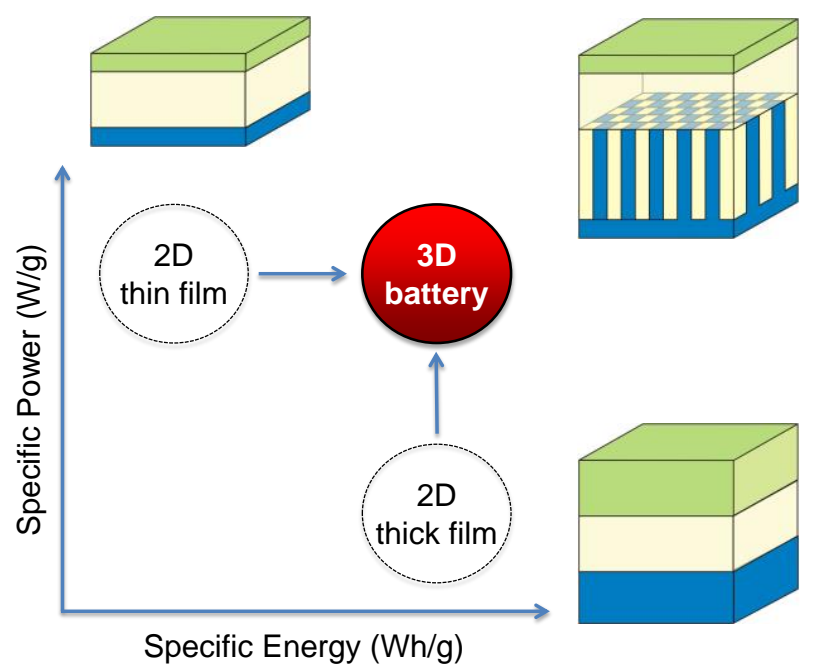

Figure 8, Schematic of battery architectures for high specific energy density (2D thick film), high specific power density (2D thin film), and both high specific power and energy density through $3 D$ architecture.

Previous studies on nanocomposites by $\mathrm{H}$. Zheng et al. suggest that the combination of a perovskite material with a spinel material will result in phase separation of the two materials during PLD growth $[17,18]$. This phase separation, combined with alignment of the nanocomposite, results in so-called Vertically Aligned Nanocomposites (VANs).

Although various epitaxial VANs have been studied in the last decade [29, 30], no lithiumbased VANs have yet been explored for energy storage. Realization of two-phase epitaxial VANs has been limited to specific material combinations such as ferroelectrics $\left(\mathrm{BaTiO}_{3}\right.$, 
$\left.\mathrm{BiFeO}_{3}, \mathrm{PbTiO}_{3}\right)$ with ferromagnets $\left(\mathrm{CoFe}_{2} \mathrm{O}_{4}, \mathrm{NiFe}_{2} \mathrm{O}_{4}, \mathrm{MgFe}_{2} \mathrm{O}_{4}\right)$. Within these systems, studies on the ionic conductivity have been limited to that of oxygen ions for solid oxide fuel cells [31] and not lithium. Understanding diffusion of lithium ions in an epitaxial VAN during intercalation, across an epitaxial interface between an electrode and an electrolyte in a solid-state battery, is crucial but has so far remained unexplored.

Several growth mechanisms for the formation of epitaxial two-phase nanocomposites have been proposed in previous studies that lead to different morphologies, such as nanopillars in a matrix, two-phase domain structures, and nanocheckerboard structures [32]. Thermodynamics and kinetics during the thin film growth are the two major factors for the final film morphology, although the exact influence of these two parameters on the overall nanocomposite structure remains complicated to model [30]. In the publications of $\mathrm{H}$. Zheng et al. nanocomposite self-assembly was demonstrated for magnetic and ferroelectric materials, allowing the ability to synthesize a 3D material during PLD [17, 18]. Furthermore, thermodynamics and kinetics can easily be influenced during PLD through parameters as substrate temperature, (oxygen) background pressure, target composition and laser fluence.

This allows creation of a material with a 3D architecture exhibiting extremely high surface area with respect to the cathode and/or anode through self-assembly. Previous research has focused mainly on achieving a 3D architecture through, for example, (cleanroom) selective etching of substrates [28]. Where the 3D architecture might exhibit high surface area and thus allow for high power density, depositing the 3D architecture on a large bulk of the active material (cathode / anode) might not only increase the specific power density, but also the specific energy density of the cell relative to a flat 2D film.

H. Zheng et al. explains this self-assembly through the differences in diffusion energy of the materials with respect to the substrate, much like the nucleation and growth mechanism 
described in [32]. During growth, the species at the film surface phase-separate into the nanostructure, which is then part of the bulk film. They demonstrate this by means of the cubic spinel $\mathrm{CoFe}_{2} \mathrm{O}_{4}$ and perovskite $\mathrm{BiFeO}_{3}$. The $\mathrm{CoFe}_{2} \mathrm{O}_{4}$ material (CFO) is a cubic spinel oxide with a lowest energy surface of $\{111\}$. During growth on a (001)- $\mathrm{SrTiO}_{3}$ substrate the CFO only partially wets the substrate and forms islands with $\{111\}$ facets. In figure 9 A1 this can be seen as the tip of the octahedron passing through the (001)-oriented substrate surface. $\mathrm{BiFeO}_{3}$ (BFO) is a perovskite that completely wets a (001)-oriented $\mathrm{SrTiO}_{3}$ substrate and grows layer-by-layer, shown in figure 9 A1 as a flat surface on top of the (001) oriented substrate.

a

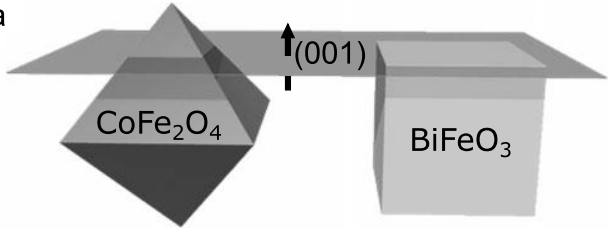

b

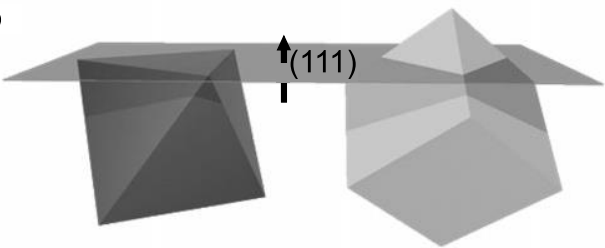

C d

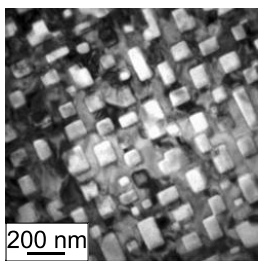

e

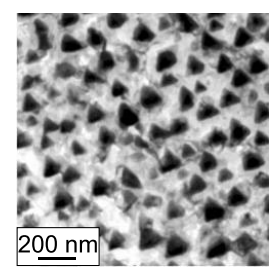

f

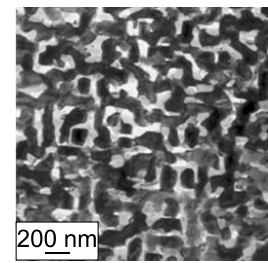
$200 \mathrm{~nm}-\mathrm{d}=\mathrm{y}$

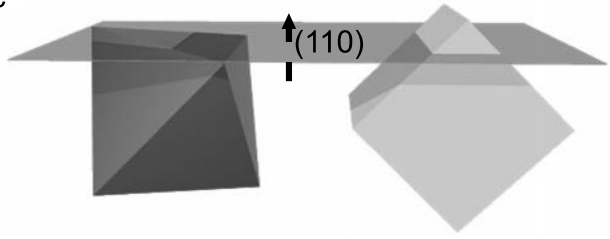

Figure 9, Schematic representation of $\mathrm{CoFe}_{2} \mathrm{O}_{4}$-spinel (dark grey) and $\mathrm{BiFeO}_{3}$-perovskite (light grey) growing on a perovskite substrate in a) (100)-, b) (111)-, and c) (110)orientation. d-f) SEM images of the grown nanocomposites. a-f) adapted from [21]. 
Due to the surface energies, for a (111)-oriented $\mathrm{SrTiO}_{3}$ substrate (figure $9 \mathrm{~b}$ ), this results in complete wetting of the substrate by the cubic spinel CFO while the BFO perovskite will only partially wet the substrate and cause pyramidal nanostructures / nanopillars to grow inside the CFO matrix. As for the (110)-oriented substrate, the difference between the surface energies is less clear, phase separation occurs due to the immiscibility of the materials but a clear matrix / nanopillar composite cannot be shown.

a)

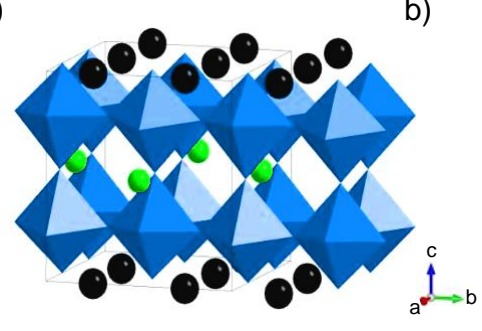

$\mathrm{Li}_{3 x} \mathrm{La}_{2 / 3-\mathrm{x}} \mathrm{TiO}_{3}$ b)

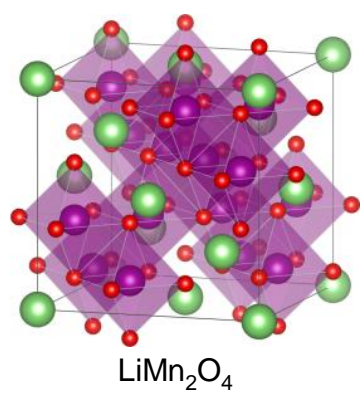

Figure 10, Crystal structures of, a), $\mathrm{Li}_{3 x} \mathrm{La}_{2 / 3-x} \mathrm{TiO}_{3}$-perovskite and, b), $\mathrm{LiMn}_{2} \mathrm{O}_{4}$-spinel.

$\mathrm{Li}_{3 \times} \mathrm{La}_{2 / 3-x} \mathrm{TiO}_{3}$ is a perovskite (figure 10a) that can be grown in very flat layers during deposition on a perovskite substrate, while $\mathrm{LiMn}_{2} \mathrm{O}_{4}$ is a cubic spinel (figure 10b) that during growth on the (001) oriented substrate forms islands with $\{111\}$ facets (chapter 2$)$.

Therefore, when $\mathrm{CoFe}_{2} \mathrm{O}_{4}$ is substituted for $\mathrm{LiMn}_{2} \mathrm{O}_{4}$ and $\mathrm{BiFeO}_{3}$ for $\mathrm{Li}_{3 \times} \mathrm{La}_{2 / 3}-\mathrm{TiO} \mathrm{TiO}_{3}$, a nanocomposite is obtained of the used cathode and electrolyte material with a 3D architecture achieved through self-assembly. Due to the epitaxial nature of the materials $\mathrm{LiMn}_{2} \mathrm{O}_{4}$ and $\mathrm{Li}_{3 x} \mathrm{La}_{2 / 3-\mathrm{x}} \mathrm{TiO}_{3}$ on $\mathrm{Nb}: \mathrm{SrTiO}_{3}$ substrates, it allows further control over the interfaces, size, and composition of the nanocomposites. On top of that, the PLD parameters allow further control over the thermodynamics and kinetics during growth. 
The $\mathrm{LiMn}_{2} \mathrm{O}_{4}-\mathrm{Li}_{3 \mathrm{x}} \mathrm{La}_{2 / 3-\mathrm{x}} \mathrm{TiO}_{3}$ thin films were grown by pulsed laser deposition (PLD) at a temperature of $750{ }^{\circ} \mathrm{C}$ on $\mathrm{Nb}$-doped $(0.5 \mathrm{wt} \%)$ single crystalline $\mathrm{SrTiO}_{3}(100,110$ or 111$)$ substrates from sintered $\mathrm{LiMn}_{2} \mathrm{O}_{4}-\mathrm{Li}_{0.5} \mathrm{La}_{0.5} \mathrm{TiO}_{3}(1: 2)$, using a $\mathrm{KrF}$ excimer laser operating at $248 \mathrm{~nm}$ at a repetition rate of $2 \mathrm{~Hz}$. The $\mathrm{Nb}-\mathrm{SrTiO}_{3}$ substrates were annealed at $950{ }^{\circ} \mathrm{C}$ for $1.5 \mathrm{~h}$ in an oxygen flow of $150 \mathrm{ml} / \mathrm{min}$. The oxygen pressure during growth was $0.2 \mathrm{mbar}$ (20 Pa), while the laser energy fluence was $2.3 \mathrm{~J} \mathrm{~cm}^{-2}$. After deposition, the thin films were cooled down to room temperature in an oxygen pressure of 1 bar at a rate of $10{ }^{\circ} \mathrm{C} \mathrm{min}^{-1}$.

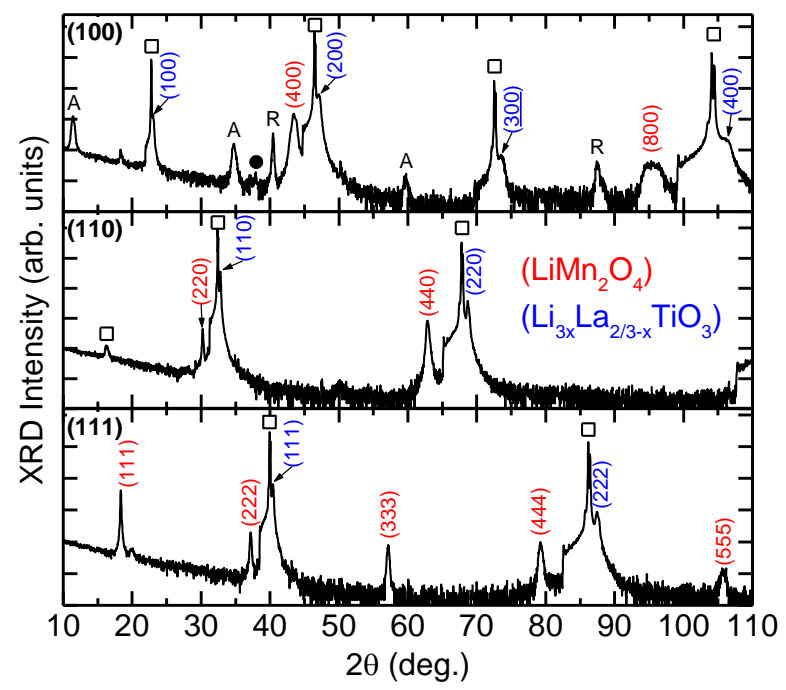

Figure 11, Crystal structures of $\mathrm{Li}_{3 x} \mathrm{La}_{2 / 3-x} \mathrm{TiO}_{3}$-perovskite (blue) and $\mathrm{LiMn}_{2} \mathrm{O}_{4}$-spinel (red) nanocomposites grown on $\mathrm{Nb}: \mathrm{SrTiO}_{3}$-perovskite in orientations (100), (110) and (111). Contributions by the $\mathrm{Nb}: \mathrm{SrTiO}_{3}$ substrate ( $\square$ ) and impurities $\mathrm{Mn}_{2} \mathrm{O}_{3}(\bullet)$, anatase $\mathrm{TiO}_{x}(\mathrm{~A})$ and rutile $\mathrm{TiO}_{x}(\mathrm{R})$ are indicated.

XRD characterization indicates that both the $\mathrm{LiMn}_{2} \mathrm{O}_{4}$ and $\mathrm{Li}_{3 \times} \mathrm{La}_{2 / 3-x} \mathrm{TiO}_{3}$ phases are stabilized within the nanocomposite thin film and epitaxially aligned to the substrate orientation (figure 11). This indicates that the self-assembly that takes place for the 
nanocomposite $\mathrm{CoFe}_{2} \mathrm{O}_{4}-\mathrm{BiFeO}_{3}$ also takes place for the $\mathrm{LiMn}_{2} \mathrm{O}_{4}-\mathrm{Li}_{3 \mathrm{x}} \mathrm{La}_{2 / 3-\mathrm{x}} \mathrm{TiO}_{3}$ combination. Interestingly, the self-assembly seems to stabilize the $\mathrm{LiMn}_{2} \mathrm{O}_{4}$ at high temperatures, normally not achievable (chapter 2). Epitaxial strain from the perovskite matrix could have induced the formation of spinel nanopillars. As far as the author knows this is the first observation of a lithium-based epitaxial VAN and allows the construction of 3D battery architecture as proposed and shown in figure 8 .

Various additional peaks are observed for the (100)-oriented substrate that correspond to the inhomogeneities as observed in figure 4. These are linked to $\mathrm{TiO}_{\mathrm{x}}$-phases and $\mathrm{Mn}_{2} \mathrm{O}_{3}$ which could indicate that the stoichiometry of both $\mathrm{Li}_{3 \mathrm{x}} \mathrm{La}_{2 / 3-\mathrm{x}} \mathrm{TiO}_{3}$ and $\mathrm{LiMn}_{2} \mathrm{O}_{4}$ cannot be maintained during deposition and impurities occur due to lithium deficiency.

Using SEM to image the synthesized material (figure 12), surfaces similar to previous studies on non-lithium nanocomposites are visible [17, 18]. For the (100)-oriented substrate rectangular domains are visible on the surface, while for the (111)-orientation triangular domains are visible similar to those shown in figure 9. For the (110)-oriented substrate, however, the surface looks like a matrix of one material, with another material growing elongated domains with have a rooftop-like surface. It is expected that the matrix of these nanocomposites is formed by the $\mathrm{Li}_{3 x} \mathrm{La}_{2 / 3-\mathrm{x}} \mathrm{TiO}_{3}$ and perovskite on perovskite growth occurs with the $\mathrm{LiMn}_{2} \mathrm{O}_{4}$-spinel forming the columns inside this matrix. 

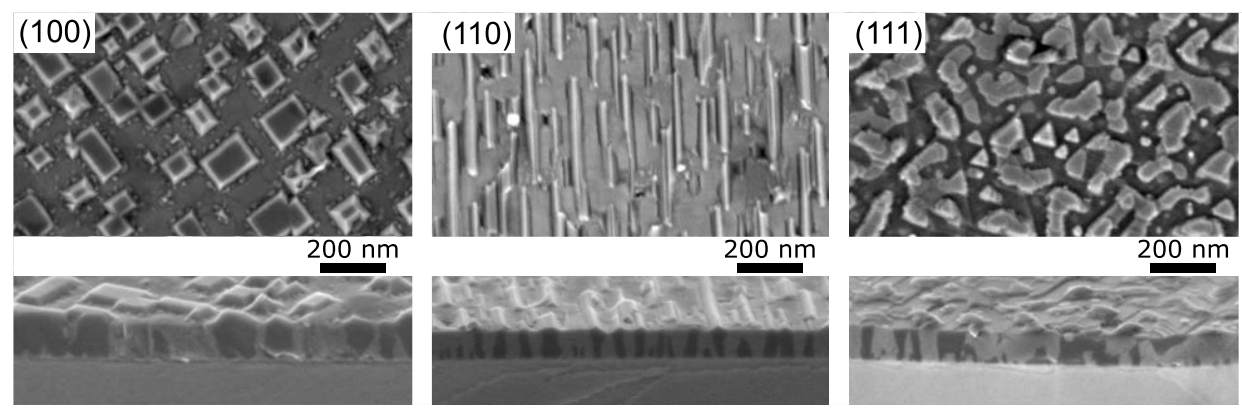

Figure 12, SEM image of the nanocomposites grown by simultaneous deposition of $\mathrm{LiMn}_{2} \mathrm{O}_{4}$-spinel and $\mathrm{Li}_{3 x} \mathrm{La}_{2 / 3-x} \mathrm{TiO}_{3}$-perovskite on perovskite $\mathrm{Nb}: \mathrm{SrTiO}_{3}$ at $750{ }^{\circ} \mathrm{C}$.

Bottom images show cross-section views by the Energy Selective Backscatter detector.

By using an Energy Selective Backscatter (ESB) detector, as opposed to the normal secondary electron detector, contrast based on atomic weight and therefore composition can be obtained. For the $\mathrm{LiMn}_{2} \mathrm{O}_{4}-\mathrm{Li}_{3 x} \mathrm{La}_{2 / 3-\mathrm{x}} \mathrm{TiO}_{3}$ nanocomposite, the atomic weight difference between $\mathrm{Mn}$ and $\mathrm{Ti}$ is low compared to $\mathrm{La}$, most contrast is therefore expected from the difference between Mn and La. Looking at the cross-sections in figure 12, good contrast can be seen between the columns and the matrix. Furthermore, contrast between $\mathrm{LiMn}_{2} \mathrm{O}_{4}$ and the $\mathrm{Nb}: \mathrm{SrTiO}_{3}$ substrate is clear due to the heavy $\mathrm{Sr}$ inside the substrate. As there is clear contrast between the columns and the substrate, it can be concluded that the columns are of the $\mathrm{LiMn}_{2} \mathrm{O}_{4}$-spinel material while the host is the $\mathrm{Li}_{3 \mathrm{x}} \mathrm{La}_{2 / 3-\mathrm{x}} \mathrm{TiO}_{3}$-perovskite grown on the perovskite $\mathrm{Nb}: \mathrm{SrTiO}_{3}$ substrate for the orientations (100), (110) and (111). This suggests a battery material with 3D architecture through self-assembly can be realized.

To characterize the electrochemical behavior of the battery material Charge-Discharge and Cyclic Voltammetry measurements are performed. Cyclic Voltammetry is performed at 1 $\mathrm{mV} / \mathrm{sec}$ between $4.8 \mathrm{~V}$ and 3.3 V. During Charge - Discharge a current of $5 \mu \mathrm{A}$ is used to 
charge to $4.6 \mathrm{~V}$ and discharge to $3 \mathrm{~V}$. This allows to characterize the electrochemical behavior expected to occur around the $4 \mathrm{~V}$ plateaus of $\mathrm{LiMn}_{2} \mathrm{O}_{4}$.

Samples are assembled as mentioned in Chapter 2's Cell assembly, where the substrate functions as current collector for the thin film cathode material. A separator soaked with 600 $\mu \mathrm{L}, 1 \mathrm{M} \mathrm{LiPF} 6$ in EC:DMC 1:1, electrolyte is inserted to prevent the protruding $\mathrm{LiMn}_{2} \mathrm{O}_{4}$ columns from the nanocomposite to contact the Li metal anode. Performed charge discharge cycles are shown in figure 13. Specific capacity for the $\mathrm{LiMn}_{2} \mathrm{O}_{4}$ cathode material inside the nanocomposite $\left(\mathrm{mAh} / \mathrm{g}_{\mathrm{LMO}}\right)$ is estimated based on the ratio between the two materials $\left(\mathrm{LiMn}_{2} \mathrm{O}_{4}-\mathrm{Li}_{0.5} \mathrm{La}_{0.5} \mathrm{TiO}_{3}(1: 2)\right)$ and a layer thickness estimated by cross-section SEM to be around a $100 \mathrm{~nm}$.
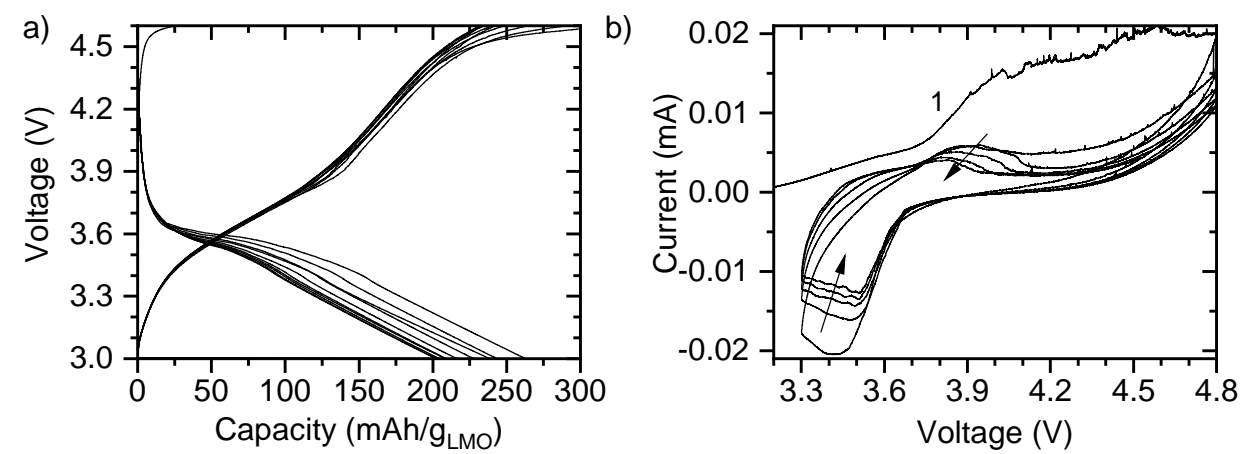

Figure 13, a) Charge - Discharge cycles, and, b), Cyclic Voltammetry of the $\mathrm{LiMn}_{2} \mathrm{O}_{4}-$ $\mathrm{Li}_{3 x} \mathrm{La}_{2 / 3-x} \mathrm{TiO}_{3}$ nanocomposite. The first cycle (1) is indicated, as well as the direction and height of the peaks (arrows) upon consecutive cycling.

In figure 13 the characteristic peaks and plateaus for $\mathrm{LiMn}_{2} \mathrm{O}_{4}$ are not clearly visible. During cyclic voltammetry a semi-reversible redox reaction is taking place around $3.6 \mathrm{~V}$. Furthermore, during the charge - discharge, there is a large specific capacity of over 200 $\mathrm{mAh} / \mathrm{g}_{\text {гмо }}$ of the layer when discharging between 4.6 and $3.0 \mathrm{~V}$ which is much larger than 
the theoretical $148 \mathrm{mAh} / \mathrm{g}_{\mathrm{Lmo}}$ that could be expected in this voltage range. As deposition is done at elevated temperatures $\left(750{ }^{\circ} \mathrm{C}\right)$, allowing to achieve the phase separation needed to obtain self-assembly, it might be possible for Ti to replace $\mathrm{Mn}$ in the $\mathrm{LiMn}_{2} \mathrm{O}_{4}$-spinel leading to the structurally similar $\mathrm{LiMn}_{2-\mathrm{x}} \mathrm{Ti}_{\mathrm{x}} \mathrm{O}_{4}$ [33]. These higher temperatures might explain the intermixing of $\mathrm{Ti}$ into the $\mathrm{LiMn}_{2} \mathrm{O}_{4}$ which is later confirmed by TEM electron energy loss spectroscopy (EELS) (figure 14). From the $\mathrm{LiMn}_{2} \mathrm{O}_{4}$ depositions (chapter 2) it is known that $600{ }^{\circ} \mathrm{C}$ is the optimal synthesis condition and from literature it is known that $\mathrm{LiMn}_{2} \mathrm{O}_{4}$ undergoes interfacial reactions at higher temperatures [1].

As the amount of cathode material could be enriched due to Ti insertion, this could contribute to a higher capacity compared to the capacity estimated from Mn alone [33]. However, the capacity is much larger than anticipated and possible intermixing of Ti into the $\mathrm{LiMn}_{2} \mathrm{O}_{4}$ spinel would not contribute to a voltage plateau or voltage peaks at $3.6 \mathrm{~V}$.

To further investigate the intermixing and the interface between $\mathrm{SrRuO}_{3}$ and $\mathrm{LiMn}_{2} \mathrm{O}_{4}, \mathrm{TEM}$ combined with EELS is used (figure 14). Energy loss analysis by TEM-EELS shows a Ti signal throughout the spectrum image. As oxygen shows negligible change and manganese shows a clear drop while lanthanum steeply increases during $\mathrm{Li}_{3 \mathrm{x}} \mathrm{La}_{2 / 3-\mathrm{x}} \mathrm{TiO}_{3}$, it is concluded that $\mathrm{Ti}$ has indeed intermixed with $\mathrm{LiMn}_{2} \mathrm{O}_{4}$-spinel to form $\mathrm{LiMn}_{2-\mathrm{x}} \mathrm{Ti}_{\mathrm{x}} \mathrm{O}_{4}$.

Figure 15 shows TEM along the (110) direction of $\mathrm{LiMn}_{2} \mathrm{O}_{4}$. Clear positions for the different atoms of $\mathrm{LiMn}_{2} \mathrm{O}_{4}$ are visible and made clear through the inset in 15a. As a guide the crystal structure of $\mathrm{LiMn}_{2} \mathrm{O}_{4}$ is added in $15 \mathrm{~b}$ showing both the full crystal unit cell as well as viewed along the (110)-direction. From figure $15 \mathrm{c}$ it became apparent that a $\mathrm{Li}_{3 \mathrm{x}} \mathrm{La}_{2 / 3-\mathrm{x}} \mathrm{TiO}_{3}$ layer of a few unit cells thick resides between the current collector layer and $\mathrm{LiMn}_{2-\mathrm{x}} \mathrm{Ti}_{\mathrm{x}} \mathrm{O}_{4}$ cathode crystal. 


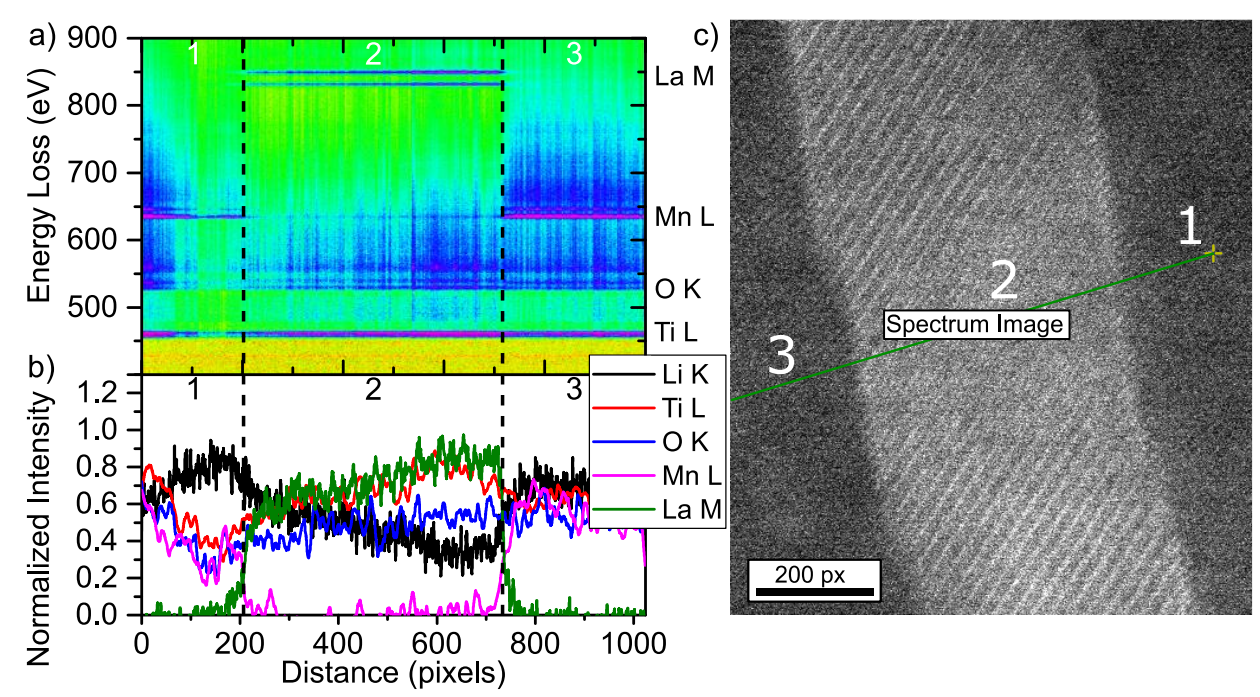

Figure 14, TEM electron energy loss spectroscopy on the nanocomposite of $\mathrm{LiMn}_{2} \mathrm{O}_{4}$-spinel and $\mathrm{Li}_{3 x} \mathrm{La}_{2 / 3-x} \mathrm{TiO}_{3}$-perovskite on $\mathrm{Nb}$ :SrTiO-perovskite substrate. a) Energy loss intensity over de line drawn in c) going from a $\mathrm{LiMn}_{2} \mathrm{O}_{4}$ column (1) through the $\mathrm{Li}_{3 x} \mathrm{La}_{2 / 3-x} \mathrm{TiO}_{3}$ matrix (2) towards another $\mathrm{LiMn}_{2} \mathrm{O}_{4}$ column (3). Corresponding element energy losses are indicated. b) Normalized intensity of the elements of a) showing composition change over the line drawn in c).

a)

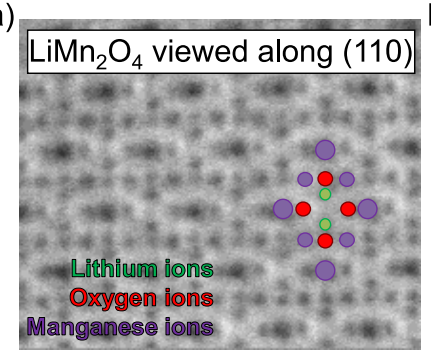

b)

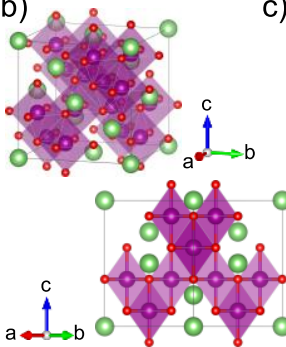

c)

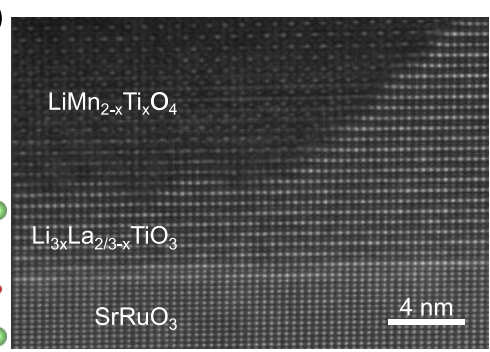

Figure 15, a) TEM along the (110)-direction of $\mathrm{LiMn}_{2} \mathrm{O}_{4}$. b) Crystal structure of $\mathrm{LiMn}_{2} \mathrm{O}_{4}$ and along the (110)-direction. c) Cross-section TEM of (100)-oriented nanocomposite showing $\mathrm{Li}_{3 x} \mathrm{La}_{2 / 3-x} \mathrm{TiO}_{3}$ under $\mathrm{LiMn}_{2-x} \mathrm{Ti}_{x} \mathrm{O}_{4}$ and covering the $\mathrm{SrRuO} \mathrm{O}_{3}$ current collector. 
From Suzuki et al. $[34,35]$ it is known that the interface between the $\mathrm{LiMn}_{2} \mathrm{O}_{4}$ and the current collector is crucial to a good performance of the $\mathrm{LiMn}_{2} \mathrm{O}_{4}$ cathode. This could explain the absence of $\mathrm{LiMn}_{2} \mathrm{O}_{4}$ plateaus; since $\mathrm{Li}_{3 \mathrm{x}} \mathrm{La}_{2 / 3-\mathrm{x}} \mathrm{TiO}_{3}$ should be an electronic isolator, the $\mathrm{LiMn}_{2-\mathrm{x}} \mathrm{Ti}_{\mathrm{x}} \mathrm{O}_{4}$ might be fully isolated from the current collector and, therefore, does not participate in the electrochemistry.

To exclude external contributions, electrochemical measurements on a bare substrate are performed where the substrate functions as current collector and "cathode" material. A separator soaked with $600 \mu \mathrm{L}, 1 \mathrm{M} \mathrm{LiPF}_{6}$ in $\mathrm{EC}: \mathrm{DMC} 1: 1$, electrolyte is inserted to prevent the substrate from contacting the Li metal anode. Performed charge - discharge cycles are shown in figure 16.

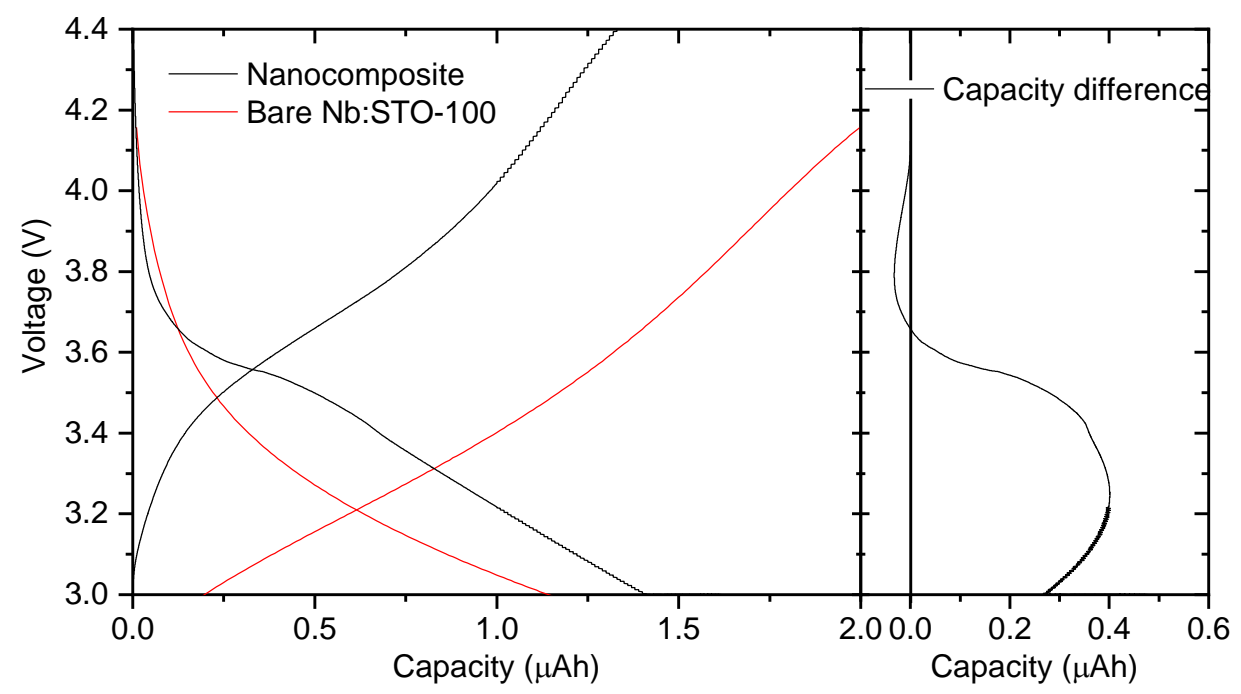

Figure 16, Charge - Discharge of the nanocomposite thin film compared to that of a $\mathrm{Nb}: \mathrm{SrTiO}_{3}$ substrate without thin films. Difference in discharge capacity is shown separately. 
During charge - discharge (figure 16) it can be observed that external contributions add to the measured capacity. However, these do not explain the small plateau around $3.6 \mathrm{~V}$ as visible through the capacity difference graph.

As TEM shows there is Ti present in the Mn-spinel, it is concluded that, even though phaseseparation takes place, intermixing also occurs. This hinders the formation of 'pure' $\mathrm{LiMn}_{2} \mathrm{O}_{4}$ and instead presents a structurally, almost identical material: $\mathrm{LiMn}_{2-\mathrm{x}} \mathrm{Ti}_{\mathrm{x}} \mathrm{O}_{4}$. This material has a lower potential and does not have a clear plateau in the measured voltage region $[19,36]$.

As $\mathrm{LiMn}_{2-\mathrm{x}} \mathrm{Ti}_{\mathrm{x}} \mathrm{O}_{4}$ does not suffer from Jahn-Teller distortion and can have high capacities (up to $290 \mathrm{mAh} / \mathrm{g}$ ) it is an interesting material [36]. Furthermore, it is surrounded by electrolyte, allowing for high-speed electrochemistry, allowing the high specific power and energy densities which are the aim of this nanocomposite. However, a high internal resistance seems to hinder good electrochemical performance. The $\mathrm{Li}_{3 x} \mathrm{La}_{2 / 3-x} \mathrm{TiO}_{3}$ layer beneath the $\mathrm{LiMn}_{2-\mathrm{x}} \mathrm{Ti}_{\mathrm{x}} \mathrm{O}_{4}$ has to be removed to avoid the high resistivity currently observed. It is advised to modify the template on which the nanocomposite is grown, either by surface modification of the $\mathrm{Nb}: \mathrm{SrTiO}_{3}$ substrate or by growing a thin layer of the cathode $\mathrm{LiMn}_{2} \mathrm{O}_{4}$ before the nanocomposite. This will prevent growth of $\mathrm{Li}_{3 x} \mathrm{La}_{2 / 3-x} \mathrm{TiO}_{3}$ underneath the cathode and will allow high-speed electrochemistry.

\subsection{Conclusions}

The solid state electrolyte $\mathrm{Li}_{3 x} \mathrm{La}_{2 / 3-x} \mathrm{TiO}_{3}$ showed the best structural crystallinity when synthesis was done at $800{ }^{\circ} \mathrm{C}$, with a stoichiometry estimated to be $x=0.13$. For synthesis at $700{ }^{\circ} \mathrm{C}$ clear crystalline peaks remained absent. Synthesis on oriented $\mathrm{Nb}: \mathrm{SrTiO}_{3}$ substrates ((100), (110) \& (111)) results in thin films with identical orientation, all of which contain $\mathrm{TiO}_{\mathrm{x}}$ phases as impurity. These $\mathrm{TiO}_{\mathrm{x}}$ phases are most likely due to lithium 


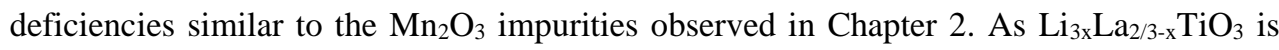
expected to grow relative flat layers, the observed cubic / rectangular domains on the surface are attributed to the $\mathrm{TiO}_{\mathrm{x}}$ phases.

Due to temperature restriction of $\mathrm{LiMn}_{2} \mathrm{O}_{4}$ to $600{ }^{\circ} \mathrm{C}$, stacks of all-oxide full solid-state batteries were synthesized by starting with the anode material $\mathrm{Li}_{4} \mathrm{Ti}_{5} \mathrm{O}_{12}$, followed by the solid electrolyte $\mathrm{Li}_{3 x} \mathrm{La}_{2 / 3-x} \mathrm{TiO}_{3}$, and finalized by the cathode $\mathrm{LiMn}_{2} \mathrm{O}_{4}$, where the thickness of the anode is matched to intercalate the same amount of lithium ions as the cathode. XRD shows all three deposited layers take the orientation of the substrate. $\mathrm{Li}_{3 x} \mathrm{La}_{2 / 3-\mathrm{x}} \mathrm{TiO}_{3}$ is less crystalline due to lithium loss and growth on top of the anode, instead of the $\mathrm{Nd}: \mathrm{SrTiO}_{3}$ substrate, causing $\mathrm{Li}_{1} \mathrm{Ti}_{1} \mathrm{O}_{2}$ formation at the cost of $\mathrm{Li}_{3 \mathrm{x}} \mathrm{La}_{2 / 3-\mathrm{x}} \mathrm{TiO}_{3}$. This $\mathrm{Li}_{1} \mathrm{Ti}_{1} \mathrm{O}_{2}$ could also cause shorts and thereby the ohmic behavior observed in electrochemical analysis. Further research and electrochemical characterization of the all-oxide full solid-state battery requires the quality of the $\mathrm{Li}_{3 x} \mathrm{La}_{2 / 3-x} \mathrm{TiO}_{3}$ electrolyte layer to be improved.

A 3D architecture nanocomposite was made by synthesis of $\mathrm{LiMn}_{2} \mathrm{O}_{4}$-cathode simultaneously with $\mathrm{Li}_{3 x} \mathrm{La}_{2 / 3-x} \mathrm{TiO}_{3}$-electrolyte. This is a first lithium based vertically aligned nanocomposite for energy storage application. As observed by SEM and confirmed by XRD, a self-assembled vertically aligned nanocomposite was formed aligned to the $\mathrm{Nb}: \mathrm{SrTiO}_{3}$ substrate with increased surface area between the two materials. XRD, furthermore, shows that again the materials take the orientation of the substrate.

Upon charge - discharge cycling and cycling voltammetry, the characteristic peaks of $\mathrm{LiMn}_{2} \mathrm{O}_{4}$ cannot be found. Instead, a plateau / semi-reversible redox peak is observed around 3.6 V. TEM-EELS confirms the intermixing of Ti into $\mathrm{LiMn}_{2} \mathrm{O}_{4}$ giving rise to $\mathrm{LiMn}_{2-\mathrm{x}} \mathrm{Ti}_{\mathrm{x}} \mathrm{O}_{4}$ in accordance to interfacial reactions shown in literature to occur at the elevated temperatures used to synthesize the nanocomposite. Furthermore, large internal resistances 
found during charge - discharge cycling are explained by TEM showing a few unit cells of $\mathrm{Li}_{3 \mathrm{x}} \mathrm{La}_{2 / 3-\mathrm{x}} \mathrm{TiO}_{3}$-electrolyte underneath the $\mathrm{LiMn}_{2-\mathrm{x}} \mathrm{Ti}_{\mathrm{x}} \mathrm{O}_{4}$ cathode, hindering the cathode from connecting to the current collector.

A large contribution in the measured capacity of the nanocomposite is from the substrate. However, when the substrate contribution is subtracted, an unexplained plateau around 3.6 V remains which cannot be attributed to the formed $\mathrm{LiMn}_{2-\mathrm{x}} \mathrm{Ti}_{\mathrm{x}} \mathrm{O}_{4}$-phase.

When the template on which the nanocomposite is grown is modified, either by surface modification of the $\mathrm{Nb}: \mathrm{SrTiO}_{3}$ substrate or by growing a thin layer of the cathode $\mathrm{LiMn}_{2} \mathrm{O}_{4}$ before the nanocomposite, it will possibly prevent growth of $\mathrm{Li}_{3 x} \mathrm{La}_{2 / 3-\mathrm{x}} \mathrm{TiO}_{3}$-electrolyte underneath the cathode and will allow high-speed electrochemistry. When this is further combined with the ability to also cycle the $3 \mathrm{~V}$ plateau of $\mathrm{LiMn}_{2} \mathrm{O}_{4}$ as shown in chapter 5 it will allow for model epitaxial ceramic battery systems with both higher energy and power density. 


\subsection{References}

[1] S. Kim, M. Hirayama, K. Suzuki, and R. Kanno, "Hetero-epitaxial growth of $\mathrm{Li}_{0.17} \mathrm{La}_{0.61} \mathrm{TiO}_{3}$ solid electrolyte on $\mathrm{LiMn}_{2} \mathrm{O}_{4}$ electrode for all solid-state batteries," Solid State Ionics, vol. 262, pp. 578-581, 2014, DOI: 10.1016/j.ssi.2013.09.040.

[2] C. H. Chen and K. Amine, "Ionic conductivity, lithium insertion and extraction of lanthanum lithium titanate," Solid State Ionics, vol. 144, no. 1-2, pp. 51-57, 2001, DOI: 10.1016/S0167-2738(01)00884-0.

[3] J. N. Mrgudich, "Conductivity of Silver Iodide Pellets for Solid-Electrolyte Batteries," J. Electrochem. Soc., vol. 107, no. 6, p. 475, 1960, DOI: 10.1149/1.2427726.

[4] Z. Zheng, H. -z. Fang, Z. -k. Liu, and Y. Wang, "A Fundamental Stability Study for Amorphous $\mathrm{LiLaTiO}_{3}$ Solid Electrolyte,” J. Electrochem. Soc., vol. 162, no. 1, pp. A244-A248, 2014, DOI: 10.1149/2.0011503jes.

[5] N. Kamaya, K. Homma, Y. Yamakawa, M. Hirayama, R. Kanno, M. Yonemura, T. Kamiyama, Y. Kato, S. Hama, K. Kawamoto, and A. Mitsui, "A lithium superionic conductor,” Nat. Mater., vol. 10, no. 9, pp. 682-686, 2011, DOI: 10.1038/nmat3066.

[6] F. Aguesse, V. Roddatis, J. Roqueta, P. García, D. Pergolesi, J. Santiso, and J. A. Kilner, "Microstructure and ionic conductivity of LLTO thin films: Influence of different substrates and excess lithium in the target," Solid State Ionics, vol. 272, pp. 1-8, 2015, DOI: 10.1016/j.ssi.2014.12.005.

[7] O. Bohnke, H. Duroy, J.-L. Fourquet, S. Ronchetti, and D. Mazza, "In search of the cubic phase of the $\mathrm{Li}^{+}$ion-conducting perovskite $\mathrm{La}_{2 / 3-} \mathrm{Li}_{3 x} \mathrm{TiO}_{3}$ : structure and properties of quenched and in situ heated samples," Solid State Ionics, vol. 149, no. 3-4, pp. 217-226, Aug. 2002, DOI: 10.1016/S0167-2738(02)00142-X.

[8] D. Mazza, S. Ronchetti, O. Bohnké, H. Duroy, and J.-L. Fourquet, "Modeling Liion conductivity in fast ionic conductor $\mathrm{La}_{2 / 3}{ }_{-} \mathrm{Li}_{3 x} \mathrm{TiO}_{3}$," Solid State Ionics, vol. 149, no. 1-2, pp. 81-88, Jul. 2002, DOI: 10.1016/S0167-2738(02)00100-5.

[9] J. Ibarra, A. Várez, C. León, J. Santamaría, L. M. Torres-Martínez, and J. Sanz, "Influence of composition on the structure and conductivity of the fast ionic conductors $\mathrm{La}_{2 / 3-\mathrm{x}} \mathrm{Li}_{3 x} \mathrm{TiO}_{3}(0.03 \leq \mathrm{x} \leq 0.167)$," Solid State Ionics, vol. 134, no. 3-4, pp. 219-228, 2000, DOI: 10.1016/S0167-2738(00)00761-X.

[10] S. Kim, M. Hirayama, W. Cho, K. Kim, T. Kobayashi, R. Kaneko, K. Suzuki, and R. Kanno, "Low temperature synthesis and ionic conductivity of the epitaxial $\mathrm{Li}$ ${ }_{0.17} \mathrm{La}_{0.61} \mathrm{TiO}_{3}$ film electrolyte," CrystEngComm, vol. 16, no. 6, pp. 1044-1049, 2014, DOI: $10.1039 / \mathrm{c} 3 \mathrm{ce} 42003 \mathrm{e}$.

[11] A. Rivera, C. León, J. Santamaría, A. Várez, O. V’yunov, A. G. Belous, J. A. Alonso, and J. Sanz, "Percolation-Limited Ionic Diffusion in $\mathrm{Li}_{0.5-x} \mathrm{Na}_{x} \mathrm{La}_{0.5} \mathrm{TiO}_{3}$ Perovskites $(0 \leq \mathrm{x} \leq 0.5)$," Chem. Mater., vol. 14, no. 12, pp. 5148-5152, Dec. 2002, DOI: $10.1021 / \mathrm{cm} 0204627$.

[12] H. Kawai and J. Kuwano, "Lithium Ion Conductivity of A-Site Deficient Perovskite Solid Solution $\mathrm{La}_{0.67-\mathrm{x}} \mathrm{Li}_{3 \mathrm{x}} \mathrm{TiO}_{3}$," J. Electrochem. Soc., vol. 141, no. 7, p. L78, 1994, DOI: $10.1149 / 1.2055043$. 
[13] Y. Inaguma, C. Liquan, M. Itoh, T. Nakamura, T. Uchida, H. Ikuta, and M. Wakihara, "High ionic conductivity in lithium lanthanum titanate," Solid State Commun., vol. 86, no. 10, pp. 689-693, Jun. 1993, DOI: 10.1016/0038-1098(93)90841-A.

[14] Y. Inaguma and M. Itoh, "Influences of carrier concentration and site percolation on lithium ion conductivity in perovskite-type oxides," Solid State Ionics, vol. 86-88, pp. 257-260, Jul. 1996, DOI: 10.1016/0167-2738(96)00100-2.

[15] Korjus [CC BY-SA 3.0 (https://creativecommons.org/licenses/by-sa/3.0)], from Wikimedia Commons

[16] D. A. H. Hanaor and C. C. Sorrell, "Review of the anatase to rutile phase transformation," J. Mater. Sci., vol. 46, no. 4, pp. 855-874, Feb. 2011, DOI: 10.1007/s10853-010-5113-0.

[17] H. Zheng, J. Wang, S. E. Lofland, Z. Ma, L. Mohaddes-Ardabili, T. Zhao, L. Salamanca-Riba, S. R. Shinde, S. B. Ogale, F. Bai, D. Viehland, Y. Jia, D. G. Schlom, M. Wuttig, A. Roytburd, and R. Ramesh, "Multiferroic $\mathrm{BaTiO}_{3}-\mathrm{CoFe}_{2} \mathrm{O}_{4}$ Nanostructures.," Science, vol. 303, no. 5658, pp. 661-663, 2004, DOI: 10.1126/science.1094207.

[18] H. Zheng, F. Straub, Q. Zhan, P. L. Yang, W. K. Hsieh, F. Zavaliche, Y. H. Chu, U. Dahmen, and R. Ramesh, "Self-assembled growth of $\mathrm{BiFeO}_{3}-\mathrm{CoFe}_{2} \mathrm{O}_{4}$ nanostructures," Adv. Mater., vol. 18, no. 20, pp. 2747-2752, 2006, DOI: 10.1002/adma.200601215.

[19] D.M. Cunha, T.A. Hendriks, A. Vasileiadis, C.M. Vos, T. Verhallen, D.P. Singh, M. Wagemaker, M. Huijben, "Doubling reversible capacities in epitaxial $\mathrm{Li}_{4} \mathrm{Ti}_{5} \mathrm{O}_{12}$ thin film anodes for microbatteries", ACS Appl. Energy Mater. 2019, 2, 5, 3410-3418, DOI: $10.1021 /$ acsaem.9b00217.

[20] Z. Zheng, H. Fang, F. Yang, Z.-K. Liu, and Y. Wang, "Amorphous $\mathrm{LiLaTiO}_{3}$ as Solid Electrolyte Material,” J. Electrochem. Soc., vol. 161, no. 4, pp. A473-A479, 2014, DOI: 10.1149/2.006404jes.

[21] G. Q. Liu, L. Wen, and Y. M. Liu, "Spinel $\mathrm{LiNi}_{0.5} \mathrm{Mn}_{1.5} \mathrm{O}_{4}$ and its derivatives as cathodes for high-voltage Li-ion batteries," J. Solid State Electrochem., vol. 14, no. 12, pp. 2191-2202, 2010, DOI: 10.1007/s10008-010-1061-5.

[22] W. D. Richards, L. J. Miara, Y. Wang, J. C. Kim, and G. Ceder, "Interface Stability in Solid-State Batteries," Chem. Mater., vol. 28, no. 1, pp. 266-273, 2016, DOI: 10.1021/acs.chemmater.5b04082.

[23] Y. Zhu, X. He, and Y. Mo, "First principles study on electrochemical and chemical stability of solid electrolyte-electrode interfaces in all-solid-state Li-ion batteries," J. Mater. Chem. A, vol. 4, no. 9, pp. 3253-3266, 2016, DOI: 10.1039/C5TA08574H.

[24] C. M. Julien, A. Mauger, K. Zaghib, and H. Groult, "Comparative Issues of Cathode Materials for Li-Ion Batteries," Inorganics, vol. 2, pp. 132-154, 2014, DOI: 10.3390/inorganics2020132.

[25] W. J. H. Borghols, D. Lützenkirchen-Hecht, U. Haake, E. R. H. van Eck, F. M. Mulder, and M. Wagemaker, "The electronic structure and ionic diffusion of 
nanoscale $\mathrm{LiTiO}_{2}$ anatase," Phys. Chem. Chem. Phys., vol. 11, no. 27, p. 5742, 2009, DOI: $10.1039 / \mathrm{b} 823142 \mathrm{~g}$.

[26] M. Pfanzelt, P. Kubiak, M. Fleischhammer, and M. Wohlfahrt-Mehrens, "TiO rutile-An alternative anode material for safe lithium-ion batteries," J. Power Sources, vol. 196, no. 16, pp. 6815-6821, Aug. 2011, DOI: 10.1016/j.jpowsour.2010.09.109.

[27] J. E. Greedan, “Geometrically frustrated magnetic materials," J. Mater. Chem., vol. 11, no. 1, pp. 37-53, 2001, DOI: 10.1039/b003682j.

[28] J. W. Long, B. Dunn, D. R. Rolison, and H. S. White, "Three-dimensional battery architectures," Chem. Rev., vol. 104, no. 10, pp. 4463-4492, 2004, DOI: $10.1021 / \mathrm{cr} 0207401$.

[29] W. Zhang, R. Ramesh, J. L. MacManus-Driscoll, and H. Wang, "Multifunctional, self-assembled oxide nanocomposite thin films and devices," MRS Bull., vol. 40, no. 09, pp. 736-745, Sep. 2015, DOI: 10.1557/mrs.2015.198.

[30] J. Huang, J. L. MacManus-Driscoll, and H. Wang, "New epitaxy paradigm in epitaxial self-assembled oxide vertically aligned nanocomposite thin films," $J$. Mater. Res., vol. 32, no. 21, pp. 4054-4066, Nov. 2017, DOI: 10.1557/jmr.2017.281.

[31] S. Lee and J. L. MacManus-Driscoll, "Research Update: Fast and tunable nanoionics in vertically aligned nanostructured films," APL Mater., vol. 5, no. 4, p. 042304, Apr. 2017, DOI: 10.1063/1.4978550.

[32] J. L. Macmanus-Driscoll, "Self-assembled heteroepitaxial oxide nanocomposite thin film structures: Designing interface-induced functionality in electronic materials," Adv. Funct. Mater., vol. 20, no. 13, pp. 2035-2045, 2010, DOI: 10.1002/adfm.201000373.

[33] J.-S. Kim, C. S. Johnson, J. T. Vaughey, M. M. Thackeray, S. A. Hackney, W. Yoon, and C. P. Grey, "Electrochemical and Structural Properties of $x \mathrm{Li}_{2} \mathrm{M}^{\prime} \mathrm{O}_{3} \cdot(1-$ $\mathrm{x}) \mathrm{LiMn}_{0.5} \mathrm{Ni}_{0.5} \mathrm{O}_{2}$ Electrodes for Lithium Batteries $\left(\mathrm{M}^{`}=\mathrm{Ti}, \mathrm{Mn}, \mathrm{Zr} ; 0 \leq \mathrm{x} \leqslant 0.3\right)$," Chem. Mater., vol. 16, no. 10, pp. 1996-2006, 2004, DOI: 10.1021/cm0306461.

[34] K. Suzuki, K. Kim, S. Taminato, M. Hirayama, and R. Kanno, "Fabrication and electrochemical properties of $\mathrm{LiMn}_{2} \mathrm{O}_{4} / \mathrm{SrRuO}_{3}$ multi-layer epitaxial thin film electrodes," J. Power Sources, vol. 226, no. March 2013, pp. 340-345, 2013, DOI: 10.1016/j.jpowsour.2012.11.008.

[35] K. Suzuki, M. Hirayama, K. Kim, S. Taminato, K. Tamura, J.-Y. Son, J. Mizuki, and R. Kanno, "Interfacial Analysis of Surface-Coated LiMn ${ }_{2} \mathrm{O}_{4}$ Epitaxial Thin Film Electrode for Lithium Batteries," J. Electrochem. Soc., vol. 162, no. 13, pp. A7083-A7090, 2015, DOI: 10.1149/2.0111513jes.

[36] R. Chen, M. Knapp, M. Yavuz, R. Heinzmann, D. Wang, S. Ren, V. Trouillet, S. Lebedkin, S. Doyle, H. Hahn, H. Ehrenberg, and S. Indris, "Reversible Li ${ }^{+}$Storage in a $\mathrm{LiMnTiO}_{4}$ Spinel and Its Structural Transition Mechanisms," J. Phys. Chem. C, vol. 118 , no. 24, pp. 12608-12616, Jun. 2014, DOI: 10.1021/jp501618n. 


\section{Summary}

Since their introduction in the 1990's lithium ion (Li-ion) batteries have become the main power source for many portable and stationary applications due to their high energy and power densities. Despite this, research is still ongoing to further enhance these properties of the batteries, as well as making them safer and more environmentally friendly.

Three major intercalation cathode materials (the olivine $\mathrm{LiFePO}_{4}$, the layered $\mathrm{LiCoO}_{2}$ and the spinel $\mathrm{LiMn}_{2} \mathrm{O}_{4}$ ) are identified. Their different lithium diffusion pathways influence the cycle-life and lifetime of the used cathode. Their interphase with the electrolyte, and stability thereof, influences the safety of the battery. $\mathrm{LiMn}_{2} \mathrm{O}_{4}$ cathode material is known as a promising cathode material due to its $3 \mathrm{D}$ lithium pathways for diffusion and ability to intercalate a second lithium ion at $3 \mathrm{~V}$. However, literature has shown that it suffers from capacity fade and poor cycle performance due to Mn-dissolution and a Jahn-teller distortion. Although various strategies have been suggested to minimize or prevent these limitations, a model system to study the lithiation mechanisms in detail is needed.

Therefore, highly controlled thin films are made to provide an excellent model system to study these mechanisms as well as to elucidate the possible limiting factors, including Liion diffusion, Li-ion transport, and electronic transport. By applying epitaxial engineering where thin films are grown on different oriented $\mathrm{Nb}: \mathrm{SrTiO}_{3}$ substrates, the crystal orientation of $\mathrm{LiMn}_{2} \mathrm{O}_{4}$ is controlled. This enables a unique insight into the relation between electrochemistry, interface and crystal directionality, not obtainable in single crystals or polycrystalline samples, and previously poorly obtainable in epitaxial films. High discharging rates with good energy capacity and good cyclability is achieved, demonstrating 
enhanced cycle life without excessive capacity fading as compared to previous polycrystalline studies.

By using Electrochemical Impedance Spectroscopy (EIS) the electrochemical behavior of the battery cell is modeled to get more in-depth knowledge of the electrochemical response of each component within the cell. By applying subsequently different voltages and thereby charge-states of the cathode a link to its capacity could be modeled. The Warburg-slope from the model was used to calculate the lithium diffusivity of the cathode thin film at different lithiation levels and compared to experimental results by Potentiostatic Intermitted Titration technique (PITT). Both values indicated lower values of the lithium diffusivity of the thin films as compared to previous studies in literature, indicating a strong interfacial contribution that cannot be neglected.

The observed capacity retention is compared to literature and found to be very high, outperforming polycrystalline thin films and being among the best performing particle cathodes.

As energy density is such an important feature in batteries, the electrochemical response of the additional discharge to $\mathrm{Li}_{2} \mathrm{Mn}_{2} \mathrm{O}_{4}$, with a focus on structure stability and the proposed rapid capacity loss is elucidated. Overlithiating $\mathrm{LiMn}_{2} \mathrm{O}_{4}$ to obtain $\mathrm{Li}_{2} \mathrm{Mn}_{2} \mathrm{O}_{4}$ gives a $3.8 \mathrm{~V}$ plateau which is hypothesized to be due to Li-Mn defect clusters. Cycling the $3 \mathrm{~V}$ plateau in the epitaxial thin films is shown to be stable with negligible capacity fade, indicating that the extra capacity at the $3 \mathrm{~V}$ plateau can be utilized effectively which allows doubling the capacity of $\mathrm{Li}_{x} \mathrm{Mn}_{2} \mathrm{O}_{4}$ cathode material.

Furthermore, cycling the $3 \mathrm{~V}$ plateau can rejuvenate any capacity loss occurring at the $4 \mathrm{~V}$ plateau. Allowing hardly any capacity fade over thousands of cycles possibly due to reverting back Li-Mn defect clusters. This allows this cathode material to by cycled deeper 
for extensive lifetimes, allowing the use of the full $288 \mathrm{mAh} / \mathrm{gram}$ capacity by using both the $4 \mathrm{~V}$ and $3 \mathrm{~V}$ plateaus as opposed to only the $4 \mathrm{~V}$ plateaus with a capacity of 148 $\mathrm{mAh} / \mathrm{gram}$.

With the addition of a solid electrolyte a first step is taken to realize all-oxide full solid state batteries. $\mathrm{Li}_{3 x} \mathrm{La}_{2 / 3-\mathrm{x}} \mathrm{TiO}_{3}$ electrolyte thin films are synthesized, but exhibit TiOx impurities most likely due to lithium deficiencies. By combining the solid electrolyte with the $\mathrm{LiMn}_{2} \mathrm{O}_{4}$ cathode a nanocomposite can also be obtained. This nanocomposite suffers from the insulating electrolyte preventing connection of the cathode to the current collector, limiting charge-discharge behavior.

Finally, an all oxide full solid-state thin film battery was synthesized by combining the $\mathrm{LiMn}_{2} \mathrm{O}_{4}$-cathode and $\mathrm{Li}_{3 x} \mathrm{La}_{2 / 3}$-x $\mathrm{TiO}_{3}$-electrolyte with the anode $\mathrm{Li}_{4} \mathrm{Ti}_{5} \mathrm{O}_{12}$. Poor growth of the electrolyte combined with shorts between the anode and cathode prevented electrochemical performance. Further investigation and optimization on the growth of the $\mathrm{Li}_{3 \mathrm{x}} \mathrm{La}_{2 / 3-\mathrm{x}} \mathrm{TiO}_{3}$-electrolyte is required to enable a cyclable all oxide full solid-state battery.

This research demonstrates the scientific potential for epitaxial ceramic battery model systems, which new insights open up the possibility of using a wider potential range for $\mathrm{Li}_{\mathrm{x}} \mathrm{Mn}_{2} \mathrm{O}_{4}$ to increase the capacity almost twofold while achieving extensive lifetimes. 
- 132 - 


\section{Samenvatting}

Sinds hun introductie in 1990 zijn Lithium-ion batterijen dé bron van energie geworden voor vele mobiele en statische applicaties dankzij hun hoge energie en stroom dichtheid. Desondanks, gaat onderzoek hierop verder om deze eigenschappen van batterijen te verbeteren, alsmede ze veiliger en meer milieuvriendelijker te maken.

De drie meest gebruikte inschuif-kathode materialen zijn: olivijn $\mathrm{LiFePO}_{4}$, gelaagd $\mathrm{LiCoO}_{2}$ en spinel $\mathrm{LiMn}_{2} \mathrm{O}_{4}$. Hun verschillende lithium-diffusiewegen beïnvloeden de gebruiks- en levensduur van het gebruikte kathode materiaal. Verder bepaald dit de tussenlaag van de kathode met het elektrolyt en de stabiliteit daarvan, en daarmee, de veiligheid van de batterij. Het kathode materiaal $\mathrm{LiMn}_{2} \mathrm{O}_{4}$ staat bekend als een veelbelovend kathode materiaal door zijn 3D lithium-diffusiewegen en mogelijkheid tot het inschuiven van een $2^{\mathrm{e}}$ lithium ion op $3 \mathrm{~V}$. De literatuur laat daarentegen zien dat $\mathrm{LiMn}_{2} \mathrm{O}_{4}$ leidt aan het verliezen van capaciteit over het gebruik en slechte prestaties heeft tijdens laad-ontlaad cycli. Dit komt doordat Mn oplost en het materiaal een Jahn-Teller vervorming ondergaat. Er zijn verschillende strategieën gesuggereerd om dit tegen te gaan, maar een model systeem om de mechanismen te bestuderen ontbreekt.

Om een model systeem te creëren zijn zeer gecontroleerde dunne films gemaakt om een excellent model systeem te bieden om de mechanismen alsook limiterende factoren te bestuderen, inclusief de Li-ion diffusie, het Li-ion transport en het elektronisch transport. Gebruik makende van gecontroleerde kristalgroei-technieken zijn dunne kristallijne films aangebracht op substraten van $\mathrm{Nb}: \mathrm{SrTiO}_{3}$ met verschillende kristal oriëntaties waarmee de kristaloriëntatie van $\mathrm{LiMn}_{2} \mathrm{O}_{4}$ kan worden gecontroleerd. Dit staat toe om een unieke kijk te verkrijgen op de relatie tussen elektrochemie, contactoppervlakten en kristaloriëntatie, 
welke niet te verkrijgen is in enkele kristallen noch polykristallijne deeltjes. Verder is dit tot nu toe slechts moeilijk te verkrijgen in gecontroleerde kristal-gegroeide films. Hoge ontlaadsnelheden met behoud van goede capaciteit en capaciteit over laad-ontlaad cycli zijn bereikt, wat laat zien dat het mogelijk is veel laad-ontlaad cycli door te maken zonder veel capaciteit verlies, in tegenstelling tot onderzoeken op polykristallijne deeltjes.

Door gebruik te maken van Elektrochemische Impedantie Spectroscopie (EIS) kan het elektrochemisch gedrag van de batterij-cel gemodelleerd worden om zo meer kennis te verschaffen over de elektrochemische processen van elk component binnen de cel. Wanneer de metingen verricht worden bij verschillende voltages, en daarmee de ontlaad-stadia van de kathode, kan een link worden gelegd met zijn capaciteit. De helling van de Warburgcomponent in het model is gebruikt om de lithium diffusiteit van de kathode, bij verschillende lithium concentraties in de kathode, te berekenen en is vergeleken met experimentele resultaten van statisch Potentiaal tussentijdse Titratie Techniek (Potentiostatic Intermitted Titration Technique, PITT). Beide waardes voor lithium diffusiteit van de dunne films vallen lager uit dan voorgaande studies in de literatuur, wat een indicatie geeft dat een sterke contributie van het contactoppervlakte niet genegeerd kan worden.

Het behoud van capaciteit over cycli is vergeleken met literatuur waarden en laat erg hoge waardes zien. Het is beter dan die van polykristallijne dunne films en komt in de buurt van de beste kathodes bestaande uit stofdeeltjes.

Aangezien energiedichtheid zo'n belangrijke eigenschap van batterijen is, is het elektrochemisch gedrag bij het verder ontladen van $\mathrm{LiMn}_{2} \mathrm{O}_{4}$ naar $\mathrm{Li}_{2} \mathrm{Mn}_{2} \mathrm{O}_{4}$ onderzocht. Hierbij is een focus gelegd op de stabiliteit van de structuur en de voorgestelde extreem snelle capaciteits-degradatie. Bij het cyclisch invoegen van een extra lithium-ion om van 
$\mathrm{LiMn}_{2} \mathrm{O}_{4}$ naar $\mathrm{Li}_{2} \mathrm{Mn}_{2} \mathrm{O}_{4}$ en weer terug te gaan wordt een extra voltage plateau bij $3.8 \mathrm{~V}$ geobserveerd. Deze wordt toegeschreven aan het ontstaan van clusters van Li-Mn defecten binnen de kathode. Laden en ontladen rondom het $3 \mathrm{~V}$ plateau laat stabiele capaciteit met verwaarloosbare capaciteitsverliezen zien van de dunne films met gecontroleerde kristalgroei. Dit geeft aan dat de extra capaciteit van het $3 \mathrm{~V}$ plateau straffeloos gebruikt kan worden waardoor effectief een verdubbeling van de capaciteit van het $\mathrm{Li}_{x} \mathrm{Mn}_{2} \mathrm{O}_{4}$ kathode materiaal mogelijk is.

Verder leidt het laden en ontladen rondom het $3 \mathrm{~V}$ plateau tot het herstellen van enige capaciteitsverliezen bij het $4 \mathrm{~V}$ plateau. Hiermee is het mogelijk om zelfs na duizenden cycli verwaarloosbare verliezen te hebben in de capaciteit. Dit is waarschijnlijk mogelijk door het weer laten verdwijnen van de Li-Mn defecten in de kathode die in de loop van het gebruik ontstaan. Dit staat toe om dit kathode materiaal dieper te ontladen met langere levensduur waardoor de volle capaciteit van $288 \mathrm{mAh} /$ gram van zowel het $4 \mathrm{~V}$ als het $3 \mathrm{~V}$ plateau gecombineerd gebruikt kan worden in tegenstelling tot de $148 \mathrm{mAh} / \mathrm{gram}$ van enkel het $4 \mathrm{~V}$ plateau.

Met het toevoegen van een vaste-stof elektrolyt is een eerste stap ondernomen tot het realiseren van volledig vaste-stof-batterijen bestaande uit oxidematerialen. Dunne films gemaakt uit het vaste-stof-elektrolyt $\mathrm{Li}_{3 x} \mathrm{La}_{2 / 3-x} \mathrm{TiO}_{3}$ zijn gerealiseerd, maar bevatten $\mathrm{TiO}_{x}$ onzuiverheden, mogelijk door tekorten aan lithium. Door het vaste-stof-elektrolyt te combineren met de $\mathrm{LiMn}_{2} \mathrm{O}_{4}$ kathode kan een nanocomposiet worden verkregen. Deze composiet leidt alleen aan een isolerende laag elektrolyt richting de stroomcollector, waardoor laad-ontlaad gedrag wordt voorkomen.

Als laatste is een volledige vaste-stof-batterij van oxidische materialen gesynthetiseerd door de $\mathrm{LiMn}_{2} \mathrm{O}_{4}$ kathode te combineren met een $\mathrm{Li}_{3 x} \mathrm{La}_{2 / 3-\mathrm{x}} \mathrm{TiO}_{3}$ elektrolyt en een $\mathrm{Li}_{4} \mathrm{Ti}_{5} \mathrm{O}_{12}$ 
anode. Door slechte kristalgroei van het elektrolyt gecombineerd met kortsluitingen tussen de anode en kathode kon elektrochemisch slechts zeer beperkt onderzocht worden. Verder onderzoek en geoptimaliseerde groei van het $\mathrm{Li}_{3 \mathrm{x}} \mathrm{La}_{2 / 3}$-x $\mathrm{TiO}_{3}$-elektrolyt is nodig om volledig vaste-stof-batterijen bestaande uit oxidematerialen, elektrochemisch te onderzoeken.

Dit onderzoek laat het wetenschappelijk potentiaal van gecontroleerde kristalgroei van keramische materialen voor een batterij model systeem zien, wiens nieuwe inzichten leiden tot de mogelijkheid om een breder potentiaal gebeid van de kathode $\mathrm{Li}_{\mathrm{x}} \mathrm{Mn}_{2} \mathrm{O}_{4}$ te gebruiken. Hierdoor kan de capaciteit van de batterij bijna verdubbeld worden terwijl ook nog een langere levensduur mogelijk is. 


\section{Acknowledgements}

A word of gratitude alone is not nearly enough for the help, love and good times I have had during my $\mathrm{PhD}$ period. Devoting a few, on the other hand, will have to suffice, as words alone cannot describe what has been learned, felt, experienced, seen and heard as I progressed through the challenges of this period.

As a start I would like to thank my family. Many a weekend have I enjoyed the countryside where I can always relax, enjoy the nature, go and do odd jobs, catch some Pokémon, get well fed, and get completely charged up for a new week. Brother, thanks again for the most amazing picture of my favorite electric vehicles which I used in chapter 1! Mom, Dad and Leo, thank you for your support, knowledge and love. Speaking about love, Michelle, thank you for being there, for your support and understanding, for your knowledge and jokes, and for your unlimited love. May you be truly blessed.

As the concept of family in my opinion is larger than the blood-bond between people, I would like to include my family at V.A.S. Arashi. The student martial arts association at the university allowed me to grow as a person. As I would like to thank the different committees I have been part of, the people I have interacted with and the teachers of Arashi, one person really stands out from the rest. Guru / Mas René, thank you for being like a second dad to me. Your teachings, wisdom and love have given me a second home. May we continue to be there for each other and may you be blessed with good health.

To my supervisor Mark, thank you for your support, during not only my $\mathrm{PhD}$, but also during my bachelor and for the future of my career. Thank you for giving me the chance to do my $\mathrm{PhD}$ in a topic I love. May we collaborate on many more papers. 
To my colleague and friend Daniel, we have had many great talks, visited many great places and conferences, and had a lot of fun. Thank you for the awesome time we have had. May we continue to be good friends and may you be blessed with good health.

Karin, thank you for the conversations we have had and the emotional support you provided in times things looked darker. Without you, as well as the other technicians of IMS, works like this are not possible.

Puck, you have been an awesome host to many parties and always have been of good will and good ideas (next to some terrible ones ;-) ). We have been editing the movie Campus Ninja V for a quite some weekends long and sometimes still editing way after midnight during these weekends. Even through all the despair we have been able to finally premiere it March 2017 with a full event. Thank you, it was awesome! Thereby, also a big thanks to the people of Campus Ninja V, it was awesome to participate, play, act and edit in a feature length film.

A special thanks to Mark Smithers of the MESA+ institute, for always taking the time to make good SEM pictures and asking how you are doing. His keen eye for beautiful pictures helps many.

Thank you, Karin, Dominic, Marion, José, Harry and Laura. As supporting members of the IMS group you are vital to works like this. This of course goes together with all the people of IMS, it was a pleasure to be a part of the group. The best of luck in your future careers!

Finally, a big thanks to my friends at Electric Superbike Twente, we have seen that motorcycles powered by batteries remain a challenge. May our friendship continue to electrify excellence and may you continue to win the MotoE. 

